\title{
Haemorrhoids : evaluation of methods of treatment
}

Citation for published version (APA):

Baeten, C. G. M. I. (1985). Haemorrhoids : evaluation of methods of treatment. [Doctoral Thesis, Maastricht University]. Rijksuniversiteit Limburg. https://doi.org/10.26481/dis.19850419cb

Document status and date:

Published: 01/01/1985

DOI:

10.26481/dis.19850419cb

Document Version:

Publisher's PDF, also known as Version of record

\section{Please check the document version of this publication:}

- A submitted manuscript is the version of the article upon submission and before peer-review. There can be important differences between the submitted version and the official published version of record.

People interested in the research are advised to contact the author for the final version of the publication, or visit the DOI to the publisher's website.

- The final author version and the galley proof are versions of the publication after peer review.

- The final published version features the final layout of the paper including the volume, issue and page numbers.

Link to publication

\footnotetext{
General rights rights.

- You may freely distribute the URL identifying the publication in the public portal. please follow below link for the End User Agreement:

www.umlib.nl/taverne-license

Take down policy

If you believe that this document breaches copyright please contact us at:

repository@maastrichtuniversity.nl

providing details and we will investigate your claim.
}

Copyright and moral rights for the publications made accessible in the public portal are retained by the authors and/or other copyright owners and it is a condition of accessing publications that users recognise and abide by the legal requirements associated with these

- Users may download and print one copy of any publication from the public portal for the purpose of private study or research.

- You may not further distribute the material or use it for any profit-making activity or commercial gain

If the publication is distributed under the terms of Article $25 \mathrm{fa}$ of the Dutch Copyright Act, indicated by the "Taverne" license above, 
HAEMORRHOIDS

EVALUATION OF METHODS

OF TREATMENT 



\section{HAEMORRHOIDS EVALUATION OF METHODS OF TREATMENT}

Ter verkrijging van de graad van doctor in de geneeskunde aan de Rijksuniversiteit Limburg te Maastricht op gezag van de Rector Magnificus, Prof.Dr.F.I.M. Bonke volgens het besluit van het College van Dekanen in het openbaar te verdedigen op 19 aprill 1985 om 4 uur

\section{door}

Cornelius Gerardus Maria Ignatius Baeten geboren te Maastricht

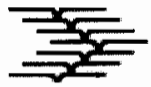


Promotores:

Referenten:
Prof.Dr.J.M. Greep Prof S.E. Hedberg. M.D. $\uparrow$

Prof.Dr.J.A. Flendrig

Dr.J.H.C. Kuypers

Prof.Dr.W.J.B.M. van de Staak.

Publication of this thesis was supported by the 'Spaarbank Limburg" 
What the Lord gives to suffer and the relief Lord can offer

to Karin, Coen, Martijn, Titia

10 my parents 



\section{List of contents}

General Introduction

Chapter 1, Anatomy $\ldots \ldots \ldots \ldots \ldots \ldots \ldots \ldots \ldots \ldots \ldots \ldots \ldots \ldots$

$1.1 \quad$ Rectum and anus $\ldots \ldots \ldots \ldots \ldots \ldots \ldots \ldots \ldots \ldots \ldots$

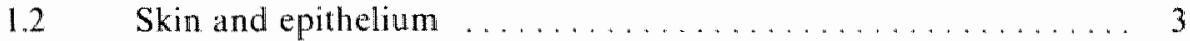

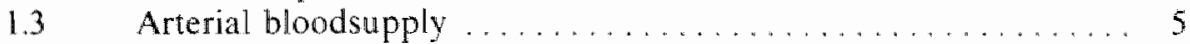

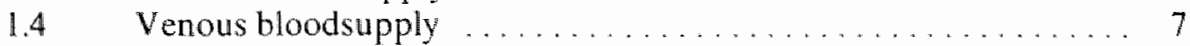

$1.5 \quad$ Nerve supply .......................... 7

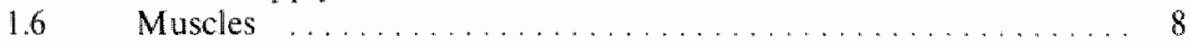

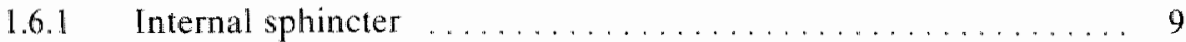

1.6.2 Submucosal anal muscle $\ldots \ldots \ldots \ldots \ldots \ldots \ldots \ldots \ldots$

1.6 .3 Longitudinal muscle $\ldots \ldots \ldots \ldots \ldots \ldots \ldots \ldots \ldots$

1.6.4 External sphincter . . . . . . . . . . . . . . . . . . . . 10

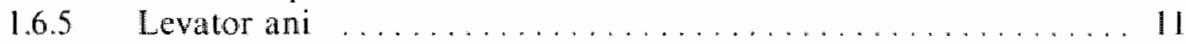

Chapter 2, Physiology $\ldots \ldots \ldots \ldots \ldots \ldots \ldots \ldots \ldots \ldots \ldots \ldots \ldots \ldots$

2.1.1 Sensibility of the anal canal $\ldots \ldots \ldots \ldots \ldots \ldots \ldots \ldots \ldots \ldots \ldots$

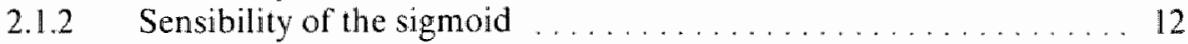

2.1.3 Sensibility of the rectum $\ldots \ldots \ldots \ldots \ldots \ldots \ldots \ldots \ldots \ldots$

2.2 Anal inhibitory reflex $\ldots \ldots \ldots \ldots \ldots \ldots \ldots \ldots \ldots \ldots \ldots$

2.3 Anal continence and defaecation $\ldots \ldots \ldots \ldots \ldots \ldots \ldots$

2.3.1 Theory of high pressure zone $\ldots \ldots \ldots \ldots \ldots \ldots \ldots \ldots \ldots \ldots$

2.3.2 Theory of $80^{6}$ angle ......................... 19

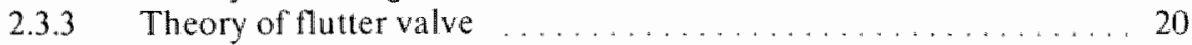

2.3.4 Theory of corpus cavernosi recti ................. 20

2.3.5 Theory of reservoir continence ................. 21

Chapter 3, Anal pressure measurement $\ldots \ldots \ldots \ldots \ldots \ldots \ldots \ldots \ldots \ldots$

3.1 Methods ................................ 22

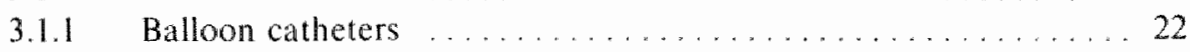

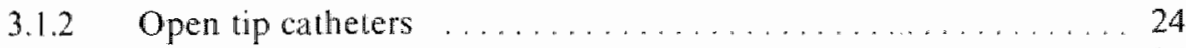

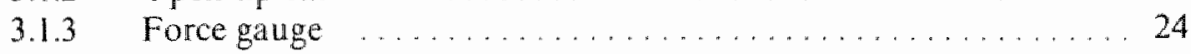




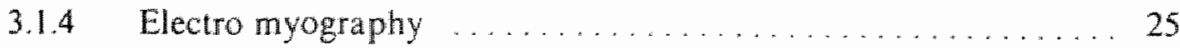

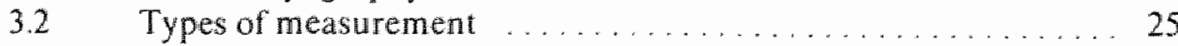

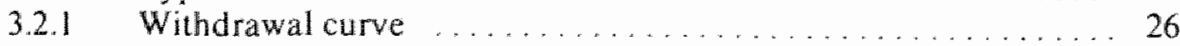

3.2 .2 Pressure measurement at one point ............... 26

3.2 .3 Resting yield pressure $\ldots \ldots \ldots \ldots \ldots \ldots \ldots \ldots \ldots \ldots$

Chapter 4, Pressure measurements with microtip transducer . . . . . . . . . 29

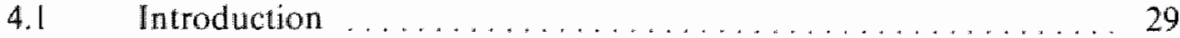

4.2 Technical aspects .......................... 29

4.3 Advantages ............................. 31

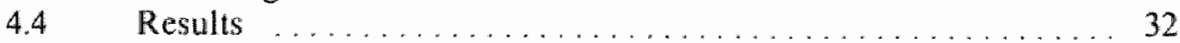

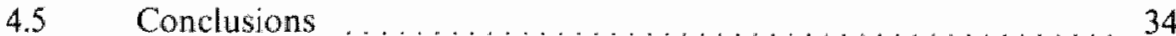

Chapter 5, Haemorrhoids $\ldots \ldots \ldots \ldots \ldots \ldots \ldots \ldots \ldots \ldots \ldots \ldots$

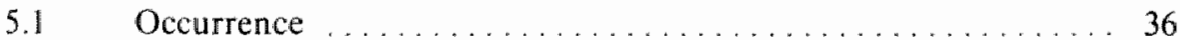

$5.2 \quad$ Number and place of haemorrhoids $\ldots \ldots \ldots \ldots \ldots \ldots \ldots$

5.3 Classification ................................ 37

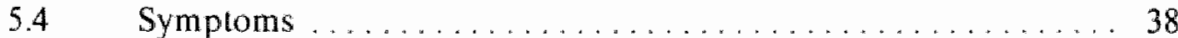

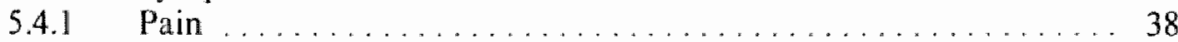

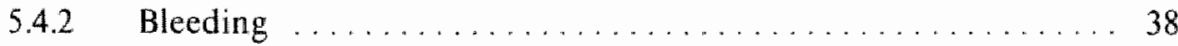

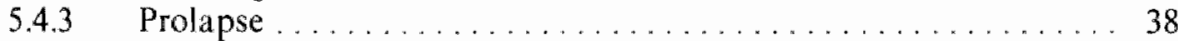

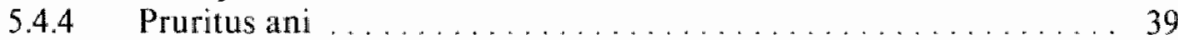

$5.4 .5 \quad$ Soiling . . . . . . . . . . . . . . . . . . . . . . . . . . . 39

5.4 .6 Thrombus . . . . . . . . . . . . . . . . . . . . . 39

5.5 Etiology of haemorrhoids ..................... 39

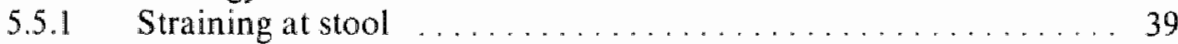

5.5 .2 Heridity ............................ 40

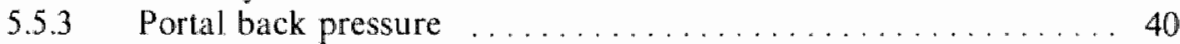

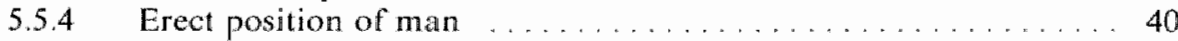

5.5 .5 Hyperplasia theory ........................ 41

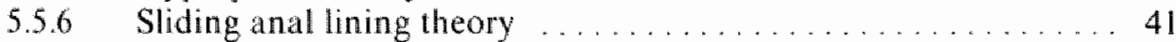

5.5 .7 Vicious circle .......................... 41

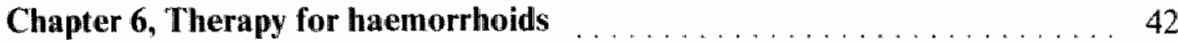

6.1 Medical treatment .......................... 42

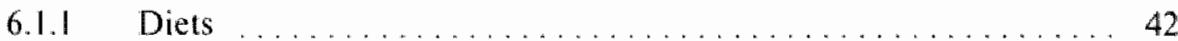

6.1.2 Local treatment ... . . . . . . . . . . . . . . . . . . . . . 43

6.1 .3 Anti-pruritus therapy $\ldots \ldots \ldots \ldots \ldots \ldots \ldots \ldots \ldots \ldots \ldots \ldots$

6.1 .4 Sclerotherapy ............................. 43

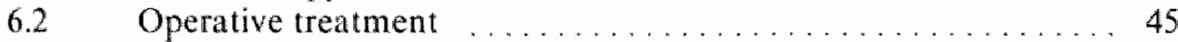

6.2 .1 Open haemorrhoidectomy $\ldots \ldots \ldots \ldots \ldots \ldots \ldots \ldots \ldots \ldots \ldots \ldots$ 


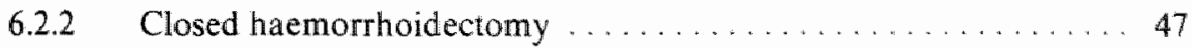

6.2 .3 Parks haemorrhoidectomy ....................... 48

6.2 .4 Whitehead haemorrhoidectomy $\ldots \ldots \ldots \ldots \ldots \ldots \ldots \ldots \ldots . \ldots \ldots$

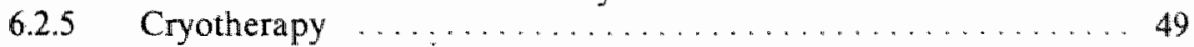

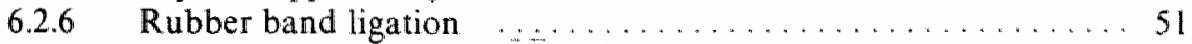

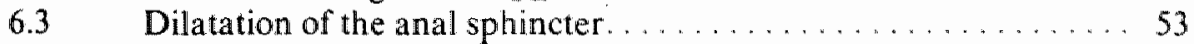

6.3.1 Anal stretch (Lord's method) $\ldots \ldots \ldots \ldots \ldots \ldots \ldots \ldots \ldots$

6.3.2 Lateral internal sphincterotomy $\ldots \ldots \ldots \ldots \ldots \ldots \ldots \ldots . \ldots \ldots$

6.3.3 Bouginage of the anal sphincter $\ldots \ldots \ldots \ldots \ldots \ldots \ldots$

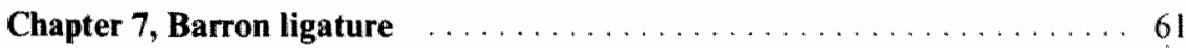

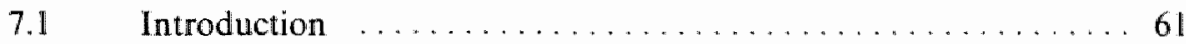

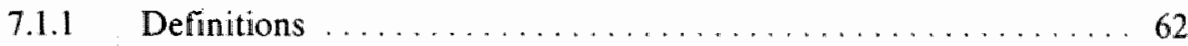

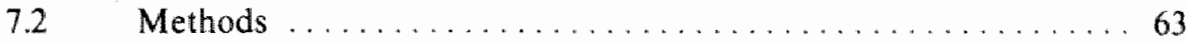

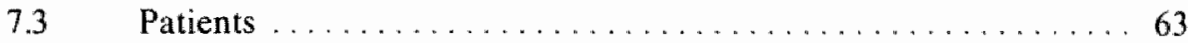

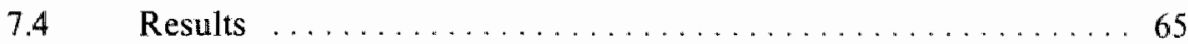

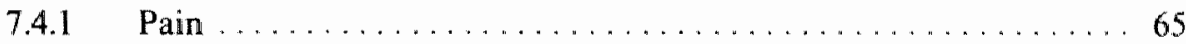

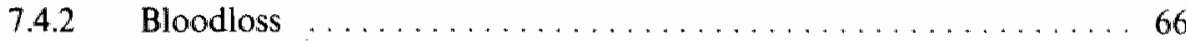

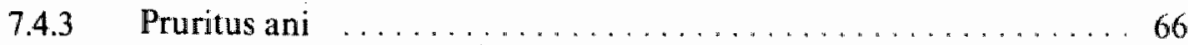

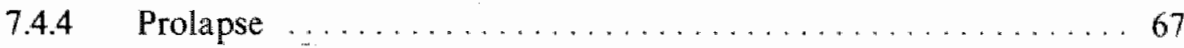

7.4 .5 Incontinence for faeces $\ldots \ldots \ldots \ldots \ldots \ldots \ldots \ldots \ldots 6 . \ldots \ldots$

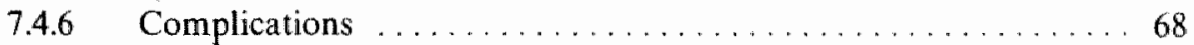

7.4.7 Postoperative proctoscopy findings $\ldots \ldots \ldots \ldots \ldots \ldots \ldots . \ldots 6$

7.4 .8 Personal judgement of the patients $\ldots \ldots \ldots \ldots \ldots \ldots \ldots \ldots$

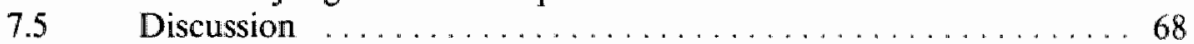

Chapter 8, Clinical trial of Lord's method versus open haemorrhoidectomy 71

8.1 Introduction and purpose of the study $\ldots \ldots \ldots \ldots \ldots \ldots \ldots$ I

8.2 Methods . . . . . . . . . . . . . . . . . . . . . . . 72

$8.3 \quad$ Patients . . . . . . . . . . . . . . . . . . . . . 76

8.3.1 General data .......................... 76

8.3.2 Preoperative complaints $\ldots \ldots \ldots \ldots \ldots \ldots \ldots \ldots \ldots \ldots 77$

$8.3 .3 \quad$ Preoperative signs ......................... 79

8.3.4 Preoperative anal pressure measurement ............. 80

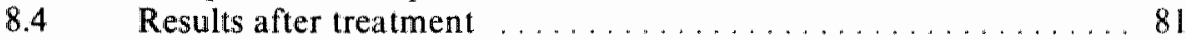

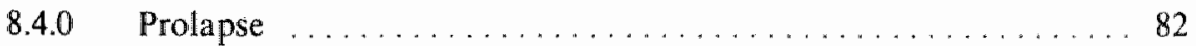

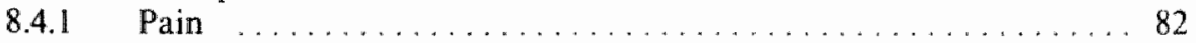

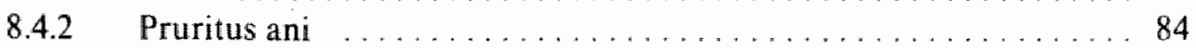

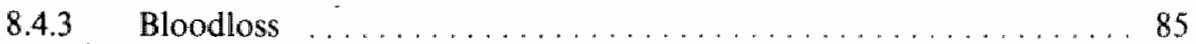

8.4 .4 Constipation and the use of laxatives $\ldots \ldots \ldots \ldots \ldots \ldots 7$

8.4 .5 Straining at stool $\ldots \ldots \ldots \ldots \ldots \ldots \ldots \ldots \ldots \ldots . \ldots \ldots$

$8.4 .6 \quad$ Skintags . . . . . . . . . . . . . . . . . . . . 89 
8.4.7 Pressure level postoperatively . . . . . . . . . . . . . . . . 89

8.4 Postoperative pressure pattern ................... 90

8.4 .9 Complications .... . . . . . . . . . . . . . . . . 90

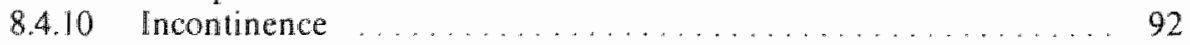

8.4.11 Time before returning to work .................. 93

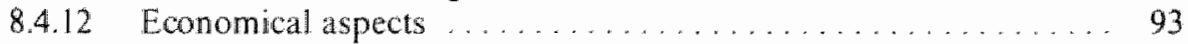

8.4.13 Personal judgements of the patients ............... 93

8.5 Discussion . . . . . . . . . . . . . . . . . . . . . . . 95

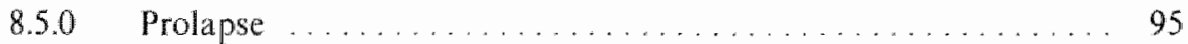

8.5.1 Pain ...................................... 95

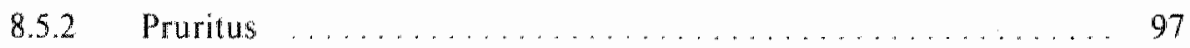

8.5 .3 Bloodloss . . . . . . . . . . . . . . . . . . . . . . . 98

8.5.4 Constipation and straining at stool $\ldots \ldots \ldots \ldots \ldots \ldots \ldots$

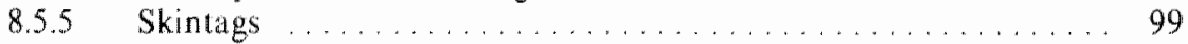

8.5.6 Pressure measurements . . . . . . . . . . . . . . . . . . 100

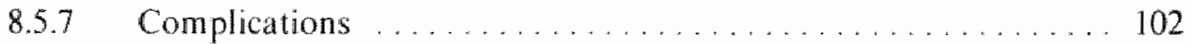

8.5 .8 Incontinence . . . . . . . . . . . . . . . . . . . . . . 102

8.5 .9 Time from work $\ldots \ldots \ldots \ldots \ldots \ldots \ldots \ldots \ldots \ldots \ldots \ldots \ldots$

8.5.10 Economical aspects ...................... 103

$8.5,11$ Personal judgement $\ldots \ldots \ldots \ldots \ldots \ldots \ldots \ldots \ldots \ldots . \ldots \ldots$

Chapter 9, Conclusions and proposal for treatment of haemorrhoids . . . . 105

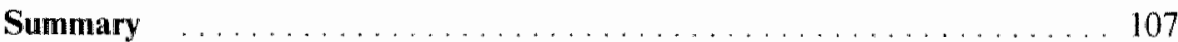

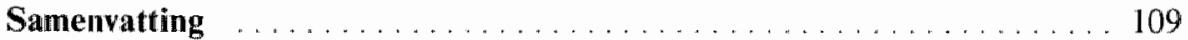

References $\ldots \ldots \ldots \ldots \ldots \ldots \ldots \ldots \ldots \ldots \ldots \ldots \ldots \ldots \ldots \ldots \ldots . \ldots \ldots 12$

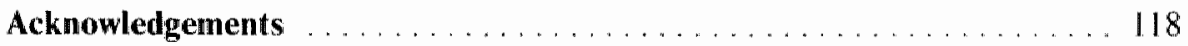

Curriculum vitae $\ldots \ldots \ldots \ldots \ldots \ldots \ldots \ldots \ldots \ldots \ldots \ldots \ldots \ldots \ldots \ldots$ 


\section{General introduction}

From ancient times mankind has suffered from haemorrhoids. It was and is one of the most common diseases in the world. The fear for pain after surgery made many patients first accept their piles and only ask for help in the severest stages of haemorrhoidal disease.

It is a task for every surgeon to find the best therapy for each individual patient. The best therapy is the one that leads to optimal results in the shortest period of time with a minimal chance of complications and with minimal costs for the society. For the last two decades surgeons have looked for alternatives for a haemorrhoidectomy as a treatment for haemorrhoids. The results of haemorrhoidectomy were eventually good, but the immediate postoperative complications such as bleeding and severe pain made it mandatory to think of these alternatives. The hospital stay necessary after haemorhoidectomy and the much higher costs were another reason to evaluate new methods of outpatient treatment.

On base of literature it is clear that haemorrhoids have to be classified in several degrees. The classification used in this study is the one generally found in literature.

This classification refers only to the symptom of prolapse. For the patient however symptoms like pain and bloodloss are more important. Bloodloss is the most common complaint (43) present in every degree of haemorrhoids. Pain is normally absent in first degree and in a part of the patients with second degree piles.

In literature Barron ligature gave excellent results in low grade piles. It can be performed at an outpatient base. It leads to quick results, has a minimal chance of complication and can be done with low costs.

The bands are placed at a level above the margin of sensibility and it is reasonable to believe that pain will not be influenced much by this procedure.

For this reason a prospective study was done to evaluate the results of Barron banding in patients with first degree piles and second degree piles without or with minimal complaints of pain. This study is described in chapter 7 .

As an alternative for haemorrhoidectomy in patients with second and third degree piles forced anal stretch seems to give good results. However, the extent after-treatment with a dilatator as described by Lord keeps the patients 
"patients" for a long tine. The method of dilatation is in principle different from others where the main aim is to destroy or excise haemorrhoidal tissue. In dilatation methods the main aim is to correct pathological conditions of the anal sphincters. Anal pressure measurements give information about physiology and pathophysiology of these sphincters. A new method of pressure measurement was used to objectivate the results.

A prospective randomized study is described to evaluate Lord's method and dilatation without after treatment compared to haemorrhoidectomy.

In fourth degree haemorrhoids necrosis of the haemorrhoidal tissue exists. In literature there is no doubt that under this condition the general surgical principle of excision forms the best therapy.

The several forms of treatment of haemorrhoids are based on different concepts about the nature of these piles. To place these therapies a literature review is given about anatomy. physiology and pathophysiology of the anal canal. 


\section{Anatomy}

This chapter will focus attention to the anatomy of the rectum and the anal canal as far as this concerns physiology, pathology and various treatments of haemorrhoids.

\subsection{Rectum and anus}

The distal part of the tractus digestivus consists of anus rectum and sigmoid. The three parts form one functional unity and it is difficult to describe the margins of each. O'Beirne (1833) thought there was a sphincter marking the passage between rectum and sigmoid and even in the beginning of this century this view was held for some time (43). Presently there is consensus that no significant anatomical demarcation exists at the rectosigmoid junction. justifying the frequent use of the term rectosigmoid to describe the lower bowel.

Caudal the rectum is continuous with the anal canal. Rectum and anal canal together form the organ of continence and as a unity they are of great importance in surgery. The anal canal varies in length from three to five centimeters. In proctoscopic studies Nivatvongs (139) found a normal length of $4.2 \pm 0,4$ $\mathrm{cm}$ in 211 persons without anal complaints.

The length of the anal canal in men is longer than in women.

\subsection{Skin and epithelium}

The inner surface of the anal canal consists of special pink shiny skin from the dentate line caudalward. Above the dentate line a multi-layered mucosa formed by cuboid cells is seen, after about one centimeter changing into the rectal epithelium with its crypts, goblet cells and mucus secreting glands. The mucosa in the anal canal is thrown into eight to fourteen longitudinal folds called the columns of Morgagni (see figure 1.1). Between two columns a crooked valvelike transition from skin to mucosa is found that is known as the dentate or pectinate line. This valve is the remainder of the proctodeal membrane. Underneath the mucosa layer the superior haemorrhoidal plexus is found, which is of great importance in the maintenance of continence. This unity of mucosa and venous plexus is called the corpus cavernosi recti by Stelzner (141). The embryological connection between the various tissues of the continence organ has been described by Stelzner (141). The rectum with its mucosa and smooth 


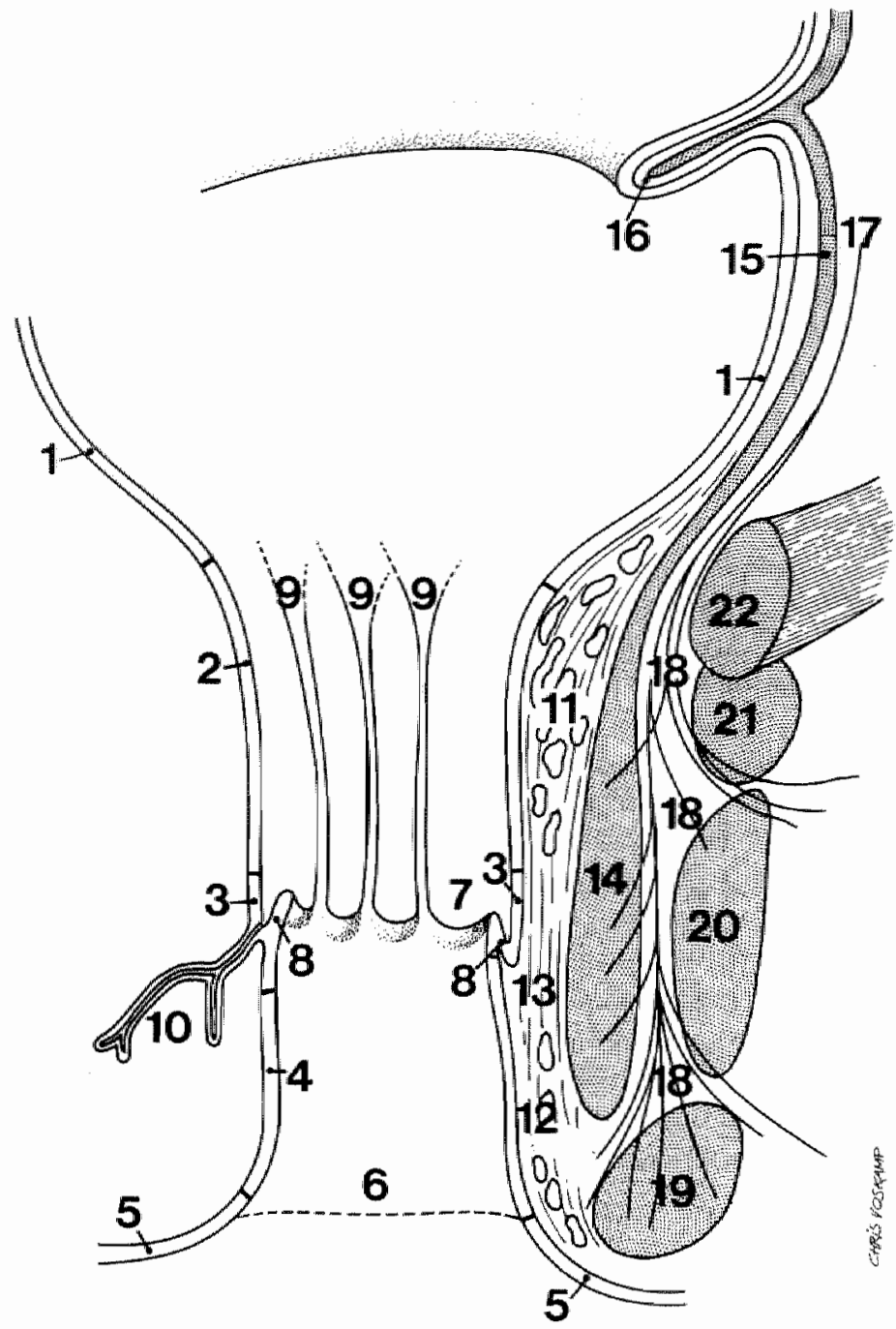

Figure 1.1 Anatomy of the anal and and

1) rectal mucosa

2) singletayered anal epithelium

3) multimyered cuboid cell epilhelium

4) anal skin

5) peri-anal skin

6) sutal verge

7) dentalle line

8) and valves

9) columns of Morgagni

10) anal gland

11) Haemorthoidal superior plexus

12) haemorthodal inferior plexus
13) submucosal amal muscle (Treilz)

14) internal anal sphincter

45) circular rectal muscle layer

16) Houston valve

17) longitudinal rectal muscle layer

18) longitudinal anal muscle

19) subcutaneows part external sphincter

20) superficial part internal sphincter

$21)$ deep part external sphincter

22) pubo-rectal sling

23) levator ani 
musculature as well as the internal anal sphincter and the anal mucosal surface originate from the entoderm. The external sphincter and the puborectal sling are formed by the mesoderm. the anal skin caudal from the dentate line being of ectodermal origin. The theory that the smooth musculature is directly of entodermal origin is likely to be erroneous. This tissue is probably formed by the entodermal covering mesenchym (52). The anal skin has a unique structure; it is very thin, closely connected to the substratum. It contains no hair follicles or other skin adnexae. Distal to the dentate line the skin gradually thickens and after about two centimeters there appear sweat and sebaceous glands and hair follicles. Behind the valves of the dentate line sinuses or crypts can be found that are covered with the formerly described multilayered transitional epithelium. From some of these crypts anal glands originate. These are ducts covered with the same epithelium as the crypts. These anal glands strongly ramify and often penetrate the internal sphincter (122), or even penetrate into the ischiorectal space through the external sphincter. According to Goligher these glands are not likely to have any secretory function (43).

\subsection{Arterial blood supply}

The blood supply of the rectum and anal canal is provided for by several arteries. The superior haemorrhoidal artery is the descending branch of the inferior mesenteric artery. This artery runs downward through the mesocolon and reaches the back of the rectum opposite the third vertebra of the sacrum. It then divides into two branches. one left and one right, descending to the lateral side of the rectum. They each break up into smaller branches which penetrate the several muscle layers and then proceed downwards submucosally through the columns of Morgagni, where they just above the anal valves of the dentate line end in a capillary plexus. In many cases it is possible to feel these submucosal artery-branches and it is possible to record the arterial pulse during an anal pressure measurement superposed on the recorded muscular pressure waves (see fig. 1.2).

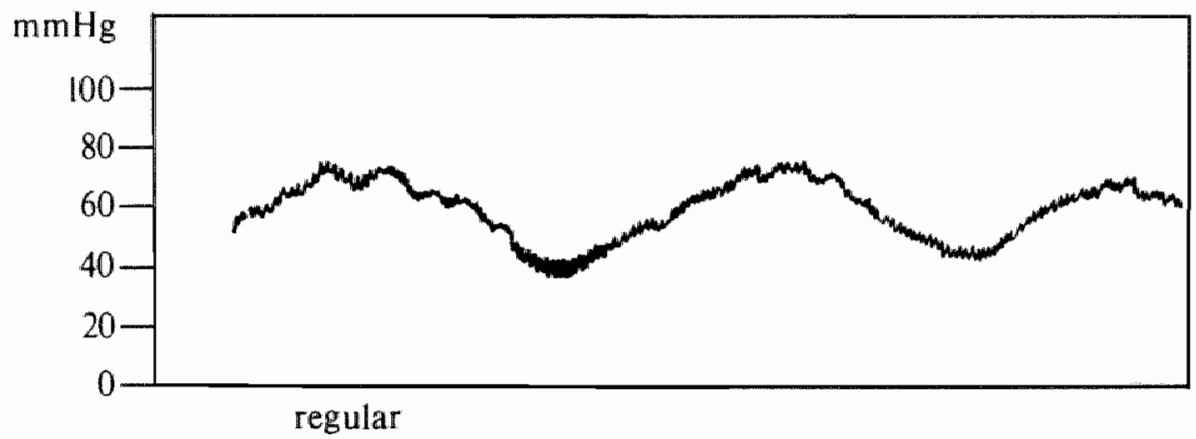

Figure 1.2 Artery pulse superposed on pressure waves 
There is a difference in the dividing pattern of the left and right main branches of the superior haemorhoidal artery (71). Mostly the left one remains undivided over a long distance, whereas the right one. usually immediately after penetrating the muscle layers. divides into two branches. These arteries are accompanied by the superior haemorrhoidal veins. This asymmetry could be the reason that uswally three main haemorrhoids are found: one at three o'clock (left), and the other two at seven and eleven (right) in lithotomy position. The several branches of the superior haemorrhoidal artery form a series of loops around the lower end of the rectum and the anal canal and anastomose there with branches of the middle and inferior hamorrhoidal artery (see fig. 1.3). Other reasons for the dividing pattern of haemorrhoids will be discussed later (see fig. 5.2). The middle haemorrhoidal arteries originate from the anterior divisions of the internal iliac arteries. There is great variety in their arrangement, but normally they reach the anus at the level of the levator ani.

The inferior haemorrhoidal arteries are indirect branches of the internal iliac arteries and spring from the internal pudendal arteries. Its branches penetrate the internal and external sphincters and form a plexus subcutaneously in the lower end of the anal canal.

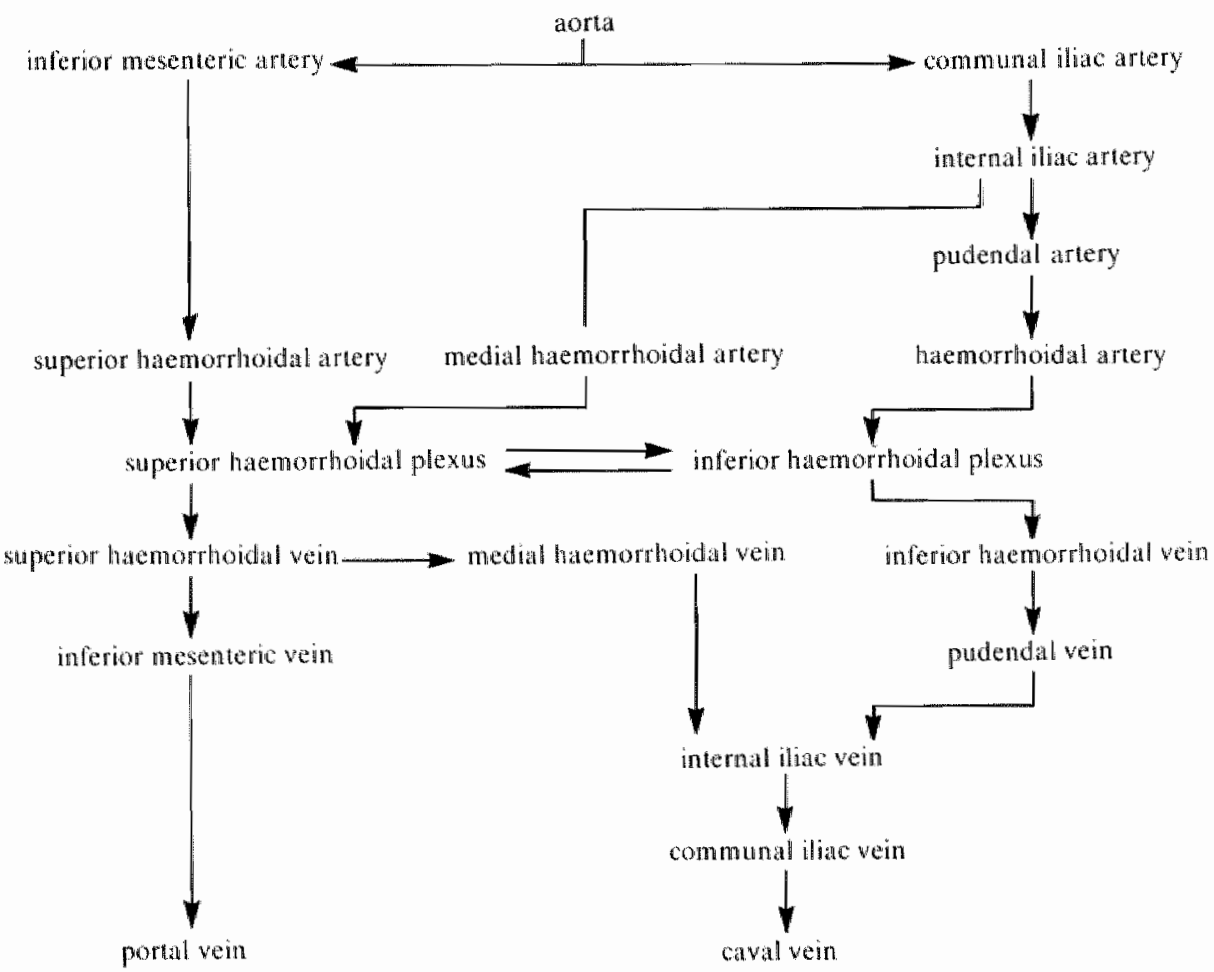

Figure 1.3 Bloodsupply of the anal canial 
The blood supply from the superior haemorrhoidal artery is by far the most important, but the contributions of the middle and inferior haemorthoidal arteries alone can be sufficient. In a low anterior resection the main blood supply of the rectum is cut off by dissecting the superior haemorrhoidal artery. The middle and inferior hemorrhoidal arteries, however, always provide the remaining area with sufficient blood, so necrosis of the distal stump almost never occurs $(5,40,43,48,105,114,139)$.

\subsection{Venous blood supply}

The veins of the rectum and the anal canal run closely along the corresponding arteries. The internal haemorrhoidal plexus lies in the submucosa of the anal canal. This plexus contains several dilated pouches from which the blood flows to the three main vein systems, the superior, middle and inferior haemorrhoidal veins (see Figure 1.3). In fact there are two plexuses. The superior venous plexus lies above the dentate line and is covered by the mucosa of the rectum and the upper anal canal. The inferior haemorrhoidal plexus is situated beneath the dentate line and is covered by the anal skin. The systems anastomose with each other. The superior haemorrhoidal plexus drains into the superior haemorrhoidal vein and from there into the inferior mesenteric vein and is therefore part of the portal system. The middle haemorrhoidal veins drain into the internal iliac vein. The inferior haemorrhoidal veins are supplied with blood from the inferior plexus and drain into the internal iliac veins and therefore into the systemic circulation. Thus, in the haemorrhoidal plexuses there exists a connection between the portal and the systemic circulations. The portal system does not have valves and is therefore especially susceptible to back pressure $(5,40,43,48,105,114,139)$.

\subsection{Nerve supply}

The rectal nerve supply contains fibres from the autonomic nervous system (43). The sympathetic fibres descend from the presacral plexus via the pelvic plexus. The presacral plexus and hypogastric nerve lie just below the aortic bifurcation. Here it divides into two nerves that reach both lateral pelvic plexuses. Post-ganglionic fibres originate from these plexuses and supply the rectum (27). The parasympathetic supply of the rectum is provided for by fibres from the sacral nerve. They synapse also in the pelvic plexuses and their post-ganglionic fibres accompany the sympathetic fibres and their ultimate branches penetrate the fascia of Waldeyer and reach the muscular layer of the rectum (see Figure 1.4).

The rectum also contains a part of the independent enteric nervous system, ganglion cells and their fibres. These cells are found in the submucosal and myenteric plexus.

The nervous supply of the anal canal is more complex. The internal splincter is 
pre-artic plexus

nervi erigentes of the sacral nerwes

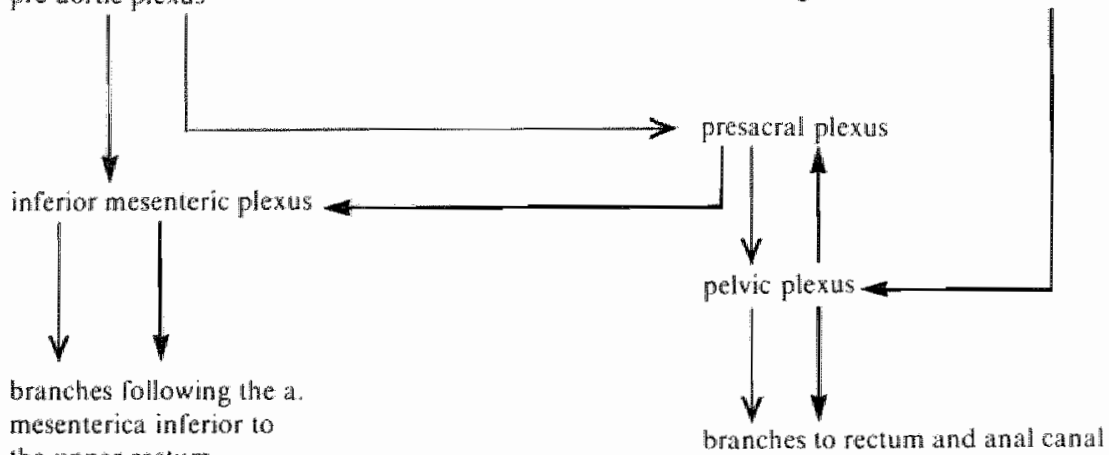

sympathetic nerve fibres

parasympot thetic nerve fibres

Figure 1.4 Autonomic nerve supply of the rectum and anal canal

supplied in the same way as the rectum by sympathetic and parasympathetic fibres. The plexuses of the enteric nervous system, however, are not present in the anal canal. The voluntary striped muscles of continence (external sphincter. levator ani etc.) have three sources of nerve supply: the inferior haemorrhoidal branch of the internal pudendal, the perineal branch of the fourth sacral nerve. and the inferior haemorrhoidal nerve.

The sensory innervation of the lower cutaneous part of the anal canal is conveyed by the afferent fibres of the inferior haemorrhoidal nerve. Microscopic study of the sensory nerve endings in the anal region by Duthie (28) showed that the perianal skin contains only peritrichial endings and free intra-epithelial endings. In the anal canal the skin contains free intra-epithelial endings and organized endings, many of which belong to the classical types, (Golgi Mazzoni. Krause, Messner and Pacini). In the mucosal part of the anal canal also free and organized endings can be found. The rectal mucosa contains no afferent nerve endings. The afferent fibres of the rectum are found in the muscle layers, and probably pressure receptors can be found in the surrounding muscles $(123,142)$.

\subsection{Muscles}

Several muscles around the anal canal, the rectum and in the pelvic floor are important to continence and have implications for therapy of haemorrhoids. 


\subsubsection{Internal sphincter}

The internal sphincter is a circular muscle, a thickened continuation of the circular muscle of the rectum. In the rectum this circular muscle forms a complete covering of the rectal cavity, being part of each Houston valve. The internal anal sphincter is about $4 \mathrm{~cm}$ in length, encircling the anal canal over almost its full length. It has a thickness of about $3 \mathrm{~mm}$. Between its lower border and the medial aspect of the subcutaneous part of the external sphincter there is a distinct depression palpable (Milligan and Morgan)(107). This intramuscular depression disappears during defaecation and under anaesthesia. The external sphincter then relaxes and is displaced outwards and upwards. The anal canal thus becomes shorter. The internal sphincter is composed of unstriped muscle fibres and is involuntarily contracted under normal conditions.

\subsubsection{Submucosal anal muscle}

The submucosal anal muscle is a thin muscle of unvoluntarily contracting longitudinal unstriped fibres. lying directly submucosally between mucosa and the internal sphincter. This muscle is a continuation of the submucosal recial muscle with addition of fibres of the conjoined longitudinal muscle which penetrates through the internal sphincter obliquely from above. At the lower end the fibres interdigitate with fibres from the external sphincter subcutaneously and partially insert in the perianal skin. Thomson (145) calls this muscle the muscle of Treitz. He describes its origin as follows: its fibres arising partly from the internal sphincter and partly from the longitudinal muscle curve inwards and downwards. It forms a metwork around the haemorrhoidal venous plexus and its fibres fan out into the perianal skin and partly rejoin the longitudinal muscle fibres around the lower border of the internal sphincter. The muscle of Treitz is found to contain a considerable amount of elastic tissue. This muscle forms the supporting tissue of the haemorrhoidal plexus.

\subsubsection{Longiadinal muscle}

The longitudinal muscles of the rectum and the anal canal are the continuation of the taeniae coli. Below the promontorium sacri the taeniae spread out over the entire circumference of the rectum. The longitudinal muscle layer does not follow the curve of the Houston valves. At the level of the levator diaphragma its fibres are joined by striped fibres of the puborectal muscle. At the level of the anal canal the longitudinal muscle is thicker and contains more fibro elastic rather than muscular fibres. Gabriel (40) and Goligher (43) both stated that the fibres of the longitudinal muscle fan out through the external sphincter (the subcutaneous part) and insert into the skin (see fig. 1.11). Some fibres pass laterally between the subcutaneous and the superficial part of the external sphincter to join the perianal fascia. Other fibres fan out through the deeper part of 
the external sphincter and reach the ischiorectal space. The last portion of fibres passes through the internal sphincter and inserrates with fibres of the submucosal muscle in the mucosa and there forms, as. Parks describes, the mucosal suspensory ligament (43). Shatik (134) describes a more complicated form of the longitudinal muscle and depicts a three layered longitudinal muscle separated by four fascial septae. In his view the lower end of this muscle is the fascia centralis from which some fibres penetrate the subcutaneous external fascia.

\subsubsection{External sphincter}

The externall sphincter is an annular striped muscle situated around the unstriped internal sphincter. Most authors describe three different parts of this external sphincter (Gabriel)(40), (Shafik)(131,132,133,134). Eisenhammer (32) and Morgan et al.)(107). In his histological sections Goligher (43) found no indication for division of the external sphincter into three separate parts. He mentions that only the lowest subcutaneous part differs from the rest of the sphincter in its traversion by the fanshaped expansion of the longitudinal muscle fibres. All other authors recognize: the subcutaneous external, the superficial external, and the deep external sphincter.

These three parts are also mentioned in the anatomy atlases $(5,48,114.139)$.

The subcutaneous part is situated immediately underneath the skin at the anal margin. directly caudal of the internal sphincter. If the subcutaneous part of the external sphincter is contracted, the length of the anal canal increases and an intramuscular depression between the internal sphincter and the subcutaneous part of the external sphincter can be felt. In surgery the fibres of the external sphincter can be recognized by their red colour. The fibres of the internal sphincter are pale white. The subcutaneous part of the external sphincter is not only an annular muscle but Shafik (133) describes its form as the base loop of his three loop system of the external sphincter (see fig. 1.5). In this base loop many fibres attach to the skin anterior to the anus or to the perineal body. The

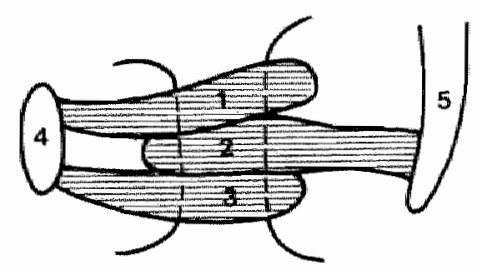

Figure 1.5 Shafik s tri-loop system

1) deep part of the externali sphincter

2) superhicial pat of the external sphincter

3) subcutaneous part of the external sphincter

4) os pubisis

5) os cocogis 
superficial part of the external sphincter is posteriorly attached to the os coccygis. It forms the intermediate loop of Shafik's three loop system. In cross-section the superficial externai sphincter is partially U-shaped. Posterior of the anus its fibres enclose the deep postanal space. This is of importance in that it provides a free communication between both ischiorectal spaces, so that if an abcess anses in the postanal space pus can spread into both ischiorectal spaces. causing a horseshoe abcess (131). The deep external sphincter is an annular muscle so intimately related to the musculus puborectalis that in sections it is impossible to differentiate between them. Posterior the fibres of the deep external sphincter encircle the anus without any attachment to the os coccygis. Anteriorly about half of the fibres completes the circle around the anus, whereas the other half crosses the midline and attaches crosswise to the ascending ramus ischiae. The deep external sphincter forms Shafik's top loop (133).

\subsubsection{Levator ani}

The musculus levator ani is a broad thin muscle. Its fibres attach peripherally to the inner surface of either side of the pelvis and medially they unite with fibres of the opposite side. It forms the floor of the pelvic cavity. The muscle is divided in to three parts.

- The puborectal sling has been mentioned before as a companion of the external sphincter. Its fibres form a U-shaped strong muscular sling. They arise from the lower back part of the symphysis pubis and the upper layer of the triangular ligament. These fibres meet the fibres of the opposite side immediately behind the bowel at the level of the rectomanal junction.

- The musculus pubo-coccygeus arises from the back of the pubis along a line extending from the lowest limit of the symphysis to the obturator canal, and from the anterior part of the obturator fascia. The fibres are directed almost horizontally backwards along the side of the lower part of the rectum as a flat ban which lies superior to the innermost fibres of the ilio-coccygeus region to fuse with their fellow fibres of the opposite side thereby constituting a broad fibrous band lying on the ano-cocygeus raphe. formed by the ilio-cocygeus. This band is continued up in front of the coccyx to be inserted into the anterior aspect of the first vertebra of the coccyx and the last segment of the sacrum (43).

- The musculus ilio-coccygeus arises from the posterior part of the white line of the pelvic fascia covering the obturator internus, and from the ischial spine. Its fibres insert into the last two segments of the sacrum and the anococcygeal raphe of the levator muscle, a median fibrous band which stretches between the anus and the superior surface of the coccyx (43).

Shafik (132) has another name for the most medial fibres of the levator ani. He speaks about the levator crurae which bound the levator hiatus. In this concept the crurae are a part of the ilio-coccygeus and the puborectal sling lies beneath them. 


\section{Physiology}

This chapter will deall with the sensory and motor innervation of the rectum and the anal canal and the function of the several muscles of the continence organ at rest and during defaecation.

\subsection{Sensibility of the anal canal}

The sensorial systems of the colon and rectum and anal canal are quite different. As shown by Duthie and Gairns (28) there is a difference in kind and amount of several nerve endings between the anal canal and the rectum.

Fifteen subjects, without any anorectal problems were tested upon. Tactile sensibility, pain and temperature discrimination tests were performed at several levels in the anal canal and compared with the histological findings in those platces..

The perianal skin has pain, touch and temperature sensation the same as, e.g.. the fingertips. In the perianal skin peritrichial nerve endings, some free nerve endings and no organized endings are found.

In the anal canal Duthie and Gairns (28) found many organized and free nerve endings up to a few centimeters cranial of the dentate line. In this region pain is felt more vividly than in the normal skin, especially near the valves of the dentate line. Pain can be felt to a cranial limit of about 1,5 centimeters above the valves. Pain sensation is more marked in the anal canal than in the perianal skin. but less well locilized, so that a subject could estimate approximately at what level in the anal canal the stimulous was given, but its localisation around the circumlerence was indefinite. The same intensified sensitivity to touch and to temperature was found, but localization was poor. The upper limit of touch sensation was at about $1 \mathrm{~cm}$ above the anal valves. For temperature the border was just above the dentate line.

In the rectal mucosa there was no sensation of touch, pain or temperature. At this level Duthie and Gairns (28) found no nerve endings.

\subsubsection{Sensibility of the sigmoid}

Goligher and Hughes (44) investigated special aspects of sensibility in rectum and sigmoid. A balloon was inflated at several levels in the sigmoid, measuring 
the minimum pressure required to produce a sensation and patients were asked for a description of this sensation. These tests were performed on normal subjects and on patients who had interrupted nerve supply to the bowel, or underwent a resection of the rectum. About three seconds after the inflation of the balloon in the sigmoid the subject felt a full sensation in the lower abdomen. sometimes pain. After forty seconds the pressure in the balloon gradually fell and the sensation waned. probably due to relaxation of the sigmoid.

\subsubsection{Sensibility in the rectum}

Goligher and Hughes (44) found that, about two seconds after inflation of a balloon in the rectum the subject experienced the sensation of flatus or faeces in the rectum requiring evacuation. The site of origin of this sensation is situated in the rectal wall. In the mucosa of the rectum it is impossible to find nerve endings, but there are nerve endings in the musclelayers. Perhaps some of these, indistinguishable from the motor nerve endings in the intramural plexuses. are responsible for this rectal sensation. Distension of the bowel up to $15 \mathrm{~mm}$ from the anal orifice causes the sensation of fullness and the desire to evacuate the rectum contents. Distension above this level produces only pain and no urge to defaecate. In patients with interrupted nerve supply to the rectum and colon, colonic pain sensation is found to be mediated by fibres in the sympathetic nerves, and the rectal type of sensation by the parasympathetic nerves $(37,43)$. The rectal type of sensation never develops in a colostomy but could remain in a very-low-anterior-resectioncolon stump. This last observation could imply that nerve endings outside the rectum in the pelvis could contribute to such sensations. The special ability to distinguish between flatus and lateces is most likely not situated in the rectum. Duthies $(28,29.31)$ suggestion that the ability to discriminate between gas, fhuid and solid originates in the mucosa of the upper part of the anal canal and not in the rectal mucosa is most likely to be correct. The mucosa of the proximal anal canal contains many nerve endings and the amazing discrimination sense is kept in tact. even after low anterior resection.

\subsection{Anal inhibitory reflex}

Several investigators have studied the influence of a mass in the rectum on the anal sphincter. Several methods for measurement of the pressure of the sphincters are used. These methods will be discussed later.

For the normal anal inhibitory reflex an intact rectal sensation is necessary. There must be a good awareness of the arrival of material in the rectum. All investigators mimicked this stimulus by insufflating a balloon in the rectum $(23,29,34,35,37.38,43,44,101$ ) (see Fig. 2.1). In normal subjects all found a high pressure zone in the anal canal with a peak at about $2 \mathrm{~cm}$ above the anal verge. The height of the peak pressure varies greatly, most likely due to the diversity 


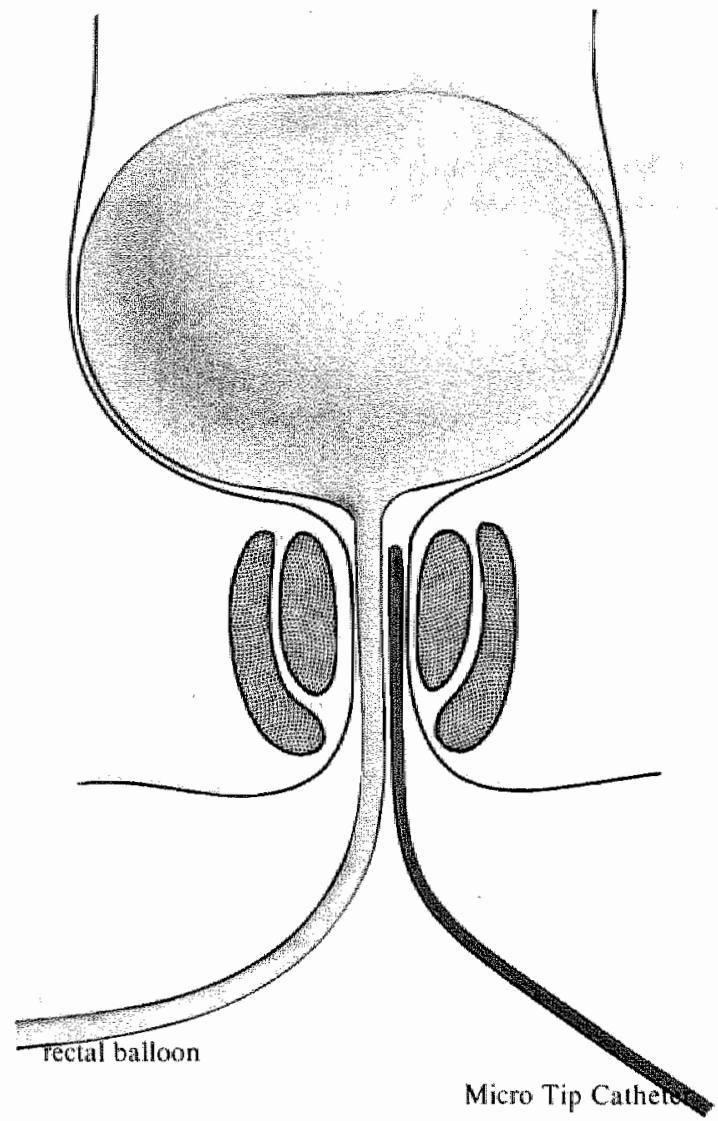

Figure 2.1 Ano-rectal inhibition reflex measurement

of the methods of measurement used. When a bolus arrives in the rectum, or a balloon is inflated, there are three patterns of response (Duthe 1975):

I Accommodation: when insufflating the balloon, the rectum expands slowly to accommodate the bolus, and the pressure measured by a probe in the anus decreases. In normal persons the internal sphincter relaxes when the rectum is stimulated by distention. The pressure fall in the anal canal is dependent on the amount of air insufflated in the balloon (23). The external sphincter reacts with a reflex contraction. This reflex causes the bolus to be retained in the rectum until a suitable time for voluntary defaecation. Reflexly at first, and then voluntarily if desired, the external sphincter pre- 
vents the anal canal from opening despite relaxation of the internal sphincter. After accommodation of the rectal wall (compliance) the internal sphincter regains its tone.

2 Sampling: a brief inflation of the balloon results in some relaxalion of the internal sphincter so that the rectal contents may come into contact with the sensory epithelium of the upper part of the anal canal. This can also be accomplished by a short valsalva manoeuvre. The ability to discriminate gas solids or liquids is a unique property of the anal mucosa (Duthie)(29). When the subject wishes to evacuate the rectum contents a voluntary relaxation of the striped muscle fibres of the external sphincter and the puborectal sling occurs and the anal canal opens. When it is not suitable to defaecate the striped muscle fibres remain contracted by voluntary effort.

3 Defaecation: when an increasing amount of air is insufflated into the balloon and a maximum tolerable volume is reached not only will a complete relaxation of the internal sphincter follow, but also an unpreventable relaxation of the external sphincter as the response to an overwhelming urge to defaecate. The maximal tolerable volume varies from person to person, but the average decreases in older subjects (43). A second form of defaecation is a voluntary relaxion of the external sphincter following sampling without a great volume in the rectum.

In patients with Hirschsprung disease there is an aganglionosis of the rectum or a part of it. The propriocepsis of the rectal wall fails and therefore the rectoanal inhibitory reflex will be absent.

Anorectal manometry is nowadays one of the most reliable methods of diagnosing Hirschsprungs disease (50).

\subsection{Anal continence and defaecation}

It is not easy to give an acceptable definition of continence, because continence is not only dependent on the occluding mechanisms of the anus, but also on the fluidity of the stool. Someone with an intact nervous and muscle system can be incontinent when he has severe diarrhea, whereas a patient with damage to his anal sphincters can be continent when he has firm stool. Beside that the personal acceptance of losing stool or lack of control over flatus and soiling is very different from one person to another. The exact meaning of the term incontinence. is mostly badly defined in literature.

Schweiger (128) defined incontinence as the state in which three of the following symptoms were present:

- no controll on firm stool.

- no controll on fuid stool

- loss of stool during coughing or other abdominal pressure rise

- controll on flatus

- no time to reach the next toilet after initial urge to defaecate

- no sensation of rectal or anal contents 
The presence of one or more of these symptoms can give a graduation in the severity of incontinence.

Anal continence is the patients personal interpretation of his ability to retain bowel contents until evacuation is suitable.

There are several theories about the mechanism of continence. These theories will be discussed in this chapter. In chapter 4 experiments with a new method of pressure measurements and conclusions about continence and defaecation will follow.

\subsection{Theory of high pressure zone}

The average anal pressure of 25 to $120 \mathrm{~mm} \mathrm{Hg}$ (varying from person to person and depending on the method of pressure measurement) is enough to be an effective barrier against the pressure in the rectum. The high pressure zone in the anal canal does not mean there is a constant high pressure over its total length. In different sections in the anal canal there can be different pressures. These variations were measures by several authors $(23,29,35,36,37,53$. $54,101,127)$. The length of the anal canal varies from 3 to $5 \mathrm{~cm}$. It is impossible to say at which distance from the anal verge the highest pressure will be found. The peak pressure can be found at any distance from the anal verge, but the average spot of peak pressure is at $2 \mathrm{~cm}$ from the anal verge. Which of the sphincters is responsible for the anal pressure has been the subject of several publications by $B$. Frenckner $(36,53,54)$. The anal pressure is mainly generated by the internal sphincter. As mentioned before the anal sphincter is innervated by sympathetic nerve fibres and by parasympathetic fibres from the sacral nerves. Additional innervation is possible from local nerve pathways in the gut wall of purinergic character as the nerve transmitter seems to be neither adrenergic nor cholinergic $(16,37,42)$. Frenckner and thre $(35,37,38)$ measured anal pressure at rest and during inflation of a rectal balloon in patients

I with low spinal anaesthesiat (parasympathetic blockade)

2 high spinal anaesthesia (parasympathetic and sympathetic blockade and partial blockade of the striped pelvic muscles)

3 with a bilateral pundendal block in which the striated muscles are partly paralysed without affecting the autonomic innervation of the internal sphincter.

At rest there was a significantly larger fall in anal pressure of the high spinal blockade than in a low spinal block or bilateral pudendal block. Their conclusion was that at rest there is a tonic excitatory sympathetic discharge to the internal anal sphincter. During relaxation of the internal sphincter by insufflating the rectal balloon the anal pressure does not decrease significantly less under low spinal anaesthesia, thus suggesting that the parasympathetic supply to the internal sphincter does not effect its relaxation. An explanation for this 
fact has not been found yet. In bilateral pudendal blockade there is a pressure fall of $15 \%$ in the anal canal at rest.

Their conclusion is that the internal sphincter contributes for $85 \%$ to the anal pressure at rest. In sudden. substantial distension of the rectum the contribution of the internal sphincter is only $40 \%$. During constant distension of the rectum a contribution of $65 \%$ of the internal and $35 \%$ of the external sphincter was found. Frenckners conchusion is that at rest the pressure in the anal canal is mainly caused by the internal sphincter.

These figures of Frenckner seem to give more preciseness than is justified. By pudendal blockide the nerve supply to the external sphincter is not completely paralysed and pudendal blockade can also be responsible for influence on the autonomic pathways to the internat sphincter: nevertheless his conclusion that the internal sphincter is chiefly responsible for anal pressure seems to be right. The same conclusions were found by Schweiger (128). He combined pressure measurement and electromyography. He studied testees before and during general anaesthesia with curare. He performed manometry at the moment that during anaesthesia all activity in the external anal sphincter had disappeared, and then found that the internal anal sphincter contributes for $79 \%$ in the pressure of the anal canal.

Own experience in manometry in only a few patients during general anaesthesia showed also a pressure fall of about $30 \%$.

Schuster's method (127) of measuring at several levels in the anal canal and his conclusion that for the pressure in the distal end of the anal canal only the external sphincter is responsible, is not correct. The anatomic situation in rest makes it unlikely that the internal sphincter had no influence on the measurements at that point (128).

In the event of sudden distension of the rectum a relaxation of the internal sphincter follows and continence is maintained only by the striated external sphincter muscles. The external sphincter cannot continue this pressure for a long time and gets support again from the internal sphincter. The internal sphincter regains its tone after adaptation of the rectum to the larger wolume. In 1965 Duthie (30) came almost to the same conclusion; at rest with no pressure in the rectum there is hardly any contribution of the external sphincter to the pressure in the anal canal when measured with a small open-ended tube. Duthie only sees a pressure contribution of the external sphincter when he performs the measurements in the anal canal with a balloon-tip catheter, and therefore suggests that the external anal sphincter only contributes to the pressure when a bolus is present in the anal canal.

Stelzner (141) has a completely different interpretation of the sphincter mechanism. He believes that the internal sphincter contracts instead of relaxes on a moderate balloon filling in the rectum. In his vision all measurements by other authors are wrong. He says that when the anal pressure is measured while dis- 
tending the rectum, the anal pressure measurement probe will always displace and the much lower pressure of the rectum instead of the pressure in the anal canal will be measured. In his vision the pressure in the internal sphincter increases on an increasing pressure in the rectum. The moment the rectal pressure is higher than the sphincter pressure the sphincter opens a little and the bolus comes into contact with the very sensible anal mucosa. At that moment the urge to defaecate is felt. Now there are two possibilities: total relaxation and defaecation or contraction of the voluntary striped external anal sphincter. and replacing of the bolus in the rectal cavity.

Shafik (133) has another theory about the sphincter working system. He believes in the separate working of his triple loop system, as mentioned in chapter 1.6.4. Each part of this system is sufficient to play the role of the total external sphincter. In his vision the internal sphincter is responsible for involuntary continence. This unstriped muscle can maintain continence for a long period, but cannot resist a call to stool and flatus. In Shafiks opinion the internal sphincter has a reciprocal function to the detrusor recti. The detrusor recti is the name for the total rectal muscle layer. Anologous to bladder function, the internal anal sphincter relaxes on a contraction of the detrusor recti. The external sphincter has a double function:

1 a voluntary inhibitory action (preventing the internal sphincter from opening on detrusor contraction) and

2 a purely mechanical function (by direct compression it can close the rectal neck entrance of the anal camal

When stool enters the rectum the detrusor will contract and the internal sphincter reffexly relaxes to open the rectal neck. The latter does not really open until the external sphincter voluntarily relaxes. When the anal canal is kept closed by the external sphincter and the internal sphincter cannot dilate the detrusor will reflexly relax. The mechanical voluntary occlusion of the anal canal by the external sphincter can only be maintained for a very short time. In condition of internal sphincter damage voluntary continence is induced only by the mechanical action of the external sphincter. In this case there is no reciprocal action on the detrusor. The latter will not relax and evacuation will follow after a short time when the external sphincter fatigues and relaxes (see fig. 2.2).

Support of the theory of the high pressure zone in the anal canal as the main source of anal continence is the fact that biofeedback in the management of partial incontinence works so well. Mac Leod (98) described a method of registrating the electric impulses, generated by the anal sphincters during contraction. The audible or visible signals were able to give the incontinent patient the feeling of what happened by contraction of the sphincter. In 74 percent of his patients there had been a successful restoration of continence by this biofeedback management. 


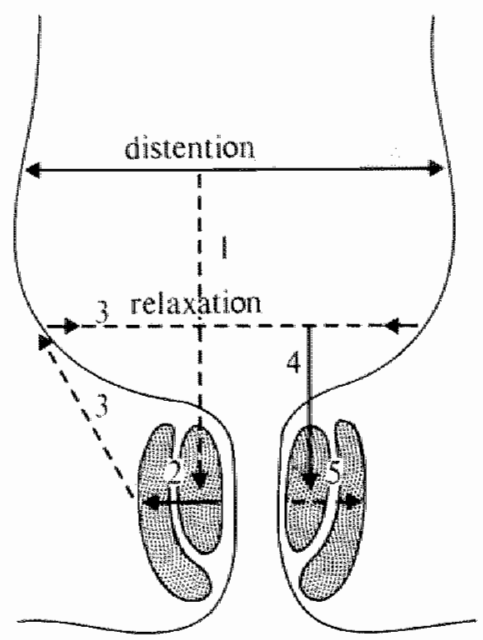

Figure 2.2 Ano-rectal inhibition rellex

1) distention of the rectum gives: relaxation of the internal sphincter

2) relaxation of the internal sphincter gives: contraction of the external sphincter

3) the tonus in the rectal wall diminishes

4) relaxation of the rectal wall gives: contriction of the intemal sphincter

5) contraction of the internal sphincter gives: refaxation of the external splincter

\subsubsection{Theory of $80^{\prime \prime}$ angle}

Besides the several theories about the pressure zone of the anal canal there are other theories on anal continence $(26,43,148)$. One of the oldest theories is the $80^{\circ}$ angle between the axis of the rectum and anal canal. This angulation, maintained by the puborectal sling, was thought to be important for continence. Kuypers (78) stated that increase in intra-abdominal pressure is not transmitted immediately on the anal canal in this way.

The effect of this 80 degree angle in maintaining continence is easily detectable. In squatting position the angle between anus and rectum disappears and in this position it is more difficult to maintain continence (26).

Another example of the effectiveness of the action of the puborectal sling is the fact that patients with an interrupted sphincter after sphincterotomy e.g. for high tistulae can be partially continent.

During defaecation the puborectal sling relaxes and the angle between anal and rectal axis increases to more than 100 degrees.

This phenomenon can be seen in defaecography. Figure 2.3 shows the flattening of the angle during defaecation. 

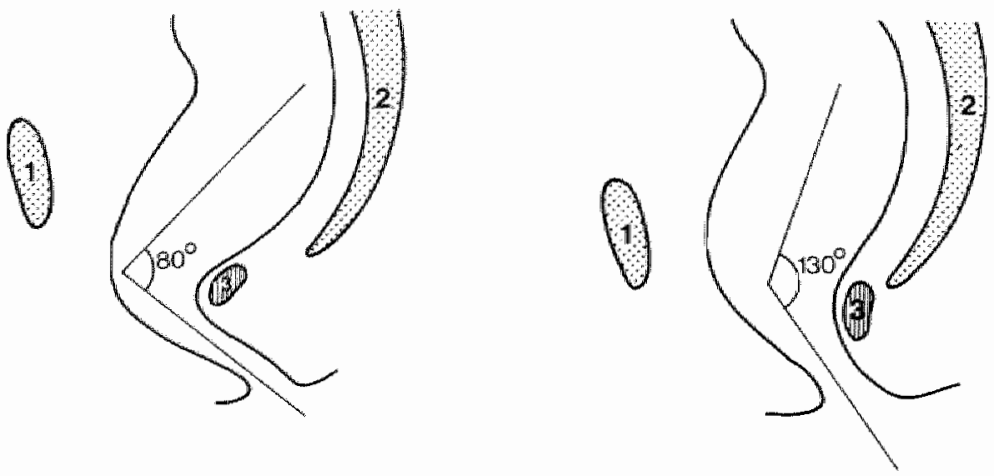

Frgure 2.3 Ano-rectal angle before and during defaecation

1) as pubis

2) sacrum

3) puborecial sling

\subsubsection{Theory of flutler valve}

Philips and Edwards $(43,127)$ thought that continence could also be maintained by intra-abdominal pressure being transmitted at the level of the levator ani laterally to the side of the anal canal in the region of the ano-rectal junction. It should work as a non-return flutter-valve by compression of the upper anal canal. About their hypothesis Goligher (43) says that he believes that their pressure measurements and their radiological findings are due to the activity of the puborectal sling and not to intra-abdominal pressure.

\subsubsection{Theory of corpus canernosi rech}

Stelzner (141) mentioned a very important additional mechasnism to maintain continence. He describes the corpus cavernosum recti. He states that the venous plexus haemorrhoidalis can act as a corpus cavernosum and can occlude the anal canal watertight by swelling inside the contracted sphincter muscle. This filled venous system gives the finishing touch to the closure of the anal canal. When the internal anal sphincter is maximally contracted always a lumen of about $8 \mathrm{~mm}$ will be left. When the sphincters are contracted, the venous backflow through the sphincters is obstructed and the corpus cavernosum is filled with blood by the normal arterial inflow. This is different from the system in the genital corpora cavemosa, that are filled by an increased arterial inflow $(58)$. 
The rectum usually contains litte or no material. The rectum wall contracts in waves of higher frequency than the sigmoid and produces a reverse pressure gradient that prohibits the stool from entering the rectum (26). When after at while faeces is propelled into the rectum it gives a reflex to defaccation. The rectum wall however is capable of adaptation (compliance)(26). It can distend during the time the sphincter does not voluntarily relax, and is even able to maintain continence for a short time in patients without a normal working anal sphincter mechanism. In tests with children Holschneider (63) found no pressure rise at volume rise in the first 4-5 water injections in the rectum. More volume gave a backflow into the sigmoid or led to pressure rise and defaecation. The rectum can contain a larger volume than its original size would suggest. 


\section{Anal pressure measurement}

For the last 20 years several methods have been used to measure the pressure in the rectum and the anal canal. The specificity of the designs of the measuring instruments often limits the information obtained. All instruments have their advantages and shortcomings. Goligher mentioned that all methods were to some extend unphysiological as they required a probe in the anal canal (43). A review of the several methods described in literature will be given. The specific method of recording anal pressure used in this study will be discussed in chapter 6 .

\subsection{Methods}

\subsubsection{Balloon catherers}

Schuster (127) describes a method of measuring anal pressure with a balloon catheter simultaneously in rectum, upper and lower anal canal (see Figure 3.1). His device, composed of a hollow cylindrical inner core of metal surrounded by two balloon compartments that fit in the anal canal is so constructed that it can maintain its position in the anal canal, when the balloons are inflated. A third balloon is inflated in the rectum at the top of the core. The fact that this device fits in the anal canal without having to be held in place seems to be an advantage. Other variations of the balloon catheter are required to be held in place manually. This requirement could predispose to artefacts. The pressure recorded by balloons increases as the diameter of the balloon gets larger (127). To approach physiological pressure the smallest possible probe should be used. Stretching the sphincter by inserting the balloon increases the anal pressure. Schuster calls this the anal reflex (127). In many of the published pressure measurements it is observed that the initial high pressure falls after a few seconds Hancock used a probe with only one balloon filled with water $(53,54,55,56,57)$. Neill (112). Arabi (6) and Frenckner $(35,36,37,38)$ followed the same procedure. Fluid-filled systems are incompressible and the results of their measurements are likely to be more physiological than the compressible airfilled systems. Katz (71). Collins (22) and Cortesini (23) measured the anal pressure with airfilled balloons. The body temperature will increase the pressure in the balloon notwithstanding the normal basic anal pressure. All these balloons 


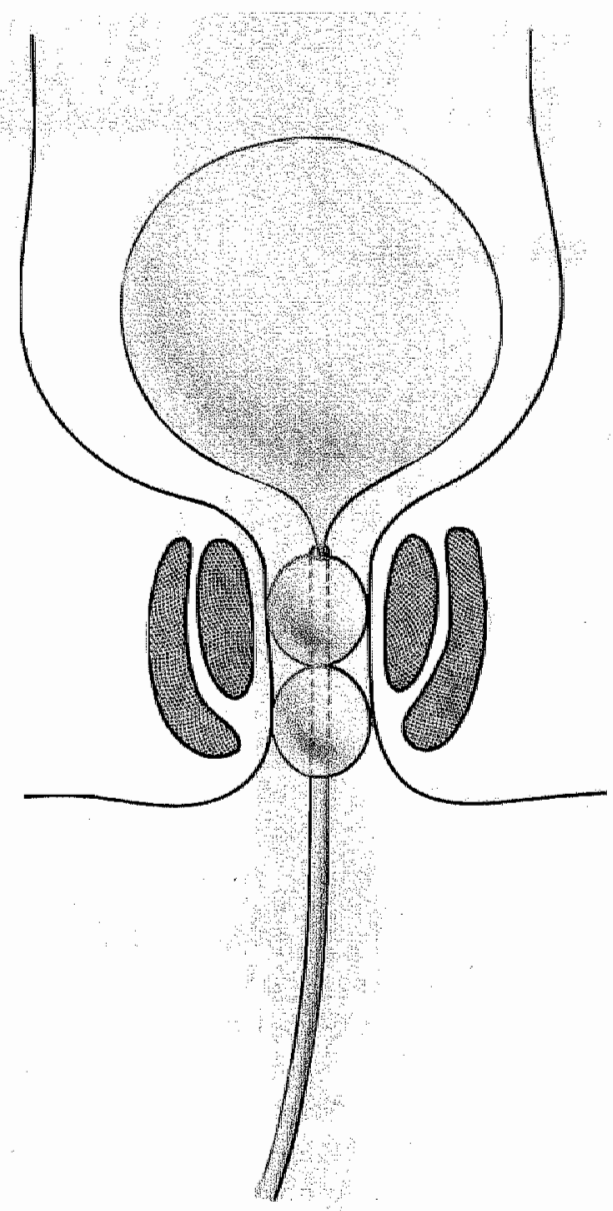

Figure 3.1 Double balloon calheter according to Schuster

have the disadvantage of needing a moderate filling before they can be used for pressure recording. Before inserting the inflated balloon the recorder should be put to zero to nullify the pressure that is already present in the balloon. But regardless of the anal pressure, the pressure reflection will rise because of the body heat, unless the standardization is performed in $37^{\circ} \mathrm{C}$ environment. In literature this precaution was never mentioned. Each balloon has its own compliance and its own characteristics. The height of the anal pressure found is dependent upon the size of the balloon. There are several uncertainties that make it impossible to interpret and compare all the findings of the different studies. 


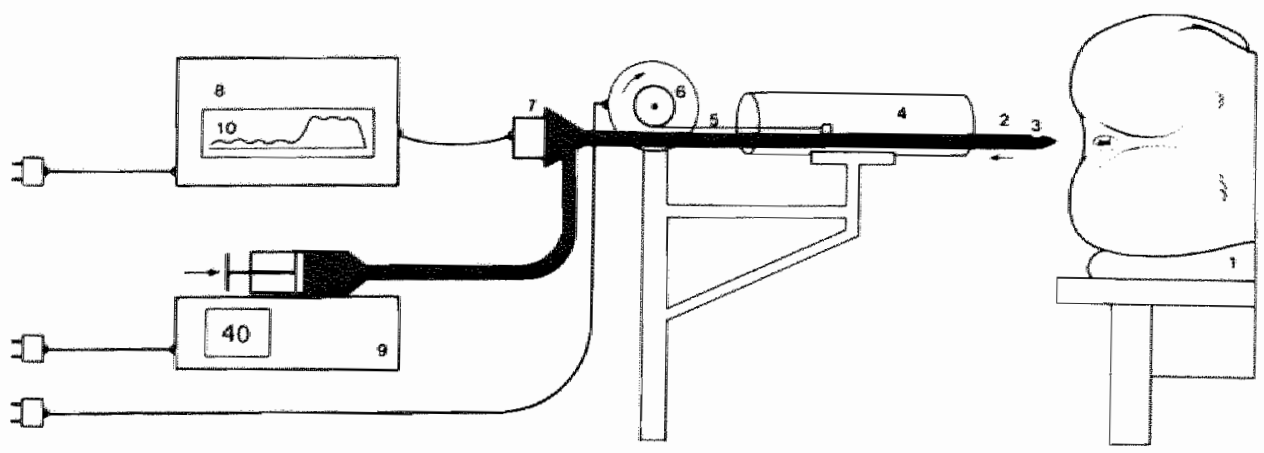

Figure 3.2 Open tip-catheter according to Kuijpers

1) patient in lateral position

2) catheter

3) side opening $4 \mathrm{~cm}$ from the tip

4) supporting lube

5) withdrawall string
6) $\operatorname{motor} v=1,38 \mathrm{~m} /$ hour)
7) transiducer
8) recorder
9) infusor
10) registration

\subsubsection{Open wip catherers}

The problem of various sizes is also present in the open tipped lubes used by Duthie (27.29,30), Harris (60). Holschneider (63), Wienbeck (153) and Kuypers (78). Their different sizes make them incomparable. Open tip catheters require the addition of water because an amount of liquid in the anal canal on top of the probe is needed in order to make proper measurements. The constant liquid flow is needed to prevent obstruction of the probe by mucosa or faecal material. The non-infunded catheter in a withdrawal curve in the anal canal gives the same pressure as found in the rectal cavity (78)(see Figure 3.2).

Kuypers (78) used an infundated catheter with a side opening. The pressure registrated was the opening pressure of the anal sphincter. When this pressure was reached the luid could flow freely into the rectum or out of the anal canal. It is likely that the results of open tip catheters are influenced by the amount of water that llows into the rectum or by the stimulus of the water itself on the sensible wall of the anal canal. Holschneider (63) found in $60 \%$ of his tests a relaxation of the sphincter internus when 5 to $20 \mathrm{ml}$ water was infundated into the rectum.

\subsubsection{Fonce gauge}

Collins, Duthie, Shelley and Whittaker (22) used a different kind of measuring instrument. They measured the radial force exerted by the walls of the anal canal with a force gauge (see Figure 3.3). The force gauge is a zeppelin-shaped cage with several bars. One of the bars is bonded to a single semiconductor 


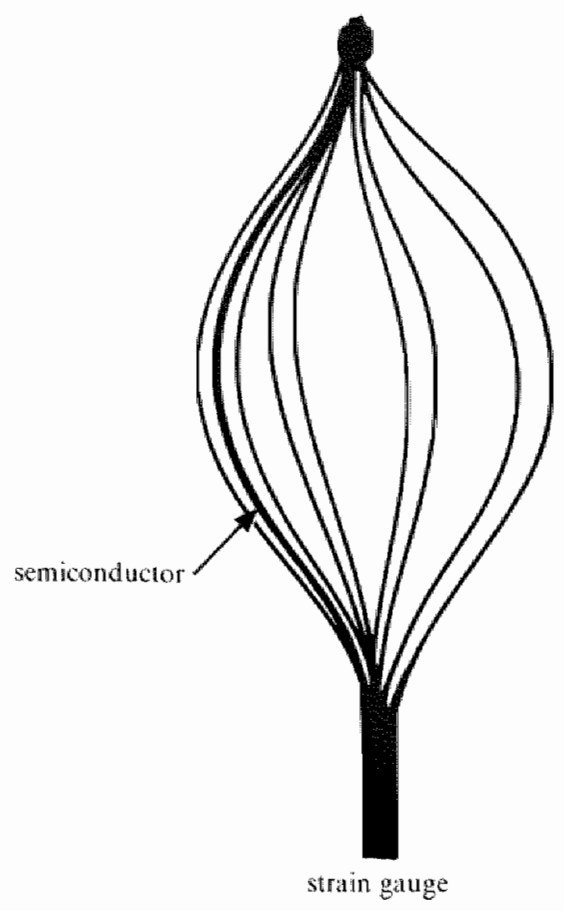

Figure 3.5 Force gauge

strain gauge. Any radial squeeze on the cage produced a change in curvature of the bars and hence a change in resistance of the strain gauge. This resistance change was sensed by means of a Wheatstone bridge circuit, the output of which was amplified and fed to a recorder. Using this instrument they found that the mean results were broadly similar to those of pressure measurement with balloon catheters. They concluded that the radial force was responsible for the pressure in the anal canal at rest.

\subsubsection{Electro myography}

Simultaneously with pressure measurements several authors performed electro myography $(22,43)$. The electrical activity of the external anal sphincter and muscles of the pelvic floor were recorded at rest and during defaecation.

\subsection{Types of measurements}

There are two types of measurement. The anal pressure can be measured at several distances from the anal verge or at a fixed location in the anal canal enabling to record the pressure as function of time. Most authors used both 


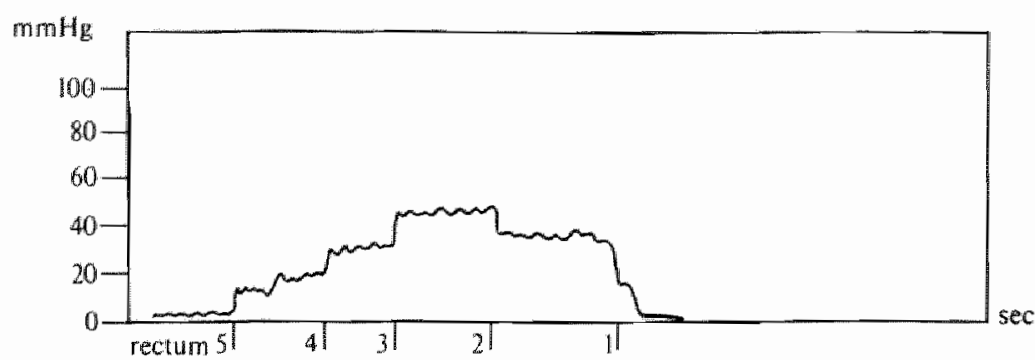

Figure 3.4 Wilhdrawal curve
5: $5 \mathrm{~cm}$ from the anal verge
2. $2 \mathrm{~cm}$ from the anal verge
4: $4 \mathrm{~cm}$ from the anal verge
1: $1 \mathrm{~cm}$ from the anal verge
3: $3 \mathrm{~cm}$ from the anal vere
0 : outside the anal canal

methods. They first made recordings at several distances in the anal canal and then they measured, for a longer period, at a fixed distance from the anal verge.

\subsubsection{Withdrawal curve}

The measurement at the various distances has revealed that the normal length of the anal canal is about 3 to $5 \mathrm{~cm}$. Mostly the highest pressure was found at 2 $\mathrm{cm}$ from the anal verge but sometimes the maximum was found at $1 \mathrm{~cm}$ and, of course, anywhere in between (see Figure 3.4). Duthie (29) diagrammed the mean pressures of functional anal sphincters in 29 normal subjects. The same pressure findings were noted by Cortesini (23), Frenckner $(35,36,37,38)$, Hancock $(53,54,55,56)$, Kuijpers (78) and Cerdan (17). The characteristic pressure pattern is a low pressure in the rectum. On withdrawing the probe the pressure increases at about $5 \mathrm{~cm}$ from the anal verge and reaches a maximum at about 2 $\mathrm{cm}$, then falling down to zero. Each individual has his own length of anal canal and his own point of maximal pressure. Therefore, it does not seem so useful to measure the second type of recording always at two $\mathrm{cm}$ as some authors did $(53,55,56,127,136)$. It seems better to find each patients point of maximal pressure and to measure there for a longer period $(35,36,37,38)$. The smaller the device of measurement the more feasible it is to find the exact point of maximal pressure. A large balloon, being too big to reflect the pressure of one specific location will always give an average pressure of several points.

\subsubsection{Pressure measurement ar one point}

Much work has been done by Hancock $(53)$ in recording pressures at one point in the anal canal $(2 \mathrm{~cm}$ from the anal verge) for a longer period. He found different motility patterns in resting patients suffering from haemorrhoids and 

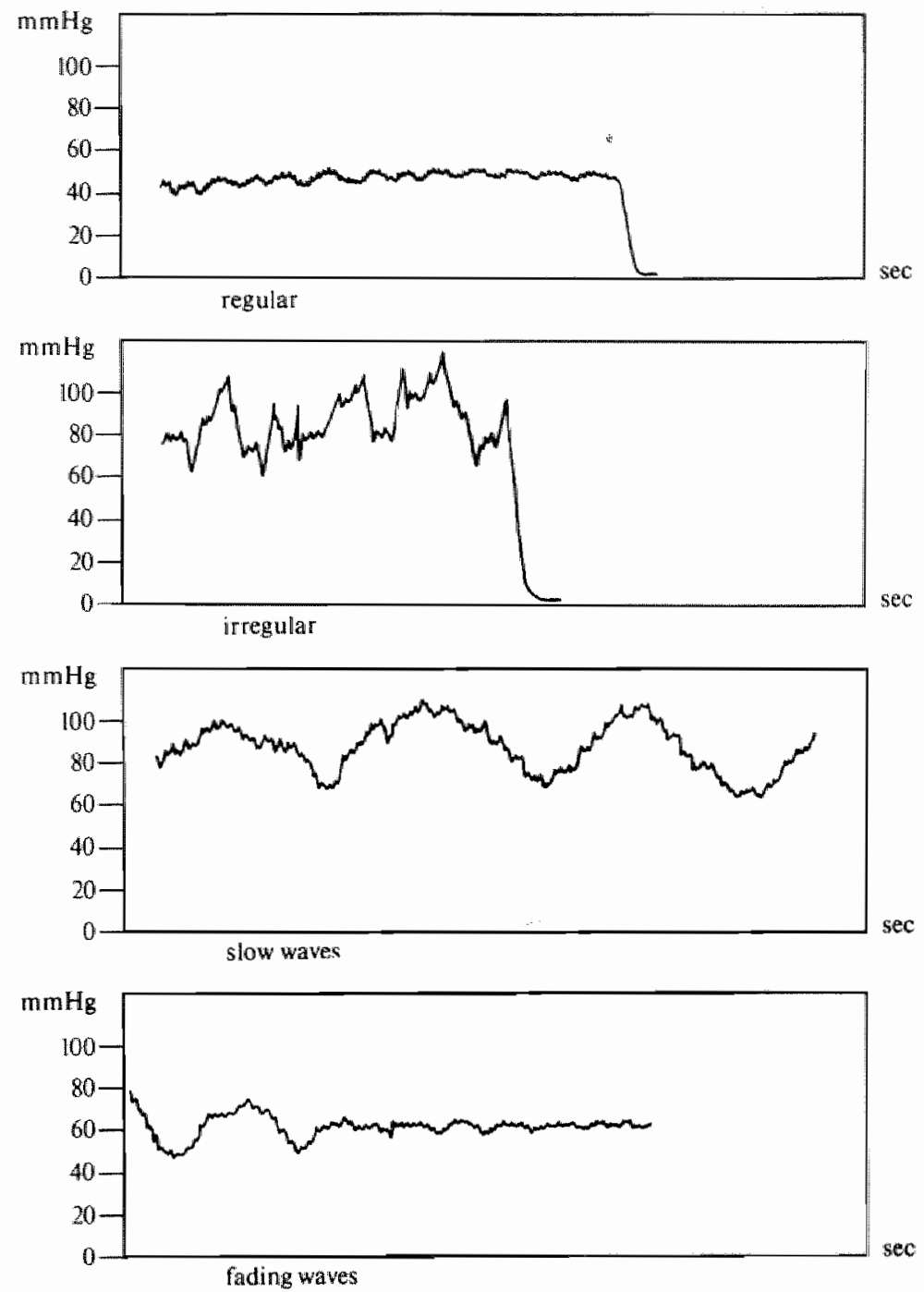

Figure 3.5 Pressure pattems

in normal subjects (see Figure 3.5). The patterns he found were:

1 flat (regular)

2 irregular

3 sustained slow waves

4 fading slow waves.

The fourth pattern is not likely to be a physiological one, but due to the stimulation during insertion of the device into the anal canal. 
In very long recordings these fading slow waves did not reappear spontaneously. They were only recorded just after inserting the balloon. This type of recording is what Schuster calls the anal reflex (127). Pressure recordings of patients with paralysed external sphincters showed the same patterns as those of patients with functional external sphincters. Therefore it is likely that the patterns of the anal pressure recordings are a reflexion of the function of the internal anal sphincter.

\subsubsection{Resting yield pressure}

A different way of recording is used by Harris (60) and $\mathrm{Katz}(71)$. They found that the force of the sphincters themselves is not so important. In their view the essence of the sphincters is the competence to resist distension. In his study Harris used open tip catheters and Katz an airfilled balloon probe. They only measured the pressure in the anal sphincter as a starting point. Then Katz filled the balloon step by step and Harris introduced small amounts of water. Both found a gradual increase of pressure. After a few steps further distension gave no further pressure increase and the sphincter accommodated to the increase of volume in the anal canal. The maximum pressure is called the resting yield pressure. This type of measurement seems very unphysiological. Harris reports that he can only record this pressure in placing his probe at a certain distance from the rectum-entrance. For his method of measurement it is required that the tip of the catheter is sealed by fluid. The sphincter and the mucosa must surround the fluid bubble at the end of the recording orifice. Katz was not able to inflate a balloon in the uppermost part of the anal canal because the distending balloon will bulge out into the rectum and he will measure the much lower rectal pressure. It is likely that an increasing amount of fluid in the anal canal can leak into the rectal cavity and influence the recorded pressure. Furthermore, the usual physiological distension of the anal sphincter first occurs in the uppermost part of the anal canal and not somewhere distal between rectum and anal verge, and $i t$ is in this part of the anal canal they both are unable to perform any measurements. 


\section{Measurements with the Millar microtip transducer.}

\subsection{Introduction}

As Goligher stated (43) every method to measure anal pressure is to some extent unphysiological because a probe is required in the anal canal. The pressure recorded by balloons increases as a larger balloon is used (127). To approach physiological pressure measurement the smallest possible probe should be used.

Studies with a force gauge (see 3.1.3) showed that the radial force was responsible for the pressure in the anal canal. The original force gauge of Collins and Duthie is larger, difficult to clean and has a zeppelin form. As replacement for this instrument we found a microtip cathether. In cardiological pressure measurements a Millar microtip catheter was used. This instrument seemed to have many advanlages above other devices for application in the anal canal. In Annadal Hospital in 1978 the first measurements were done in the anal canal. Technical aspects, advantages above other methods and applications in proctological practice will be discussed in this chapter.

\subsection{Technical aspects}

A Millar microtip catheter consists of an ultraminiature pressure sensor located in the distal end of the catheter. The electric connection is mounted on the proximal end of a Dacron catheter (see Figure 4.1). The Transducer Control Unit produces an electrical output signal that is in direct proportion to the magnitude of the sensor pressure.

This Millar catheter is normally used in cardiological pressure measurements and is extremely sensible to high frequency pressure movements. This catheter has a good thermal stability and the output will not vary more than $1 \mathrm{mmHg}$ over the range of $25^{\circ} \mathrm{C}$ to $40^{\circ} \mathrm{C}$.

The Microtip pressure sensor is a linear device and has an output accuracy of $0.5 \%$ from minus 300 to plus $400 \mathrm{mmHg}$.

The used catheter is a single pressure sensor transducer model P.C.370. The length of the catheter is $120 \mathrm{~cm}$ and the diameter $2.3 \mathrm{~mm}$. (see Figure 4.2 ).

The pressure on the tip of the catheter is converted to a proportional electric signal and this signal is transduced through an extension cable (Model TEC 


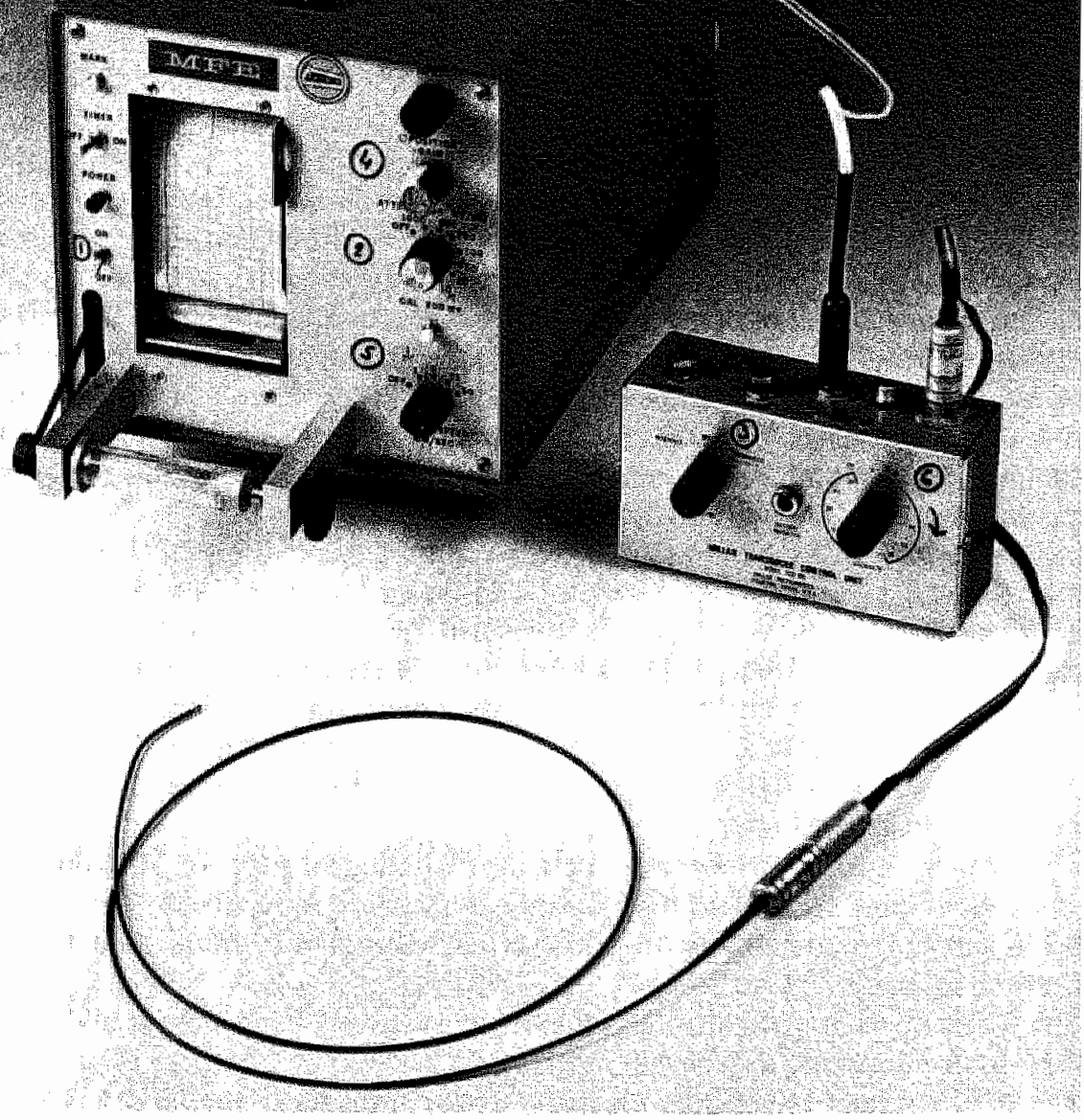

Figure 4./ Micro-tip pressure transducer with transdncer control unit and recorder 

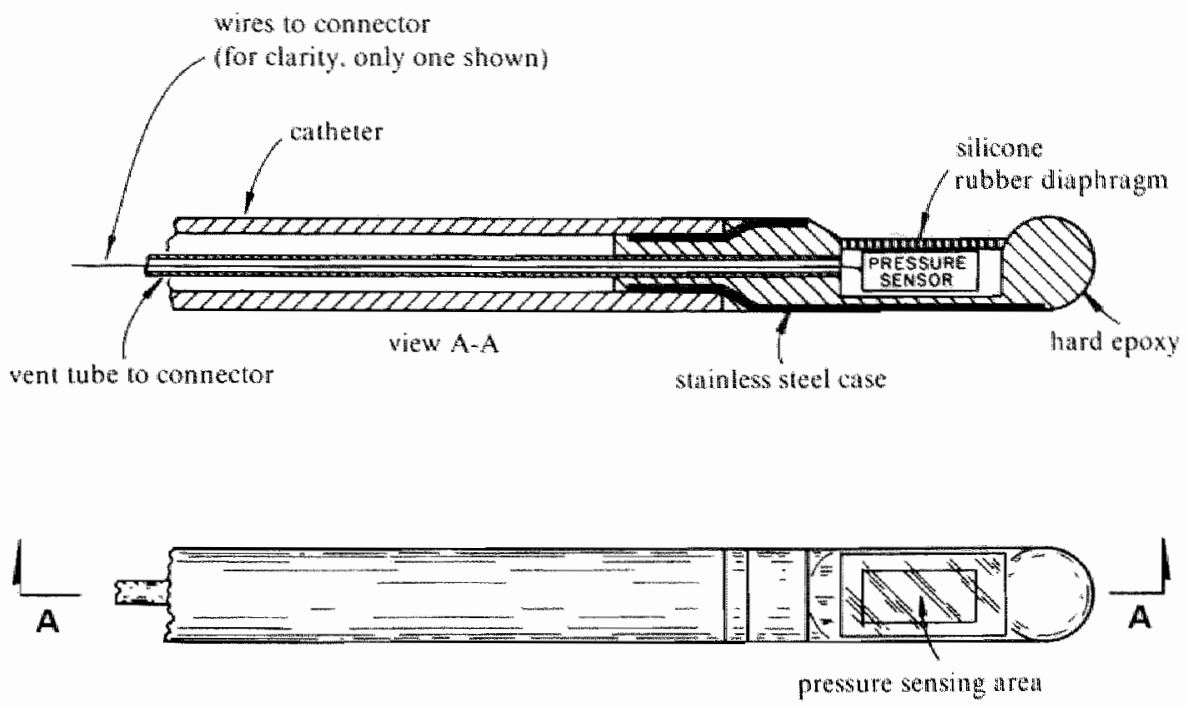

Figure 4.2 Millar Micro-tip catheter presstre transducer

5.B) to a battery operated transducer-control-unit (Model TCB 100).

This transducer-control-unit supplies Bridge Excitation Voltage and signal amplification. The transducer-control-unit has a calibration switch that provides calibration from -100 to $+100 \mathrm{mmHg}$ in $20 \mathrm{mmHg}$ steps.

The signal is further amplified and recorded on a MFE recorder writer. All recordings were made with a running speed of the writer of $1 \mathrm{~mm} /$ second.

\subsection{Advantages}

The technique of measuring the pressure in the anal canal with the Millar catheter lacks many of the disadvantages of the other types of measurement described in chapter 3.1 :

- The size of the Millar catheter is very small $(2.3 \mathrm{~mm})$ and causes almost no irritation of the anal canal. Most patients were hardly aware of the fact that this measuring device was brought into the anus. The initial pressure rise on inserting a measuring device as seen in some publications (128) did almost never appear in the present series.

- The rise in temperature between calibration and the actual measurement had no influence on the recordings.

- No fluid was necessary for the measurement in contrary to the method with the open tip catheter. Therefore, there was no influence on the recordings of filling the rectum with water or irritation of the anal mucosa. 
- The flat model of the Millar catheter prevents this measurement device from displacement in the anal canal which is likely with balloon catheters and strain gauges as indicated by Stelzner (141).

- The part of the catheter where the pressure is recorded is very small, only 2 millimeters. That means, that the recordings give a better information of the pressure at several distances from the anal verge than the balloon catheters or the force gauges which always will reflect the pressure of the whole area that comes into contact with the measurement device.

\subsection{Results}

Measurements were done in persons without any complaints in the anorectal region, in patients with haemorrhoids, fissura ani, problems of incontinence. anal atresia. M.Hirschsprung and (iatrogene) sphincterotomy.

All measurements were performed with the patient in left lateral position exept for a few measurements to objectivate the possible influence of other positions on the pressure in the anal canal.

In all measurements the lubricated tip of the Millar catheter was first brought into the rectum. There a pressure level of almost zero was found. Only pressure rise by breathing was recorded reflecting the normal intra abdominal pressure. Then a withdrawal curve was made to determine the length of the anal canal and the point of maximal pressure. Recordings were made at 5,4.3.2 and $1 \mathrm{~cm}$ from the anal verge.

The average length of the anal canal was $4.5 \mathrm{~cm}$. the same as found in literature. The point of maximal pressure varied from 2 to $4 \mathrm{~cm}$ from the anal verge. The fact that there was such a broad variety in the point of maximal pressure, made it reasonable to make a longer recording exactly at that point of maximal pressure to determine the pressure level and pressure pattern as a function of time (see 3.2) at that spot.

\section{Tablin 4.1}

\begin{tabular}{|c|c|c|c|c|}
\hline & n & $\begin{array}{l}\text { length of } \\
\text { and canal } \\
\text { bit } \mathrm{cm}\end{array}$ & $\begin{array}{l}\text { pressure } \\
\text { levell } \\
\text { in m } m \mathrm{Hg}\end{array}$ & $\begin{array}{l}\text { anall } \\
\text { reflex }\end{array}$ \\
\hline normal persons. & 25 & 4.5 & $50.2 \pm 15.2$ & + \\
\hline patients with hamemorthoids & 138 & 4.5 & $70.9 \pm 16.3$ & + \\
\hline patients will fissures & 10 & 4.5 & $75.1 \pm 15.8$ & $(+)$ \\
\hline $\begin{array}{l}\text { pationts with Hirschsprung } \\
\text { new born babies) }\end{array}$ & 2 & 2 & 45 & - \\
\hline patients with anal atadsia & 3 & - & $(\$)$ & - \\
\hline patients with disrupted sphincter & 4 & - & - & - \\
\hline
\end{tabular}

(+) No attempl was made to insert the rectab bulloon beause it was too painful.

\$. Small pressure zone of $\# 1 \mathrm{~cm}$. 


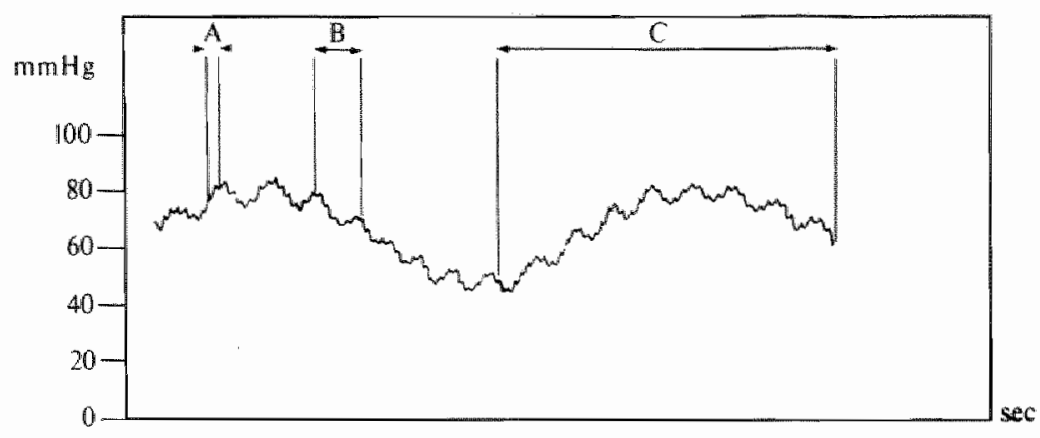

Figure 4.3 Superposition of pulse and breathing on ana pressure measurements
A) superposition pulse
B) superposition breathing
C) slow wave

In normal persons the average pressure level at the point of maximal pressure was $50.2 \pm 15.2 \mathrm{mmHg}$ (see chapter 8 ). This was different from the level found by others. Schweiger (128) found a level of $128 \pm 57 \mathrm{mmHg}$. This difference could only be explained by the difference in method and the size of the measuring catheter. In pathological situations such as haemorrhoids and lissures a higher pressure level was found $(70.9 \pm 16.3 \mathrm{mmHg}$ ) (see Table 4.1 ). In normal persons the same pressure patterns as described by Hancock (53) were found. The more exact method with the Millar catheter made it possible to show superposition of breathing and pullse (see Figure 4.3).

The superposition of an artery pulse is caused by the fact that the side opening of the Millar catheter is directed towards an artery in the anal canal. By turning the catheter the pulse superposition will disappear, while the pressure pattern. pressure level and breathing superposition will stay the same.

The direction of the side opening of the Millar catheter had no influence on pressure level and pattern whether it was turned to left. right, anterior or posterior as long as the distance to the anal verge stayed the same.

In 5 persons measurements were made in left lateral, right lateral and sitting position. In every position the same pressure level and pattern was found. This indicated that the position of the patient had no influence on the pressure in the anal canal.

Pressure measurements in patients with haemorrhoids and anal fissure showed an increased resting pressure and at more frequent presence of slow wave patterns or irregular patterns.

The average pressure level in these patients was $70.9 \mathrm{mmHg}$ against 50.2 $\mathrm{mmHg}$ in symptomfree testees. The results of pressure measurements in haemorrhoid patients will be discussed later in chapter 8 . 


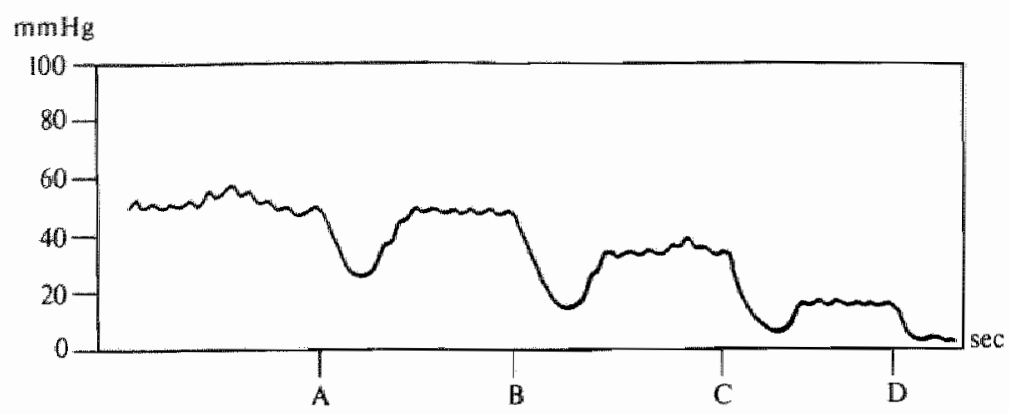

Figure 4 Ano-rectal reflex

Insufflation rectal balloon to $50 \mathrm{ml}: \mathrm{A}$
$100 \mathrm{ml}: \mathrm{C}$
$150 \mathrm{ml}: \mathrm{C}$
$200 \mathrm{ml}: \mathrm{D}$

Pressure measurements of the anal canal during inflation of a rectal balloon showed the anorectal reflex as described in chapter 2.2 .

Inflation of a rectal balloon caused a sudden fall in pressure level. This pressure fall was followed by a pressure rise probably due to contraction of the external sphincter and restoration of the pressure of the internal sphincter (see 2.3.1). When this inflation was repeated several times in steps of $50 \mathrm{cc}$ of air, it was obserwed that after a few steps the pressure in the anal canal could not reach the original level again (see Figure 4.4). This possibly indicated, that the rectum has a limited capacity and filling above a maximum will lead to an irrisistable urge to defaecate and relaxation of the sphincters.

The measurements in the anal canal during inflation of the rectum can be influenced by the rubber catheter leading to the rectal balloon. Inflation of the balloon may also give a dilatation of the rubber catheter leading to the rubber bahoon. When the side opening of tro Minar eatheter is disected towards the catheter of the balloon a short pressure rise will be visible during inflation. When the Millar catheter is rotated $180^{\circ}$ to the wall of the anal canal the und islurbed anal reflex will be visible again (see Figure 4.5).

\subsection{Conclusions}

Pressure measurements with the Millar Microtip Transducer give a precise information about the physiological working of the anal sphincters. Distension of the rectum causes a pressure fall. This pressure fall is due to the anorectal reflex that gives a dilatation of the internal sphincter. After a few seconds the pressure level in the anal canal is restored. Repeated cumulative inflations of the rectal balloon show that the original pressure level cannot be reached and defaecation will follow. For a continent sphinctermechanism are necessary: 


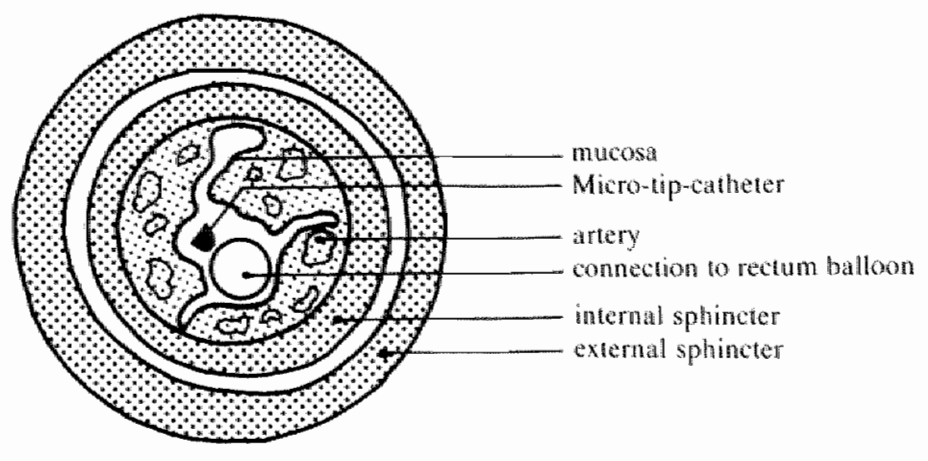

Figure 4.5 position of Micro-lip catheter and rectal-ballooncatheter in crossection of the alnat cimal

intact sphincters, intact nerve supply, intact sensation of rectum and upper anal canal.

The normal anal canal has an average length of $4,5 \mathrm{~cm}$ with the peak pressure at about $2 \mathrm{~cm}$ from the anal verge. Measurements at this point of peak pressure as a function of time show three different patterns of which the flat curve is found most in normal persons. The Millar catheter is a good instrument to objectivate proctological disorders and to evaluate therapy in the rectoanal region. 


\section{Haemorrhoids}

\subsection{Occurrence}

The haemorrhoidal plexus in the anal canal forms the corpus cavernosum recti and is essential in maintaining continence (141,145). There is a fluent transition from physiology to pathology. When this corpus cavernosum grows bigger in certain places one can speak of haemorrhoids. The only form of piles that is important are haemorrhoids responsable for complaints. The term haemorrhoids or pile will further be used for troublesome dilatations of the plexus haemorrhoidalis.

Haemorrhoids are among the most common diseases in the world. Over $50 \%$ of all older people are supposed to have a certain degree of haemorrhoids (43). But also younger people, even children and babies, can suffer from this disease. Haemorrhoids can often be found during routine examination or, during coloscopy in patients who had never had any complaints referable to piles. Because of the fact that they may remain unnoticed it is hard to say how frequent haemorrhoids really are. In 1919 Miles (105) wrote that about $80 \%$ of all people over forty suffer from internal piles, and that when younger people are affected there is usually a predisposing cause. Haas (50) found in routine proctoscopy small haemorrhoids in $82 \%$ in 241 asymptomatic patients.

The existence of small haemorhoids without complaints is no problem at all. They are a variation of the normal anatomy and no therapy is necessary. The frequency of irritating haemorrhoids is not exactly known, in spite of the estimations of Goligher (43) and Miles (105). Especially in the earlier stages patients treat piles by themselves and do not ask for professional help. In most parts of the world it is indecent to speak about haemorrhoids, and professional heip is only sought when piles have reached more severe degrees. Haemorrhoids seem to be more frequent in the civilized western world than in the third world. Probably this is due to differences in diet which, in the western world. leads more easily to constipation (146).

\subsection{Number and place of internal piles}

As mentioned before there are three constant locations around the circumference where the three main haemorrhoids can be found: at 3.7 and 11 o'clock in lithotomy position $(40,43,105)$. In some cases there are accessory haemorr- 
hoids at 1 and 5 o'clock. It is amazing to see that this arrangement holds good in almost all cases. In the dividing pattern of the superior haemorrhoidal artery Miles (105) found the main cause of the arrangement of piltes. However, in his study Thomson (145) found a very inconstant course of this artery pattern in 95 cadaveric anorectal specimen and he believes that piles arise from the three main cushions always present in the anal canal at 3.7 and $110^{*}$ clock. even in newborn babies. In his view cushions are an adaptation of the mucosa and the submucosa to the changing lumen-size of the anal canal with regard to that of the rectum. The cushions consist of the venous plexus, submucosal longitudinal muscle fibres and connective tissue. In Thomsons view haemorrhoids are displaced cushions prolapsing due to rupture of the connective tissue (see 5.5.6).

\subsection{Classification}

From ancient times a differentiation has been made between internal and external piles. External piles arise from the external subcutaneous haemorrhoidal plexus. Internal piles arise from the internal superior submucosal haemorrhoidal plexus. This difference refers only to the site of origin of haemorrhoids. When internal piles enlarge they bulge into the anal canal and prolaps into the anal orifice, and appear at the same locations as external piles. Sometimes it is hard to say if haemorrhoids are of internal or external origin. Normally the internal haemorrhoids are covered with the single-layered rectum epithelium and the multi-layered cuboid cell epithelium of the anal canal. External piles are covered with anal skin, and are sometimes difficult to distinguish from skin-tags or marisques. The large third and fourth degree internal piles are sometimes also partly covered with anal skin at their distal sides.

External piles have no further classification. Internal haemorrhoids can be divided into several degrees.

First degree haemorrhoids are swellings of the internal plexus bulging into the anal canal at proctoscopy, not visible from the outside, mostly painless, sometimes bleeding and not palpable in rectal examinations unless there is a thrombus in this plexus.

Second degree haemorrhoids are enlarged swellings. During defaecation they protrude into the anal orifice and become visible for a short time. They retreat spontaneously in to the upper part of the anal canal after defaecation.

Third degree haemorrhoids are continuously prolapsed larger piles. They do not return spontaneously into the anal canal. They can only be replaced digitally, and they often reappear without there being any defaecation.

Fourth degree haemorrhoids are large swollen irreducible piles with inflammation, necrosis and thromboses. They are almost always very painful. 


\subsection{Symptoms:}

Several complaints are attributed to haemorrhoids. The four most important complaints are pain, bleeding, prolapse and pruritus.

\subsubsection{Pain}

Pain is not clearly related to the piles themselves. There are several conditions causing pain that coincide with haemorrhoids, e.g. a fissura ani, inflammation or a small abcess. The piles can also directly give pain, especially the larger third and fourth degree haemorrhoids with thrombus and inflammation. and the external skin-covered piles. The pain can be continuous or only present during defaecation. Though pain during defaecation is the most common complaint of patients with haemorrhoids, it is not the most common symptom attributable to haemorrhoids. In literature an average frequency of about $70 \%$ of the patients complaining of pain $(43,118.130)$ is found.

\section{4 .2 Bleeding}

The second complaint is that of bleeding. Most frequently a slight streak of blood on toilet paper or on the stool is the first symptom. This slight bleeding occurs mostly when the patient is constipated. Regulation of the bowel suffices to avoid these symptoms. In a later stage the blood loss can worsen. Dripping of blood during and after defaecation or heavy bleeding without defaecation can occur. Even slight bleeding always deserves a thorough examination to exclude other causes of bleeding. In literature an overall frequency of bleeding as a symptom of haemorrhoids is found in about $70 \%$ of all patients not divided into groups referring to the degree of piles $(43,118,130)$.

\subsubsection{Prolapse}

Prolapse is a very common complaint of patients with haemorrhoids. Longer existing piles almost always prolapse at defaecation (second degree), or are permanently prolapsed (third and fourth degree). Most patients who visit a surgical clinic suffer from this symptom. Very often they have tried to treat pain and bleeding with ointments and suppositories for many years, but a severe prolapse is almost always seen as a reason to ask for medical advice. Prolapse in itself is not harmful, but it can lead to complaints such as soiling, itching, thrombus forming, ulceration and even necrotisation (fourth degree). Prolapse without any other complaint does not necessarily mean that treatment is mandatory. The frequency of a prolapse cannot easily be found in literature. It is dependent on the frequency of patients with second, third and fourth degree pilles. In most articles only these degrees of haemorrhoids are discussed, without indicating their proportions compared to the total number of haemorrhoids. By definition all 2 nd, $3 \mathrm{rd}$ and 4 th degree haemorrhoids have prolapse as symptom. 
The fourth complaint of many patients with piles is that of pruritus ani and anal irritation. The intense itching of the anal region is a serious problem but seldom directly related to haemorrhoids. There are many conditions to which pruritus ani is commonly secondary as there are parasitic, mycotic and bacterial infections. gynaecological causes and all causes of general pruritus (diabetes. uremia, liver disfunction, etc.). It is clear that the symptom of pruritus ani will react poorly to all the different kinds of treatment of haemorrhoids. Nevertheless among patients with haemorrhoids there are many more who suffer from itching than among people without haemorrhoids. The mucous discharge from haemorrhoids may cause pruritus $(40,43)$. About $30 \%$ of the patients complain of this symptom.

\subsubsection{Soiling}

Mucoid discharge is frequently seen in patients with prolapsing haemorrhoids. Such leakage of mucus is always a reason to look for other causes of mucus forming in the rectum. such as polyps, carcinomas and inflammatory bowel diseases.

\subsubsection{Thrombosis}

Every degree of haemorrhoids can give thrombosis, but especially prolapsing haemorrhoids are more likely to form thrombi. Thrombi make haemorrhoids extremely painful. Oedema can be found around the piles. This condition is known as an 'attack' of piles. These thrombi normally disappear spontaneously after a few days but in a few cases strangulation, ulceration and necrotisation of the thrombosed pile will follow. Sometimes there is only one big thrombus (easy to remove) but mostly there are several small thrombi in one pile. Such an attack of piles is an indication for operation.

\subsection{Etiology of haemorrhoids}

Several causes of the development of haemorrhoids are known but in many cases it is not so easy to find the underlying conditions.

\subsubsection{Straining at stool}

One of the most quoted causes of haemorrhoids is constipation and straining at stool. Miles and Lord paid special attention to this etiology $(87.105)$. The attempts to pass firm stool leads to a rise in intrarectal pressure. This intrarectal pressure level, increased by the intensified intra-abdominal pressure during straining, exceeds the normal venous pressure and causes congestion of the haemorrhoidal plexus. Lord $(86,88,89,90)$ states that the difficulty in passing 
stool is a combined action of firm consistency of stool and resistance of the pecten bands. In later articles he describes these pecten bands no longer as fibrous constructions, for which there was no patho-histological evidence, but as a part of the internal sphincter (91). Not only constipation, but also diarrhea is considered to be an important cause of haemorrhoids. Patients with tenesmus and futile straining are especially prone to develop piles. Ironically the effort to relieve constipation by means of laxatives can lead to diarrhea and therefore to the worsening of complaints of haemorrhoids. Faulty habits of defaecation, reading newspapers e.g. in which patients stay in the toilet for 15 minutes or more lead to protracted straining.

\section{5 .2 Heredity}

Other reasons for the origin of haemorrhoids are not so obvious. Most of the time no reasonable explanation can be given. Heredity could be an etiological factor. Haemorrhoids and varicose veins of the legs often coexist. suggesting a general defect of the walls of the veins. It seems that certain families are predisposed to develop piles and varicose veins (43).

\subsubsection{Portal back pressure}

As mentioned before, the superior haemorrhoidal plexus, as part of the portal vein system, is wery susceptible to back pressure. The veins in the portal circulation have no valves. Every obstruction in the portal system will be reflected in a higher pressure in the superior haemorrhoidal vein, e.g. cirrhosis, portal vein thrombosis etc. This cause of haemorrhoids is not seen very frequently (43,145). Most of the time when this cause is present other symptoms of this severe illness are so remarkable and lifethreatening that haemorrhoids are not noticed under these circumstances. The pressure in the portal system can also be increased by outside compression on the venous backflow in the superior haemorrhoidal vein. The most common cause of this type of haemorrhoids is pregnancy. Pregnancy gives not only venous compression in the pelvis but allso an increased vascularity (93). Normally the piles of pregnancy disappear after parturation, but sometimes they only improve a little after the delivery and stay small until a subsequent pregnancy or later years (43). Ot her causes of obstruction can be a rectal carcinoma or impaction of firm faecal masses in the rectal cavity or venous obstruction by sphincter spasm in which the venous return is cut off especially during defaecation $(40,43,85,91)$.

\subsubsection{Erect position of man}

Prolonged standing in several professions such as surgeons, shopassistants etc. and heavy lifting by construction workers and furniture movers can also cause haemorrhoids. The erect position of man leads to the effect that the entire column of blood in the portal system presses on the haemorrhoidal plexus (43). 


\subsubsection{Hyperplasia theory}

All the previous theories about the origin of piles start from the conception that haemorrhoids are dilated varicose veins. Thomson (145) mentioned two other basically different theories. The first one is the vascular hyperplasia theory. In the 19th century several authors considered haemorrhoids as a result of erectile tissue metaplasia similar to the cavernous tissue in the genital region. The finding of arterio-venous communications in histological studies should support this theory. In this century Stelzner (14l) has adopted this theory. In his view the corpus cavernosum recti has an erectile function and piles represent hyperplasia of this cavernous tissue.

\subsubsection{Sliding anal lining theory}

The second theory mentioned by Thomson (145) is the sliding anal lining theory. Gass and Adams (145) found fragmentation of the supporting connective tissue in 200 haemorrhoidectomy specimen. Thomson described the muscle of Treitz, a longitudinal muscle arising partly from the internal sphincter and partly, by passing through the internal sphincter, from the conjoined longitudinal muscle. This muscle passes downwards in the anal submucosa and forms a supporting scaffold around the veins of the hamorrhoidal plexus. In his view piles are nothing more than normal vascular tissue sliding downwards due to disrupting of this supporting muscle of Treitz. Thomson believes that the sliding anal lining theory is the most plausible. In anatomical studies he found no evidence of venous dilatation or of vascular hyperplasia.

\subsubsection{Vicious circle}

The vascular tissue of the anal canal is enlarged in haemorrhoids, due to venous compression. This tissue contains many arterio-venous anastomoses. The venous backflow runs partly through the sphincter. By enlarged shear force this tissue prolapses into the anal orifice. In the early stage of hatemorrhoids a high tonus of the internal sphincter develops and this is the beginning of at vicious circle. The high tonus gives further venous obstruction and pain at defaecation. This, in its turn. will increase the hypertonus of the sphincter and therefore cause more pain and more venous congestion. Allgöwer, Rüedi and Hochuli (2.62) mentioned this vicious circle not only in relation to haemorrhoids but to several benign anal diseases. In their views the internal sphincter is practically devoid of ganglia from Auerbachs plexus. This gangliopenia causes a permanent state of closure, and requires passive dilatation for opening. Several stimuli are able to start this vicious circle. One of the stimuli can be an incipient haemorrhoid, but also e.g. the pain of an anal fissure. The hypertonus of the internal anal sphincter can cause or perpetuate haemorrhoids. 


\section{Therapy for haemorrhoids}

In history several forms of treatment for haemorrhoids have been described:

I medical therapy

2 operative treatment

3 dilatation of the anal sphincter.

\subsection{Medical treatment}

This is the oldest form of therapy for piles. Medical treatment can be divided into diet advices, local treatment with ointments and suppositories, anti-pruritus therapy and sclerotherapy.

\subsubsection{Diets}

The relation between constipation, straining and haemorrhoids was well known in ancient times and led to dietary recommendations. In the last decade the problem of obstipation is seen as due to the low residue diet of the western civilized world. Nowadays the most popular prescription is unprocessed bran, or other bulk increasing laxatives. Goligher (43) mentioned two controlled studies in which these laxatives were compared to placebos in patients with haemorrhoids (Broader 1974, Webster 1978)(151). In the Broader study there was no statistical evidence of the usefulness of this treatment. Webster et al (151), however, found that simple addition of fibre to the diet was adequate to relieve symptoms of haemorrihoids in patients with first and second degree piles. In patients with third degree piles no improvement could be established. The use of high fibre diet is seen as an important reason why haemorrhoids are so rare among rural Africans (146). Another recent study of Moesgaard (108) shows a slight improvement with the use of a high fiber diet (Vi Siblin, R-) in patients with symptomatic first and second degree piles. But the results are less satisfactory than other forms of outpatient treatment. Perhaps high residue diets can be of help in the prevention of haemorrhoids and as accessory treatment, but the diet in itself is insufficient as therapy for the haemorrhoids that are most presented in surgical clinics. 
Numerous ointments and suppositories are available without prescription in every drugstore. These preparations mostly contain local anaesthetics, antiphlogistics, desinfectants, astringents and sometimes steroids $(12,100,144)$. All these topical preparations claim to give complete relief of all haemorrhoid symptoms such as pain, itching. bleeding and prolapse. Of course the local anaesthetics will give a shortterm relief of the pain, but it is difficult to see if long-term improvement is due to the treatment or to the natural course of piles. It is wellknown that the symptom pattern in haemorrhoids is always a very fluctuating one. Without treatment symptoms can disappear spontaneously, but usually return after a short time. All local applications of anti pile preparations can be said to have shortterm. if any, results and the symptoms will often reappear. The shortterm relief caused by these freely available preparations can mask symptoms of more serious illnesses in the ano-rectal region. A second disadvantage of this topical type of therapy is that it can lead to allergy and contact-dermatitis $(65,144)$. Many allergies are found against contents of antihaemorrhoid preparations (144) like: anaesthaesin, perubalsam, extr.hamameledis, menthol. thiosinamin and resorcin.

The corticoid component in many anti-haemorrhoid preparations can worsen purulent infections in the rectum (144).

In case of a haemorrhoidal 'attack' with strangulated piles a patient can be treated successfully with an icewaterbath or with local application of aethylchloride (11). This will reduce oedema, swelling and pain until further treatment is possible.

(Best treatment for a haemorrhoidal attack remains immediate operation).

\subsubsection{Anti-prurims therapy}

Pruritis, as mentioned before, is quite often not directly related to the actual haemorrhoid. In many cases pruritus is due to candida infection or worms. Of course a local or systemical antimycotic or anthelmintic can give relief of this symptom (74).

Pruritus ani, caused by general illnesses such as diabetes mellitus "leukemia, icterus etc, of course has to be treated by the general medical therapy for the underlying disease.

Only in a minority of the cases antihaemorthoid therapy will give relief of pruritus.

\subsubsection{Sclerotherapy}

The only topical medical therapy of value for longer time in the treatment of piles is probably the injection therapy. This type of therapy was first used by Morgan of Dublin in $1869(40,43)$. In that decade this method did not become 
popular in England. Morgan used an injection with persulphate of iron. A few years later Mitchell of Clinton. Illinois, introduced sclerotherapy in the United States, using a solution of $33 \%$ carbolic acid and $66 \%$ olive oil. His method was kept secret and was sold by his family to a number of quacks after his death. They used carbolic acid solutions of various strengths during the next years. Around the turn of the century sclerotherapy was used again by the medical profession. In England the method was rediscovered in 1888 by Swinford Edwards, who used a solution of carbolic acid in glicerine and water (40). The present method of injecting haemorrhoids was introduced in England by Morley $(40,43)$. He injected a much weaker solution of $5 \%$ phenol in almond oil, not into but just above the pile. This injection method is nowadays very popular in Britain; in the rest of the world the method is also used in some medical centres. In the USA a direct injection in to the piles is used consisting of a solution of quinine and ureahydrochloride $(43,74)$. Other sclerosants in use are ethanolamin oleate, sodium morrhuate and quinine bihydrochloride.

Sclerotherapy in the pile shows the same inflammatory reaction as a submucosal injection. Studies about the histology of haemorrhoids after such injections showed, within 24 hours, infiltration by leucocytes, red blood cells and mononuclear cells but no immediate thrombosis. Clotting was evident after the fifth day, besides an obvious increase in fibrous elements of the submucosa. Clinically this fibrous induration is the most significant feature in follow-up studies after sclerotherapy. The fibrous tissue constricts the veins and will protect the pile from bleeding. Furthermore, Goligher (43) mentioned the mechanism of the fixation of the pile to the underlying muscular coat in order to prevent the haemorrhoid from prolapsing.

First and second degree haemorrhoids are indications for sclerotherapy. Third degree haemorrhoids normally cannot be cured by injection therapy. Injections are contra-indicated in cases of simultaneously present anal fissures or fistulae, or in severe third or fourth degree haemorrhoids. Some authors consider pregnancy as a contra-indication (93). Goligher (43), however, has always treated pregnant women with sclerotherapy in all stages up to term without problems. As mentioned before the method of sclerosing is very popular in Britain. Goligher (43) treated $85 \%$ of his patients and Gabriel (40) $72 \%$ with sclerotherapy.

For sclerotherapy a proctoscope, a special syringe and injection needles are required. The three finger grip syringe was designed by Gabriel (40). The injection treatment is performed as an outpatient procedure. No anaesthesia is required. Injections are always given above the dentate line, submucosally in the British method and right into the pile in the American method. The proper location for injection can be found by withdrawing the proctoscope from the rectum to the upper part of the anal canal. The present sclerosing solutions are: $5 \%$ phenol in almond oil for the submucosal injection and quinine urea hydrochloride for intrahaemorrhoidal injections. Normally 3 to $5 \mathrm{ml}$ is used for each pile. 
There are only a few complications known of this therapy mostly due to errors in technic. Necrosis and ulceration can occur after injection with an excessive large dose when the solution is too strong (43) or when the injection side was rather intramucosal. than submucosal (146). In exceptional cases an abcess can develop at the injection site. An inflammatory reaction to the almond oil can give an oleogranuloma in the rectum wall or in the perirectal tissue (146).

In many cases complaints in the anal region are not related to the piles themselves but to coincidential inflammation in the anal canal, fissura ani, fistulate etc. In these cases injection therapy is not indicated and can worsen the complaints. In the more severe degrees of haemorrhoids sclerotherapy is not a treatment of choice. Most publications about sclerotherapy came from Great Britain (112). Obviously comparatively fewer people with uncomplicated first degree haemorrhoids ask for medical help elsewhere. In many centres in other countries other nonoperative treatments are preferred (74). Of course injection therapy can never be used in external haemorrhoids (40).

\subsection{Operative treatment}

A great variety of operations have been designed to treat second, third and fourth degree haemorrhoids. It is impossible to describe all these forms. The following forms will be discussed:

1 open haemorrhoidectomy

2 closed haemorrhoidectomy

3 Parks haemorrhoidectomy

4 Whilehead haemorrhoidectomy

5 cryotherapy

6 rubberband ligation

\subsection{Open haemorrhoidectomy}

The most common method of haemorrhoidectomy in the world is the ligation and excision method described by Milligan (107) in 1937. It is a modification of an ancient way of treatment. In the Greek and Roman periods and in the Middle Ages haemorrhoids were treated by ligation of the entire haemorrhoid. The ligature included mucosa and anal skin. The pile was dissected above the tie. Salmon, the founder of St. Marks Hospital in London, introduced another technic. He started with an incision at the muco-cutaneous junction and stripped the pile up to the upper part of the anal canal where he ligated the base of the haemorrhoid. The method was criticized by later surgeons because of the development of scar tissue resulting in stenosis. In 1919 Miles (105) introduced his low ligation method. He made the ligature at the level of the dentate line. The painfulness of this method brought Milligan (107) to his adaption of this haemorhoidectomy.

When internal haemorrhoids have reached the second or third degree this is 
usually seen as an indication for operation. As Gabriel (40) stated the continuously prolapsed third and fourth degree haemorrhoids. external haemorrhoids and haemorrhoids combined with skintag need an operation. The combination of second degree piles with a fissura ani or a fistula is also a good indication.

The Milligan ligation-excision operation can be performed under general or spinal anaesthesia. Gabriel (40) mostly used a combination of local and general anaesthesia. Goligher (43) performs his operations under general anaesthesia. but he starts with a local infiltration of $1 / 100,000$ solution of adrenaline hydrochloride, in order to diminish bleeding during the operation. After proctoscopy the three primary haemorrhoidal sides are grasped with an artery forceps at the level of the perianal skin. Traction brings the internal haemorrhoids into view and the haemorrhoids are pulled down further by application of a second forceps near the base of each pile. Goligher describes the pink colour of the rectall mucosa that becomes visible and can be distinguished from the purple colour of the anal mucosa. With blunt scissors a V-shaped cut is made in the perianal skin with the base of the $V$ at the dentate line. The pedicle of the pile is further freed by incision about $1 \mathrm{~cm}$ above this dentate line. The pedicle is then ligated. Gabriel (40), Goligher (43) and Thompson (146) use silk for this ligature. Many others prefer catgut and apply it as a transfixion ligature. The two other main haemorhoids are treated in the same way. Skin bridges of about $1 \mathrm{~cm}$ must be left between the wounds of the excised piles. In the wounds the white fibres of the internal sphincter and the external sphincter are visible. Gabriel (40) advised to cut the lower end of the internal sphincter subsequently when the fibres appear to be fibrous and thickened. Goligher (43) sees no advantage of this sphincterotomy or in anal stretch subsequent to the haemorrhoidectomy. This method of stretching the anal sphincter is advocated by many surgeons (43) in order to diminish the postoperative pain in haemorrhoidectomy. Secondary piles having no rectal pedicles (107) are resected and ligated in the same way as primary haemorrhoids, but at a lower level. After the operation many surgeons insert a rubber tube into the anal canall $(40,107,146)$. sometimes covered with vasiline gauze to compress the wounds and to admit passage. Goligher uses only a gauze soaked in Milton outside the anal orifice (43). Wohlwend (154) uses intraanal Spongostan.

The normal postoperative aftercare includes a prescription of a mild laxative. wound irrigation and application of fresh dressings. Thomson (146) describes the present St. Marks Hospital method in which a rectal examination is performed one week after the operation and the use of a dilator is prescribed when there is spasm or tightness. Goligher (43) doubts if much good comes from this practice. In his view spasm after a week is the normal reaction to pain and will disappear spontaneously when the wounds are healled. He only advocates the use of the dilator when there is a stricture after about a month, the usual time in which the wounds should have healed. 
A variety of postoperative complications has been described form this excisionligation method.

- As the major disadvantage of operative treatment most authors mentioned the postoperative pain, not only on the first or second day, but especially during and after the first motion. They all mention the necessity of postoperative narcotic injections. In a study about suture material in haemorrhoidectomy (76) it was found that the use of polyglycolic acid sutures has advantages over catgut in respect to pain as well as to other complications. Kirkman (77) found significantly more relief from posthaemorrhoidectomy pain after subsequent anal stretching than after injection with local anaestherics.

- A second complication is that of urine retention. In a study of Khubchandani (76) the percentage was 3.7. Goligher (43) found 3\%. Scoma (129) described the necessity to catheterize patients after haemorrhoidectomy in, almost unbelievable, $52 \%$ of the cases, and Gopalakrishnan (45) even in $57 \%$ Efforts to prevent urine retention are made by limiting the administration of intravenous fluid to $200 \mathrm{ml}$ on the day of operation (129).

- Golligher (43) and Gabriel (40) both saw the formation of skintags after haemorrhoidectomy as a result of oedema in the skin bridges between the wounds.

- Secondary haemorrhage occurs in 0.5 to $1.5 \%$ of the cases as described by Gabriel (40).

- Postoperative infections are very rare and abcesses and fistulae seldom appear after the open haemorrhoidectomy technic.

- Fissure formation happens only in a few cases and can be treated by forced anal stretch or sphincterotomy under general anaesthesia.

- Stricture formation is also an uncommon complication. If it occurs it can be treated by the use of a dilator. Strictures were a commonly described complication of the Whitehead operation.

\subsubsection{Closed haemorrhoidectomy}

An alternative for the Milligan method is the 'closed' haemorrhoidectomy described by Ferguson (45). The indication for this type of haemorrhoidectomy is the same as described for the Milligan excision and ligation method. For this operation there exist also several modifications. but the essention is that the wounds in the anal canal are closed after the excision of the pile. This method is widespread in the USA. Gopalakrishnan (45) describes the closed haemorrhoidectomy under general anaesthesia combined with local infiltration with novocaine. The piles are exposed by using a Hill-Ferguson retractor. An elliptical incision is made around the pile and with scissors all tissue within this ellips is removed until the fibres of the internal sphincter are visible. A Bouieclamp is placed across the pedicle. The pedicle is ligated with a transfixion ligature and the same catgut suture is used to close the wound to its distal margin. Langen- 
beck performed his closed haemorrhoidectomy with a clamp around the pile. He excized the pile above the clamp with cautery and closed the wound with a running catgut suture around the clamp. After removing the clamp the suture is tightened. In $2 / 3$ of the patients the sutured wounds break down and heal by secondary intention $(50)$.

\section{Literature results in haemorrhoidectomy.}

Militarev and Protasevitsch (106) described the long-term results of open and closed haemorrhoidectomy in 1477 patients. They found better results with the open excision and ligation method of Milligan. There was a lower recurrence rate: $1.2 \%$ against $4.5 \%$. An interesting finding was that the recurrence rate was higher in patients with concurrent gastro-intestinal diseases such as colitis, gastritis, duodenal ulcers etc.

The complications of the closed haemorrhoidectomy are almost the same as described in 6.2.1. Watts (150) described the proctoscopic findings a few days after several forms of haemorrhoidectomy. In his study he found that after 10 days there are similar rough wounds in patients with closed haemorrhoidectomy as there are in patients with an open haemorrhoidectomy. In the closed haemorrhoidectomy methods there is a greater chance of postoperative haematomas.

Only one report is found in literature about a closed haemorrhoidectomy in which an attempt is made to preserve the Treitz muscle. The short term results were good, but there was not yet a long term evaluation (4l).

\subsubsection{Parks haemorrhoidectomy}

Parks (120) developed a submucosal haemorrhoidectomy that should cause less pain. This operation is performed under general anaesthesia. A specially designed anal retractor is inserted into the anal canal. After grasping a haemorrhoid it should be possible to see a sulcus between the internal and external haemorrhoidal areas. on the spot where the mucosa is adherent to the muscle by a fibrous band. Here he infiltrates with an adrenaline solution in saline ( 30 to $40 \mathrm{ml}$ in each pile). An incision is made and the internal and external haemorrhoidal plexuses are liberated from mucosa, skin and underlying muscle ribres. The base of the wedge lormed by vascular tissue is at the rectal side. Normally the base is too big a mass for one ligature; it can be ligated in parts. At the side of the perianal skin a little dissection is made of the keratinized zone of the anal epithelium to prevent the formation of skintags. The wounds are not closed. The wound edges will spontaneously come together by the oedema that is always present in the first postoperative days.

Parks (120) claimed good results in his series of 50 patients. There was almost no bleeding, little pain and only one case with postoperative infection and no 
anal stenosis. In $12 \%$ some haemorrhoidal tissue was left but this caused no complaints. Others also reported good results of this operation (130, 137). The Parks haemorrhoidectomy is not so widely used around the world, probably due to the fact that at the same time alternative methods were developed by which patients could be treated on an outpatient basis.

\subsubsection{Whitehead haemorrhoidectomy}

In 1882 Whitehead (152) published his method. He started the operation with forced anal dilatation. Then the circumference of the anal camal is divided into four portions by longitudinal incisions. Each portion is divided transversally at the level of the anal verge and dissected upwards to the thighest limit of the haemorrhoidal plexus. Here the mucosa is transversally divided. The haemorrhoid plexus covered with a quadriangled piece of anal mucosa and anal skin is at that moment only attached by its pedical vessels. This unity is twisted to close and subsequently removed. The free margin of the rectal mucosa is sutured with silk to the perianal skin at the side of the former anal verge. All four portions are treated in the same way. Mostly it is not necessary to remove the whole circumference but bridges of anal mucosa and anal skin are left.

Whitehead (152) was fearful of postoperative strictures, and followed his patients scrupulously. No strictures were seen in his long-term follow-up. Others found many strictures and ectropion after this operation. The Whitehead operation is still performed today on a small scale, because of this severe complication feared by most surgeons and described many times during the last century. Laird (79) says that if done in a proper way this operation is good and safe. Several modifications of Whitehead's method now exist $(47,79.124)$ and are known as anoplasty.

\section{2 .5 Cryotherapy}

For the last 20 years several methods of out-patient treatment have been tried. Most methods were modifications of the excision and ligation operations. Exci* sion of tissue by freezing has been performed by dermatologists and ophtalmologists for a long time. 300 Years ago Boyle studied the effect of low temperature on tissues (18), and in 1851 the use of low temperature in surgery for cancer was published by Arnott (18). In 1969 Lewis et al published the use of cryotherapy in haemorrhoids for the first time (83). Freezing leads to irreversible damage to body-tissues. Ice crystals can be formed intracellularly or extracellularly. Slowly frozen. ice crystals are formed between the cells and these crystals withdraw water from the cells. The cells collapse due to dehydration. In acute freezing intra- and extracellular water will form ice crystals simultaneously. A second effect of freezing is the increased permeability of the vascular walls. After thawing there begins a stasis of blood cells in the vessells because of the loss of fluid to the surrounding tissue. Ischaemia in its turn leads to necrosis. 
In cryohaemorhoidectomy two types of cryo-instruments are used: nlled with nitrous oxide or liquid nitrogen. With liquid nitrogen a lower temperature of $-196^{\circ} \mathrm{C}$ can be reached, but the storage of liquid nitrogen needs special precautions which are not possible in many hospitals. The temperature of $-89^{\circ} \mathrm{C}$ reached by the use of nitrous oxide, however, is sufficient for tissue destruction. Experiments on dog skin (18) showed increasing oedema with a maximum on the third day after freezing. In the center of the wound gangrene develops in a few days with full demarcation in one or two weeks. The gangrene is accompanied by discharge from the wound. By 2 to 5 weeks the wound healed rapidly. The same pattern is found in frozen haemorrhoids. It takes longer for the haemorrhoidal wounds to heal than for those in the dog skin and the healing time usually is three to six weeks after freezing. The normally used freezing time is 3 to 5 minutes. Oedema develops around the necrosis tissue during the first days. Complete necrosis is found on the fourth day.

Some authors use a combination of freezing and ligation of the haemorrhoids $(18,72)$. The method of freezing is not widely used, probably because of several complications on one side, and the need of special instruments and the problem of storage of liquid nitrogen on the other. Goligher (43) and Meyers (104) mentioned the problem of adherence of the freezing probe to the frozen haemorrhoidal tissue. A spheric iceball is formed at the tip of the cryoprobe. This requires waiting until the end of the instrument is thawed, without moving the instrument to prevent tearing the pile. The principal complication of cryotherapy is the severe discharge from the wound margins and the liquifaction of the gangrenous tissue. Normally this discharge with a bad odor persists for several weeks $(1,18,43,72,97,138)$. Other postoperative complaints are bleeding $(18,19,97,138)$ and pain $(1,19,97,138)$. The claim that cryohaemorrhoidectomy can be performed without anaesthesia is not shared by all authors. Changyul (19) mentioned that twothirds of his series of 1000 patients complained of pain and Goligher (43) saw postoperative pain in $58 \%$ of his cryohaemorrhoidectomized patients. The percentage of pain immediately following cryotherapy varies considerably among other authors (19,43,72,73,81). Cangyul (19) found a recurrence rate of haemorthoids after cryotherapy in $6.3 \%$. Goligher (43) in $25 \%$. Ghangyul (19) saw skintags in $24 \%$ of 1000 cryohaemorrhoidectomy patients but only $0.8 \%$ required excision. Changyul's conclusion (19) is that the overall complication rate of cryotherapy does not exceed that of surgical haemorrhoidectomy.

Mac Leod (97), in his retrospective study, compared the results of cryotherapy with injection sclerotherapy and rubberband ligation. He found equal results in second stage haemorrhoids. In third stage haemorthoids cryotherapy was more effective and caused less discomfort.

In his view many of the complications in cryotherapy can be avoided by freezing only $2 \mathrm{~cm}$ above the dentate line, by treating only one haemorrhoid at a session, and limiting the freezing time to one minute at each session. 
Ligation of haemorrhoids is a very old form of treatment (1). In the Middle Ages the whole prolapsing thaemorrhoid including the skin covered portion was ligated and must have caused a lot of pain by including the very sensitive anal skin.

Samuel Sharp (135), surgeon in the St. Guy's Hospital in London, described the procedure in detail in 1750 . The third degree prolapsed haemorrhoids were ligated with a cord outside the anus. In cases of second degree haemorrhoids the patient had to sit above a foot stove and to strain until the haemorrhoid became visible at the anal verge. The surgeon was ready with a needle to stitch the pile at the moment the haemorrhoid came out, knowing that it would return into the anus when he waited too long. Then a ligation was made. Haemorrhoids were always treated one at a time because of the fact that the pain would be unbearable in multiple ligations. (He also saw the method of dissecting haemorrhoids, but stated that a massive haemorrhage followed and the patient almost died). Salmon and later Miles reintroduced the ligation method $(1.7,105)$ at the dentate line, combined with dissection.

Blaisdell (10) originally started with the ligation of haemorrhoids as an office procedure. He destroyed the internal haemorrhoids high in the anal canal, only the part that was coverd by mucosa and not with anal skin. He used silk for his ligature and designed a special instrument for this ligating method. Barron (7) modified Blaisdell's instrument and used rubber bands for ligation. The instrument can be loaded with rubber bands with the help of a conical metal tip. The instrument itself consists of a small metal cylinder on a long handle. The rubber bands around the cylinder can be pushed off by pulling the handle. The Barron ligator is used through a proctoscope to make the haemorrhoid visible. The metal cylinder is placed around the internal pile. The pile is grasped by at forceps and pulled through the metal drum of the ligator, then the rubber bands are pushed off around the base of the haemorrhoid. The problem of an assisting hand to hold the proctoscope during Barron ligation with the original Barron ligator and the grasping forceps. could be avoided by another modification of the ligator. The suction ligator of Lurz (156) can be used with one hand and the second hand can hold the proctoscope. The ligator consists of two concentric barrels. The inner one is connected to a suction apparatus. By pulling the handle the rubber band is pushed off the inner cylinder by the outer one over the base of the haemorrhoidal tissue that is succed into the inner drum (see Figure 6. 1 ).

The results reported by Barron (7) were good. When the bands were placed in such a way that no sensitive transitional epithelium and no anal skin was included there was almost no complaint of pain. $70 \%$ of his 200 patients did not need any medication (more than 4 capsules of Demerol ${ }^{\text {B }} 50 \mathrm{mg}$ ). All patients felt a dull ache during the first 2 days after the ligation. By this time the haemorrhoidal tissue became necrolic and the nerve endings were destroyed. 


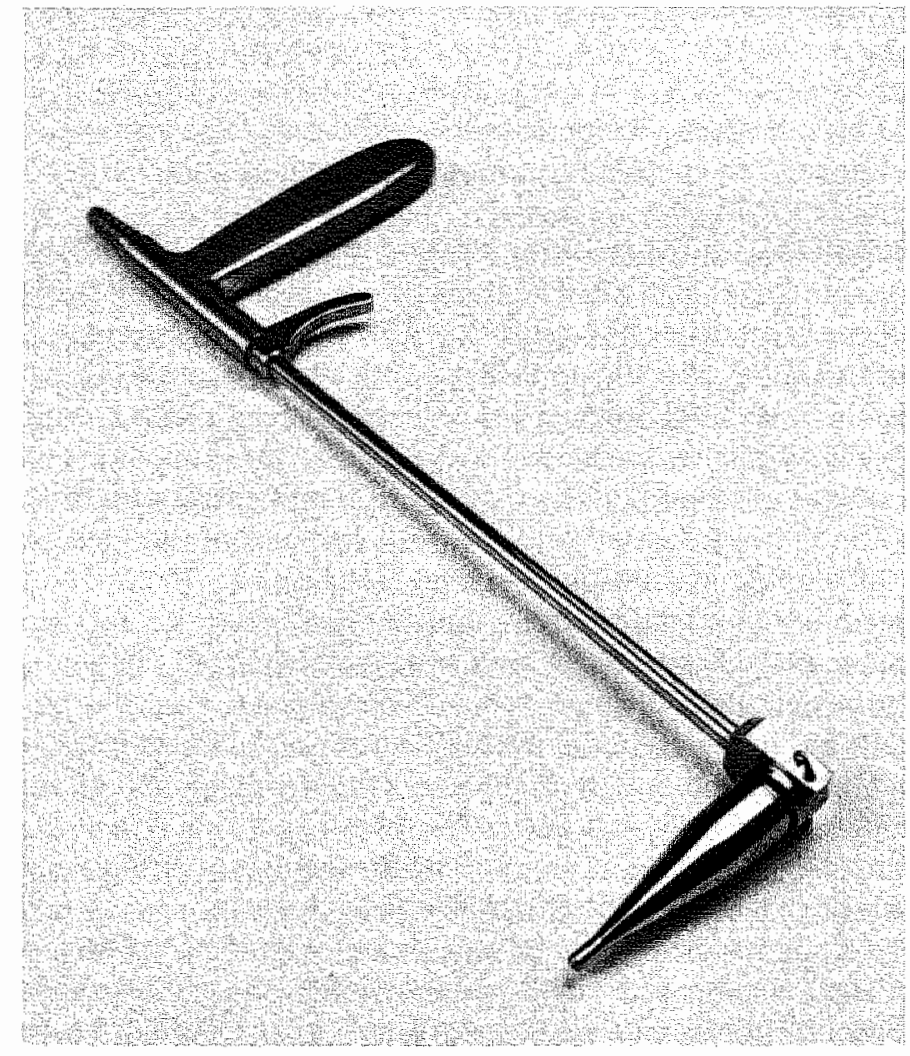

Figure 6. I Suction ligator (Lurz

Apparently the discomfort during the first two days is minimal. In $2 \%$ of his patients bleeding followed the ligation procedure but this complication was so mild that no hospital admission was required. As the great advantage of this method Barron mentioned that patients normally lost far less time from work than after operative haemorrhoidectomies (7). Many authors described good results with this treatment $(1,7,10,109,138,140)$. Anaesthetics are not necessary for the procedure (1) and many patients are able to return to work immediately after the ligation. Alexander Williams (1) does not encourage his patients to have remaining skintags removed. His results with 800 patients were good. As complications he mentioned bleeding and severe pain when the ligature was not properly placed. In such a case it is necessary to remove the rubber band immediately. Another solution is given by Tchirkow (143). He injected profylacticly a local anaesthetic solution in the just banded haemorrhoidal bundle and saw in only 2 out of 62 patients a reason to give additional oral anaesthetics. 
There is some discussion on the problem whether it is good to ligite the three main haemorrhoids at the same time. Barron (7) advocates to treat only one pile at a time. Lau (80) reported very good results of three ligations in one session and saw no special problems. Recently there were reports $(69,117)$ on a fatal clostridial infection after haemorrhoid ligation. After this complication O'Hara (69) uses only one ligation at a time. The overall results of Steinberg et al (140) show a complete cure in $56 \%$ but great improvement in $89 \%$ of the cases. The Barron ligation was used for haemorrhoids of various degrees. The first reports were very enthousiastic about the method $(1,7,66,140)$, also for large third degree piles. However, the prospective trial of Lewis (82) with 112 patients with large third degree haemorrhoids showed that the results with Barron ligation were poorer compared to haemorrhoidectomy or anal dilatation. The same experience had Möller (109), Smith (138). Mc Lead (96) and Wrobleski (155), who found less good results in third degree haemorrhoids. Their results in first and second degree piles were excellent. Wrobleski (155) found good results in $79 \%$ in first degree, $76 \%$ in second degree and $66 \%$ in third degree haemorrhoids.

Table 6. $\Downarrow$ Good results after Barron banding

\begin{tabular}{llll}
\hline & Ist degree & 2nd degree & 3rd degree \\
\hline Wrobleski & $79 \%$ & $76 \%$ & $66 \%$ \\
Leod & & $73 \%$ & $58 \%$ \\
\hline
\end{tabular}

The use of Barron ligation method is nowadays widespread. The method is very simple, can be performed as an office procedure. requires no anaesthesia and has very good results in first and second degree haemorrhoids. The complications are few compared with other methods. In a prospective trial Murie et al (110) found the same good long-term results for second degree haemorrhoids in patients treated with rubber band ligation as in patients treated by haemorrhoidectomy. In third degree haemorrhoids rubber band ligation does not achieve such good results as haemorrhoidectomy but in both degrees of haemorrhoids rubber band ligation had far less complications and had great economical advantage above haemorrhoidectomy. In his view rubber band ligation is the first choice of treatment for second and third degree haemorrhoids (110). A study with Barron bands will be discussed in chapter 7.

\subsection{Dilatation of the anal sphincter}

The dilatation of the anal sphincter is not new. In 1810 Copeland advocated 'bouginage' of the anal canal. In his view haemorrhoids were caused by a hypertonic sphincter. The method of bouginage is still used. Furthermore, anal dilatation was used as an additional therapy to several operations in the 
anorectal region. Several forms of dilatation nowadays exist as a treatment for haemorrhoids:

1 forced anal stretch (Lord's method)

2 lateral internal anal sphincterotomy (Eisenhammer)

3 bouginage of the anal sphincter.

\subsubsection{Anal strerch (Lard's method)}

In 1968 Lord described his method of treatment of second and third degree piles for the first time. He re-introduced the old idea of Copeland that the hypertonic condition of the anal sphincter was the main cause of haemorrhoids, and by dealing with this cause it should be possible to cure haemorrhoids. In 1829 Recamier (32) described 'La Methode de Dilation Forcée' as treatment for fissura ani. Lord (92) rediscovered this method by accident. A patient with severe complaints of haemorrhoids had an important appointment and could not stay in hospital for haemorrhoidectomy. Knowing that anal stretch could give a relief of pain Lord only performed this generally accepted adjuvant method of anal stretch. After a few days, to his surprise all symptoms of bleeding and prolapse had disappeared together with the pain. After this success he started to treat hundreds of patients with forced anal dilatation. In bidigital rectal examination he found narrowing bands in almost all patients with haemorrhoids. These bands had already been described by Miles (105). According to Lord these palpable bands were the cause of the development of hatemorthoids. By stretching these bands the etiological factor for haemorrhoids was gone and the haemorrhoids should disappear. In his first publications Lord adapted Miles's theory that the bands were fibrous alterations in the submucosa due to congestion in the varicous haemorrhoidal veins $(85,86,87)$. Sections, however, never showed fibrous tissue in or above the anal canal. In 1977 Lord described the palpable bands as a part of the internal sphincter (91). The aim of anal stretch is to break the vicious circle (Allgöwer, 3 ) in which the anal sphincter is narrowed and hypertonic because of pain in the anorectal region. The hypertonus in its turn perpetuated pain as described in chapter 5.5.7. For anal stretch no instruments are required. After sigmoidoscopy the patient is anaesthetized and two fingers are brought into the anal canal. The anus is dilated gently in all directions until eight fingers can pass the anal canal. Care must be taken not to damage the tissues at the weak points. especially on 6 and 12 o'clock in lithotomy-position. Anus and lower part of the rectum will both be dilated. Lord always performs this anal stretch with the patient in left lateral position. After the dilation a moistened plastic sponge is immediately packed into the anus and lower rectum to prevent the development of haematomas in this region. The sponge is removed after one hour when the patient is in the recovery-room. The patient can leave the hospital after a few hours.

The after-treatment consists of postoperative laxatives (Normacol ${ }^{\text {in }}$, ) and the 


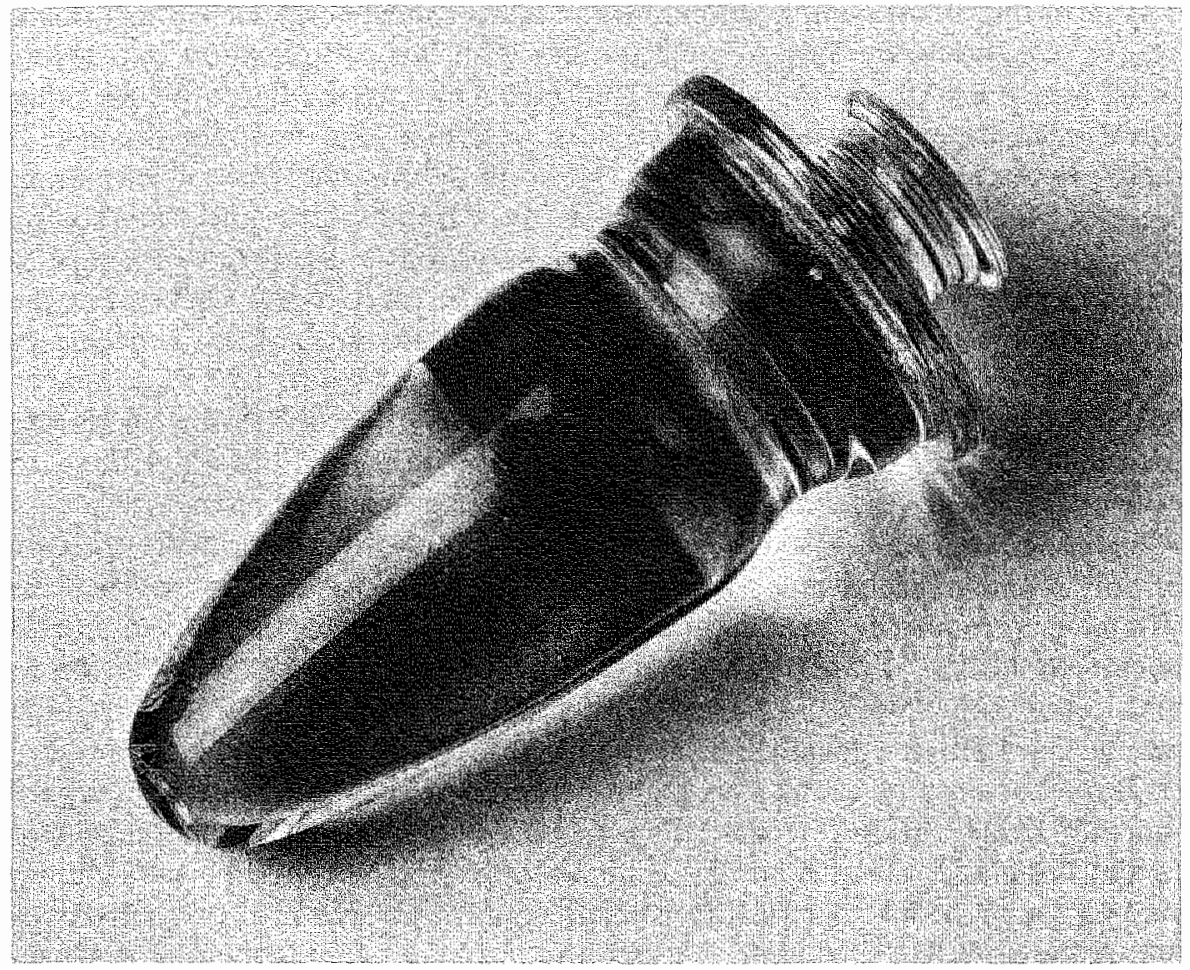

Figure 6.2 Lord's dillitor

use of a large perspex dilator (made by Vann Bros, London). Lord described a special regime for the use of this dilator (see Figure 6.2: dilator).

'The dilator must be passed to its fullest extent and left in position for about one minute.

- The dilator is passed once every day for 14 days after operation. followed by

- every other day for 2 weeks. followed by

- wice a week for 2 weeks, followed by

- once a week for 2 weeks, followed by

- once a month for 6 months'.

Lord (85) described only one follow-up after two weeks. When the patient was symptom-free he was discharged. If he still had complaints a second follow-up was done after two months. Longterm follow-up was achieved by questionaires. The results described by Lord were very good, but he never published exact numbers of patients, results and complications, or compared his results to other methods. He never classified the haemorrhoids or mentioned the indications for haemorrhoidectomy or anal stretch (87). Nevertheless Lord mentioned several complications which were all very mild. 
The most important complication and the fear of most surgeons is incontinence. If there should be only a small number with this complication in a severe form, forced anal dilatation would be unsatisfactory as an alternative for other forms of treatment of haemorthoids. Lord described that real incontinence of faeces never occurred in his patients. He only saw minor types of temporary incontinence. Many people showed a lack of control on flatus and some soiling during the first postoperative weeks. Lord states that patients have to learn to adapt themselves to the new situation and that it takes a few weeks after the dilatation to recover full control of their muscles. In some cases it is necessary to stop laxatives.

A second complication that frequently occurs is splitting of the mucosa during anal dilatation. In almost all cases this 'fissure' will heal within a few days. In only one case Lord saw an infection and severe pain from such a tear (87).

Remaining prolapse was seen several times but Lord often describes a prolapse of only a part of rectal mucosa without real haemorrhoidal tissue inside. This would occur in one in every eight patients (87). He believes that it is not a real haemorrhoid that is prolapsing after the dilatation because of its pink collour and flaccid appearance. The prolapsing 'real' haemorrhoids were always blue and turgid. Lord designed a special clamp to deal with this problem of prollapse. It is a haemostatic clamp that can be placed across the base of the prolapsed mucosal tissue. After resection of the mucosa above the clamp the clamp remains in place for one hour and is then removed. No bleeding occurs and no sutures are necessary. The clamp is also useful in the removal of anal polyps and skintags. When the clamp is used in the same session as the one in which the forced anal dilatation is performed care must be taken to first remove the sponge and then the clamp to prevent bleeding. Bleeding almost never occurs postoperatively. The postoperative symptom of the bleeding of the haemorrhoids normally disappears within a few days. Lord described only one complete failure of the method, in which the bleeding continued and after a few days a haemorrhoidectomy had to be performed.

After Lord's first publications in 1968 many surgeons used bis method in the treatment of haemorrhoids. Some of them reported only the results of the method itself $(39,49.57,94,95,111,116,-118,126,147.148)$, others compared it with haemorthoidectomy $(4,-20,59)$, or with rubber band ligation (66). The several reports are not completely comparable. In only some of them the degree of haemorhoids is mentioned, in none of them the results in second and third degree hamorrhoids are given separately. The results in literature are mostly a mixture of the results in first, second and third degree haemorrhoids. Nevertheless it is possible to draw some conclusions form the several reports (see Table 6.2).

In ten series $(4,20,49,59,66,95,118.147) 259$ patients had the following preoperative complaints: bleeding per anum in $82 \%$, prolapse at the time of the examination in $68.7 \%$ (this includes all patients with third degree haemorhoids and some of the patients with second degree haemorrhoids). pain during and after 


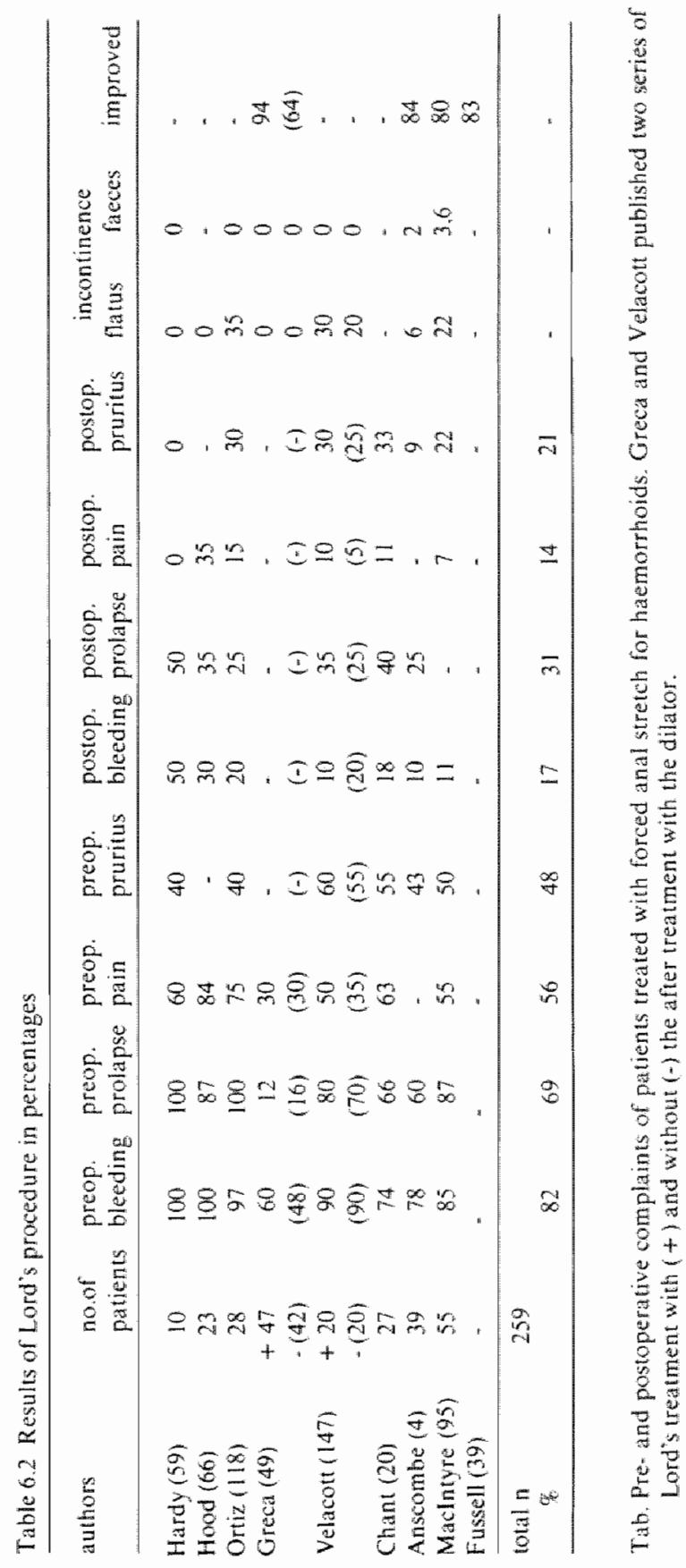


defaecation in $56 \%$ and pruritus ani in $48 \%$. It can only be concluded that patients treated with the method of Lord find much relief for the symptoms of bleeding and pain. and that prolapse and itching do not react so well on anal stretch. In five series $(4,39,49.95,126)$ the patients gave their subjective ideas about the effect of the procedure. Greca mentioned a good improvement in $88 \%$. Anscombe in $84 \%$. Macintyre in $80 \%$. Fussell in $78 \%$ and Saes in $82 \%$, all about six months to one year after the procedure. Even authors who do not recommend Lord"s procedure (Ortiz et al 118) find that the method cures haemorrhage and pain.

Incontinence is a serious problem, but the percentages given by various authors vary too much (Table 6.2). Fussell (39) says that although some of her patients had prolonged difficulty in control they were satisfied with the treatment. The psychological factor in the judgement of incontinence remains very important.

Ortiz et at. have problems with Lord's procedure because of the chance of incontinece. Ortiz (118) gives a percentage between 16 and 25 for his own series and compares that with the figures of Macintyre (95) and Fussell (57). They both indeed gave a percentage of 16 to 25 percent incontinence for flatus after three to six months. Other authors gave much lower percentages for fatus incontinence and, more important, in the other series there was no incontinence of faeces (see Table 6.2). All authors mentioned incontinence as a small problem during the week after the procedure, but in almost all cases the problem. disappeared spontaneously. On the other hand another advantage of the Lordprocedure is only mentioned by a rew authors $(95,111,147)$. In many cases the preoperatively existing constipation and faecal impaction disappeared after Lord's procedure and patients who had used laxatives for many years could now live without drugs.

Another point of discussion in literature about Lord's procedure is the value of the perspex dilator after the anal stretch. There are only two studies in literature that compare the results of anal stretch alone with anal stretch followed by a program in which Lord"s dilator was used for several months, Velacoti (147) found no evidence in his study that the use of the dilator could improve the results. Greca (49), however, saw that in his series only $9 \%$ of the patients who used the dilator had not improved while $36 \%$ of the patients treated by anal stretch alone required further treatment.

Despite the reports of an overall success rate of about $80 \%$ Lord's method is not accepted everywhere in the world. The simplicity of the method and the fear of incontinece probably prohibited a worldwide acceptance. Further discussion will follow in chapter 8 .

\subsubsection{Lateral imternal spinincteroromy}

The second form of treatment of hamorrhoids by manipulating the internal anal sphincter is the lateral internal sphincterotomy. The principles of this treatment are the same as those of Lord's procedure. Eisenhammer (32) stated 
that the internal sphincter as the innermost layer of the muscular tube of the anus is liable to undergo spastic or structural narrowing from pathological stimuli.

The internal sphincter possesses the inherent character of the involuntary circular muscle of the alimentary tract to become spastic through abnormal influences. The internal sphincter has almost no ganglia especially in the lower end (3). The abnormal stimuli could be inflammation (cryptitis, proctitis), pain by trauma. haemorrhoids, etc. The spasm of the anal sphincter, if persistent, could lead to organic changes in the muscle which could give rise to contracture. The spasm as the beginning of the vicious circle can lead to venous congestion in the haemorrhoidal tissue or displacement of the haemorrhoidal cushions as Thomson (145) mentioned. In Eisenhammer's as well as in Lord's view it is necessary to treat the spastic condition of the sphincter to cure the haemorrhoids. Spasm is probably not the right term for the condition of the sphincter. The internal sphincter is hypertonic but can relax during defaecation. Sphincterotomy was first described by Boyer in 1818 as a treatment for fissura ani (32). In France and England the sphincterotomy also remained popular as an additive treatment in other surgical anorectal procedures (Allingham. Brodie, Duypuytren and Demarqua) (32). Brodie (13) described the sphincterotomy in 1835 followed by Bounginage.

The internal anal sphincterotomy is a simple operation and can be performed. under general anaesthesia (3) as well as under local infitration (32), or a regional block. Eisenhammer (32) starts with a longitudinal incision through the anal skin from the dentate line to the anal verge. The white fibres of the internal sphincter become visible and will be cut from their lower margin to the side of the dentate line. The wound is left open. Allgöwer (3) cuts the internal sphincter in the midline but much higher than Eisenhammer. He goes up to three centimeters above the dentate line to the level of the pubo-rectal sling. He cuts mucosa and muscle with diathermy. The wound is closed with catgut to prefent soiling. Both authors sometimes add other treatments to this form of therapy. Allgöwer (3) partly excised large haemorrhoids with diathermy and Eisenhammer (32) destroys hamorrhoidal tissue with scissors submucosally after placing haemostatic ligatures.

Both authors claim good results but their results are not comparable with each other. nor with the results of Lord's procedure because of the combinations with other treatments. Allgöwer (3) saw one case of mild incontinence for diarmea, and three times obserwed marked soiling, but never serious incontinence. Hochhuli (62) published some useful figures. In 128 patients he saw 14 with bad results; that makes a success rate of $88 \%$. He saw no incontinence. Martelli (101) used sphincterotomy as a treatment for obstipation. 


\subsubsection{Bouginage of the anal sphincter}

In 1814 Copeland described the use of large bougies to overcome the painful spasm in the anal canal. The method never became very popular but survived almost two centuries and is still the first choice of treatment of haemorrhoids in several centres. In literature nothing has been published about this form of treatment in the last decades. This is understandable because most of the time this form of dilatation is used in addition to other treatments.

In a retrospective study at Massachusetts General Hospital in Boston in June and July 198122 patients with mean age of 51.8 years were treated for haemorrhoids with dilators. The sex-ratio was 12 men to 10 women. The patients had to use dilators of several sizes. Starting with the smallest one they gradually had to try to pass the larger sizes through the anal canal.

Results: Eight Patients of the 22 continued to have problems after the use of dilatators. Six of them had a prolapse and 7 out of these 8 continued to have bleeding. In 3 of these patients the complaints were so serious that they needed a haemorrhoidectomy within one year. Another patsent underwent rubber band ligation and one patient forced anal stretch with an excision of a simultaneously occurring fissura ani. It is hard to draw conclusions out of these small series, but the method seems insurficient as singular treatment.

Long experience with this bouginage brings Hedberg (61) (personal communications) to the following conclusions:

- Bouginage as single treatment is only effective in few cases. Its advantage lies in the fact that this therapy relieves the anxiety usually preceeding the first visit to the surgical clinic. When a patient hears from his friends that a simple form of therapy is possible and the feared haemorrhoidectomy not always necessary, this will reduce the threshold fear.

- It places the responsibility to the patient and makes him a compagnion in the therapeutic effect to relieve the symptoms and to avoid surgery. - This dilatation facilitates later digital examination, proctoscopy or rubber band ligation.

- Lowering of the pressure of the anal sphincters by bouginage works preventive on possible later anal pathology (fissure cryptitis, stenosis. etc).

- Self administered dilatation avoids the risk of damage to the sphincters and to incontinence.

- This method even when it cures not even half of the patients is of value because of the low costs in time, money and suffering of the patients. The management of the non cured patients is made less uncomfortable, less risky and more permanent.

It can be concluded that bouginage as single form of treatment is less effective, but its advantages have to be seen in the additional, initiating and preventive perspective. 


\section{Barron ligature.}

\subsection{Introduction.}

Nowadays the four most used methods to treat low grade haemorrhoids without any form of anaesthesia are Barron ligation, sclerotherapy. cryotherapy and infrared coagulation. This last form of therapy is not mentioned in chapter 6 , but the aim of the method is equal to cryotherapy; to destroy haemorrhoidal tissue by heat instead of freezing. In all four methods the main goal is to reduce abundant haemorrhoidal tissue to physiological proportions and to give support to the remnant of the haemorrhoidal tissue to stay in the anal canal and prevent it from further prolapse by inflammation.

Of these four methods Barron ligation seems to be the most accurate. Not more tissue is destroyed than the part strangulated in the rubber band. Barron banding can be performed with very low costs, the method is very easy to perform and in cases of unfortunately misplaced bands these bands can immediately be dissected without damage of the tissue.

In literature Barron banding gave good results in low grade haemorrhoids. The results in third degree piles were not so satisfactory (see 6.2.6). The classification of haemorrhoids in 4 degrees refers to the symptom of prolapse. Pain is seldom seen in first and sometimes in second degree piles. Pain proved to be treated very well with forced anall stretch. Results will be given in chapter 8 . The frequency of pain as presenting symptom was low in reports about Barron ligation. Hood (66): $45 \%$ and Steinberg (140): $43 \%$ or was not mentioned at all $(109,110)$.

Bleeding and prolapse were the main indications for Barron ligation in literature. Rubber bands are placed above the margin of sensibility and it seems reasonable to believe that pain will not be influenced much by this procedure.

For these reasons Barron ligature was chosen to treat first and second degree pilles in patients who did not or hardly suffer from pain. In cases where pain was an important presenting symptom, forced anal stretch was the therapy of choice.

In fact the study described in chapter 8 was done before the study about Bar- 
ron ligature. The good resulis with respect to pain made that patients with second degree haemorrhoids and severe pain were treated with forced anal stretch and were not included in the study about Barron banding.

In literature there is discussion whether or not more than one haemorrhoid should be ligated at one time.

Barron stated (7) that more than one pile at a time should predispose for tenesmus and treated only one haemorrhoid at each visit. This method was followed by Steinberg (140), Hood (66), Smith (138) and Möller (109). Wullink (156) and Alexander Williams (1) chose for two opposite piles each time. while Murie (110) and Lau (86) treated the three main haemorrhoidal cushions in one visit.

In some publications a ligation was always performed with two bands $(1,7,68,109)$. Others use only one band. In a recent publication Katchian (76) investigated the strength of warious types of rubber bands. He found that the quality of the bands was not always optimal and the low constrictive force could be cause of subsequent bleeding. In using good and reliable bands it must be sufficient to ligate haemorrhoids with only one band.

In literature every one states that preoperative rectosigmoidoscopy is necessary to exclude other pathology before treatment of haemorrhoids. However, never have figures been given of concurrent pathology in colo-rectum in patients with symptoms referable to piles. To evaluate the method of rubber banding a study was performed in 100 patients with first and second degree piles.

To minimize the problems for the patients all haemorrhoids were banded in one session. At the same visit a sigmoidoscopy was done. Each haemorrhoid was ligated with only one rubber band.

\subsubsection{Definitions}

The following definitions were used in the studies presented in chapter 7 and 8: Pain:

A troublesome feeling in the anal canal sometimes described by the patients as burning. Pain was subdivided in spontaneous or continuous pain during the whole day, and in pain related to defaecation.

No attempt was made to quantify pain according to the use of analgetics. Every level of pain was scored as positive.

Bloodloss:

Loss of red blood from the anal canal was subdivided in bloodloss at defaecation (on the stool or tolletpaper) and spontaneous bloodloss during the whole day not related to defaecation.

Pruritus ani: Feeling of itching in the anus and perianal region. 
Constipation:

Use of laxatives:

Prolonged straining:

Prolapse:

Continence:
Irregular difficult defaecation with mosily firm stool and low defaecation frequency.

Every form of therapy for constipation by means of medical treatment or diets.

An according to the patient abnormally long time of straining ( $>2$ minutes).

Prolapse of haemorrhoid: spontaneously reducing, digitally replacable or irreducable.

Ability to controll mucus, flatus and faeces.

\subsection{Methods}

In this study only patients with first and second degree haemorrhoids were treated with Barron ligation. The indication was about always bloodloss.

Preoperatively all patients were questioned about pain. Severe pain at defaecation and spontaneous pain were an indication to perform manual dilatation. Minor pain at defaecation was accepted to perform rubber banding. Almost all patients had bloodloss on defaecation and they were also questioned about prolapse, pruritus ani and continence. Perianal inspection and rectal examination gave information about the haemorrhoids and possible other anal and perianal pathology.

In all patients first a sigmoidoscopy was performed with a flexible Olympus sigmoidoscope. Patients with other anal pathology were excluded except for a few patients with minor additional anal papillomas. These papillomas were also ligated with Barron bands at the same time. After sigmoidoscopy a proctoscope was inserted and the haemorrhoids were visualised. With the Lurz suction ligator one rubber band was placed at the base of the pile at one to two centimeters above the dentate line. When the suction was painful the apparatus was not fired but a new attempt was made more proximal. In patients with one haemorrhoid only one band was used. in patients with more haemorrhoids two or three bands were required.

All patients underwent a controll proctoscopy 2 weeks after treatment. Attention was paid to the scars of the ligation and to possible remaining haemorrhoids. At that visit all patients were questioned again about the initially presenting symptoms and possible complications. A second follow-up visit was arranged at three months after first treatment. All patients were advised to use a fibre-rich diet. No laxatives were prescribed.

\subsection{Patients}

One hundred patients entered the study (see Table 7.1). There were 71 men and 29 women. The mean age was 47.8 years. $10 \%$ Of the patients was younger than 30 years and $9 \%$ older than 70 years. In the group of first degree haemorr- 


\begin{tabular}{llll}
\hline & lotal & Ist degree & 2nd degree \\
\hline number of patients & 100 & 32 & 68 \\
sexpatio of $/ 9$ & $71 / 29$ & $21 / 11$ & $50 / 18$ \\
miecan age in years & $47.8 \pm 14$ & $39.3 \pm 12$ & $52.8 \pm 14$ \\
\hline
\end{tabular}

hoids the mean age was lower than in the second degree group. $95 \%$ of the patients had had their complaints for more than one year. Pain at defaecation was present in $23 \%$ of the patients. No continuous. spontaneous pain was seen (see Table 7.2). 93\% Of the patients complained about bloodloss at defaecation. Pruritus ani was present in $24 \%$ of the patients. Prolapse at defaecation was a complaint in $68 \%$ of the patients. Minor problems of faecal incontinence were mentioned by $5 \%$ of the patients. All patients used suppositories and ointments without results before they were referred to the surgical outpatient clinic.

In most cases there was a combination of several complaints. Table 7.2 gives also the figures of single presenting symptoms. There were $68 \%$ with second degree and $32 \%$ with first degree haemorrhoids. At sigmoidoscopy 12 patients were found with colorectal polyps. All turned out to be adenomateous polyps. In 5 patients there were signs of diverticulitis, 5 had a mild proctitis and $I$ an angiodysplasia in the sigmoid (not bleeding). No malignancies were seen in this group of patients (see Table 7.3). Signs of diverticulitis were rednes and oedema around the diverticulae but no severe stenosis that would have led to operation.

Six times additional anal papillomas were found and two times additional external haemorrhoids.

Table 7.2 Preoperative complaints $(n=100)$ in patients with first and second degree haemorrhoids treated with Burron bands.

\begin{tabular}{|c|c|c|c|c|c|}
\hline & tollit. & $\begin{array}{l}\text { single } \\
\text { problem }\end{array}$ & $\begin{array}{l}\text { in combination } \\
\text { with other } \\
\text { complaints }\end{array}$ & $\begin{array}{l}\text { Ist degree } \\
n=32\end{array}$ & $\begin{array}{l}\text { 2nd degree } \\
n=68\end{array}$ \\
\hline Pain al defnecation & $23 \%$ & $0 \%$ & $23 \%$ & 194 & $25 \%$ \\
\hline Blood at defaecation & $93 \%$ & $21 \%$ & $72 \%$ & $93.8 \%$ & 92.79 \\
\hline Pruritus ani & $24 \%$ & 78 & $17 \%$ & $19 \%$ & $26 \%$ \\
\hline Prolapse & $68 \%$ & 09 & $68 \%$ & $0 \%$ & $100 \%$ \\
\hline incontinenee for facces & $5 \%$ & $0 \%$ & $5 \%$ & $0 \%$ & $7 \%$ \\
\hline
\end{tabular}


Table 7.3 Preoperative fundings $(n=100)$ in patients with hirst and second degree pies treated with Barron bands.

Tirst degree haemorthoids

second degree haemorrhoids

anal papillomas

colo/rectal polyps (adenomateous)

diverticulitis (mild)

proctitis (mild)

angiodysplasia (sigmoid)

melanosis coli

skintags

perianal eczema

\subsection{Results}

All patients with one haemorrhoid were treated with one band $(n=10)$. Patients with two haemorrhoids with two $(n=38)$ and patients with more piles with three bands $(\mathrm{n}=52)$. All postoperative complaints were noted.

\subsubsection{Pain}

Pain was experienced in the first two weeks after treatment by $25 \%$ of the patients. In only $4 \%$ this pain was severe, and more intense than preoperatively. Two of these 4 patients needed other treatment (see 7.4.4), in two cases the pain disappeared spontaneously. The results after 2 weeks and 3 months were equal for first and second degree haemorrhoids.

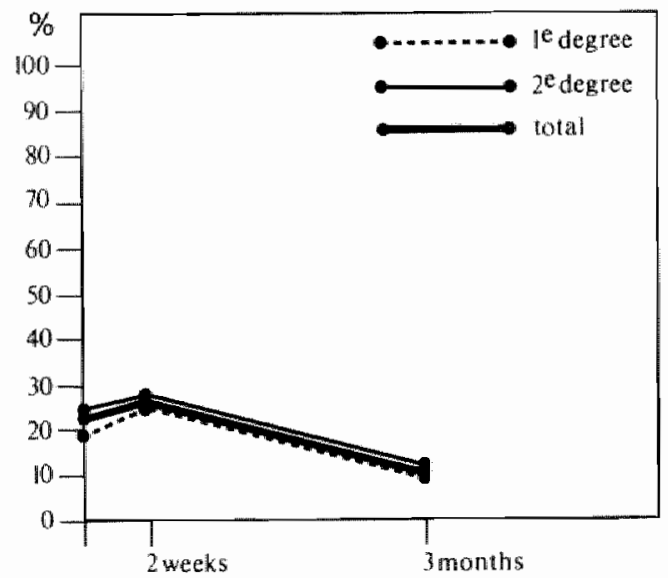

Figure 7.4 Pain after Barron-banding 
After three months 10 patients still had pain. Of these 10 patients there were 6 who experienced pain preoperatively and in 4 patients the pain developed after treatment (see fig. 7.4).

\section{4 .2 Bloodlos:}

Bloodloss during the first two weeks after treatment was experienced in $30 \%$ $(n=100)$ of the patients. Bloodloss was always minimal. In mo case hospitalisation or bloodtransfusion was required. After 3 months $10^{\circ}$ still had minor bloodloss $(n=100)$. These 10 patients had already bloodloss preoperatively. So bloodloss was never a new complaint after treatment (see fig.7.5).

In first and second degree piles the results were equal.

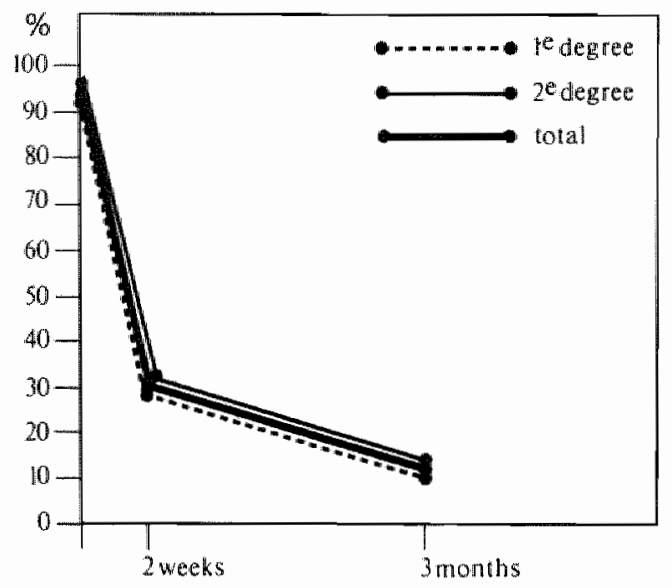

Figure 7.5 Bloodloss after Barron-banding

\subsection{Pruritus ani}

Seventeen percent of the patients $(n=100)$ had itching after two weeks. Fourteen of these patients had experienced pruritus preoperatively. For three patients it was a new complaint. After three months $15 \%$ still had problems with pruritus ani. Two of the three patients who experienced pruritus for the first time after treatment were now free of itching (see Figure 7.6). In the first degree piles the frequency of pruritus stayed the same. In the second degree haemorrhoids it decreased to $20 \%$. 


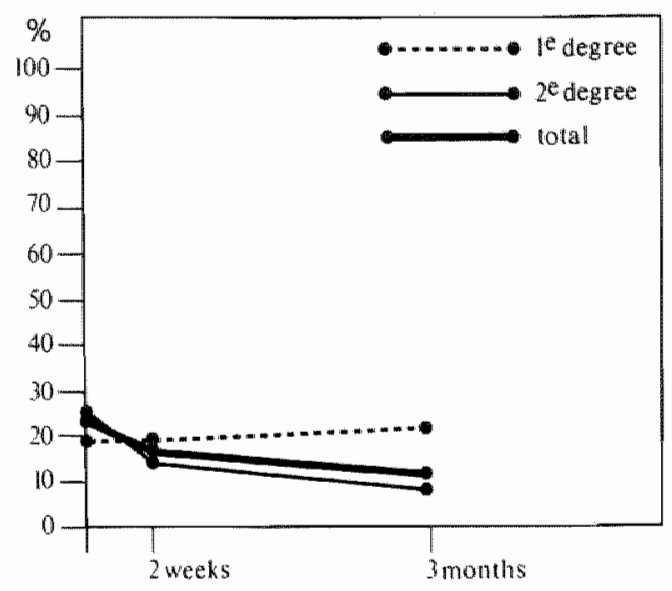

Figure 7.6 Pruritus after Barron-banding

\subsubsection{Prolapse}

After 2 weeks in $14 \%$ of the cases there were still prolapsing haemorrhoids. Ten times new Barron bands were placed ( 8 times 2 remaining haemorrhoids were ligated and 2 times 1 band was used). Of the 4 remaining patients 3 underwent a haemorrhoidectomy and 1 patient forced anal stretch (in 2 of the 4 reinterventions pain was an indication).

After 3 months there were still 2 patients with a remaining haemorrhoid. One underwent a third ligation and the other patient a haemorrhoidectomy (see fig.7.7).

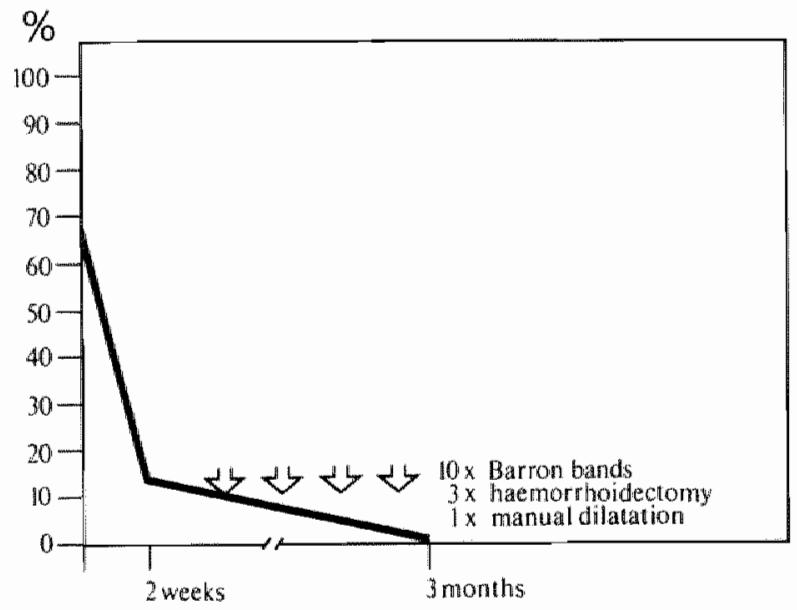

Figtre 7.7 Prolapse after Barron-banding 


\subsubsection{Inconinence for faeces}

Of the 5 patients with minor complaints of incontinence for faeces, after two weeks only one patient had suffered from incontinence once. After three months the same patient still had this complaint. One patient experienced soiling after two weeks, but this disappeared in three months. All incontinence problems occurred in the second degree group.

\subsubsection{Complications}

Twice an emergency haemorhoidectomy was done due to acute prolapse strangulation and severe pain. These patients have already been mentioned in 7.4.4. Once a Barron band slipped off after one day and caused a minor bleeding (this case was included in 7.4.2).

No other severe complications could be detected in these $\mathbb{1 0 0}$ patients. There were no cases with urine retention and no infections.

\subsubsection{Postoperanive proctoscopy findings}

At proctoscopy 2 weeks after Barron ligation in all cases the scars of the ligations were seen. In only one case one of the bands was still present after two weeks. Ten times remaining haemorrhoids were ligated (already mentioned in 7.4.4). In the 6 cases with additional anal papillomas, these papillomas had dis* appeared after two weeks. The two patients witla additional external haemorrhoids were symptomfree after treatment of the internal haemorrhoids. The external haemorrhoids disappeared.

\subsubsection{Personal judgmen of the patients}

After three months 6 patients underwent further treatment, 4 times a haemorrhoidectomy and 2 times manual diatation. Five patients had initially second and one firs degree haemorrhoids.

In all other cases patients were satisfied. Of the 94 patients who said they were salisfied, 12 patients still had pruritus, 8 had bloodloss and 5 had pain. These complaints were minimal. Some of these patients had combined complaints left. 14 Patients out of 94 had remaining complaints but judged the results ats good.

\subsection{Discussion}

The group of patients was a selected one and can not be compared with the patients who underwent haemorrhoidectomy and forced anal stretch in chapter 8. In this selection pain was an important issue. Pain proved to be treated very well by manual dilatation (see chapter 8 ). In the series of patients treated with 
Barron ligation pain was always minimal and never the single reason for haemorrhoid treatment. In the present series 6 patients out of 23 still had pain after Barron ligation. It is hard to say whether this was a continuation of the preoperatively experienced pain or the ligation in itself caused the pain. Normally treatment above $1 \mathrm{~cm}$ proximal of the dentate line causes no pain sensation. A strange experience was that in the six cases where anal papillomas were ligated with the haemorrhoids and the bands were placed at the level of the dentate line no postoperative pain was experienced. However, there is an individual diversity in the level above which pain can be experienced. This may be the explanation for the postoperatively initiated pain. The demonstration of the pain sensation level with the suction method (see 7.2) is not perfect. In literature there are no large figures published about pain at defaecation. Mostly it is gathered up with other symptoms under the term discomfort $(66,109,140)$. The preoperative pain at defaecation seems to be an initiating cause for the development of haemorrhoids (see chapter 8) and not a symptom of these piles. In 17 cases however in this ligation series pain disappeared after Barron banding. Perhaps the moderate dilatation of the anal canal with the proctoscope is the cause of this fact.

As mentioned before many authors always treated one haemorrhoid at a time (see 7.1 ) because of possible postoperative pain. Others thought that multiple applications had no influence. In our series we tried to treat all present haemorrhoids at one time. Table 7.8 shows that in the small series of patients treated with one band there was no postoperative pain. But in this series no other hatemorrhoids were left unbanded and cannot be compared with other series.

Tabel 7.8 Number of Bands and postoperative pain.

\begin{tabular}{llll}
\hline $\begin{array}{l}\text { Number of bands } \\
\text { placed at first }\end{array}$ & $\begin{array}{l}\text { \% of patients } \\
\text { with pain } \\
\text { after } 2 \text { weeks }\end{array}$ & $\begin{array}{l}\text { \% of patients } \\
\text { with pain } \\
\text { after } 3 \text { months }\end{array}$ & $\begin{array}{l}\text { number } \\
\text { reinterv. }\end{array}$ \\
\hline $1(n=10)$ & $0 \%$ & $0 \%$ & $0 \%$ \\
$2(n=38)$ & $26 \%$ & $18 \%$ & 1 \\
$3(n=52)$ & $29 \%$ & $13 \%$ & 5 \\
\hline
\end{tabular}

The symptom of bloodloss disappeared very well after Barron banding. In the first two weeks bleeding was experienced in $30 \%$ of the cases probably due to necrosis and disappearance of tissue and Barron bands. In 3 months after banding only $10 \%$ had minor bloodloss.

Three of these 10 patients underwent haemorhoidectomy becaluse of severe prolapse and minor bleeding.

Hood (66) described in 17\% of the patients treated with Barron ligation bleeding as a persistent symptom. Murie (110) found persistent bleeding in $10 \%$.

Rubber banding had only little effect on pruritus ani in patients with second 
degree piles and almost no influence in patients with first degree haemorrhoids. Three patients had to be treated postoperatively for perianal eczema. In literature about Barron bands itching was never an important issue.

The intermittent prolapse of the patients with second degree piles diminished after initial banding to 14\%. Of these 14 patients 10 underwent Barron banding for a second time and were further prolapse-free. A second banding is hardly a problem for the patients because it was always done during the control proctoscopy after two weeks. Of the remaining 4 patients 3 underwent haemorhoidectomy and I patient forced anal stretch, because of this prolapse and other symptoms. So only in $4 \%$ Barron banding was not sufficient to treat the complaint of prolapse.

Hood (66) and Murie (110) find higher percentages of persisting prolapse (17\% and $8 \%$.

Problems with incontinence are not mentioned in literature about Barron bands. We saw minor problems preoperatively most of which disappeared after treatment. In one case minor incontinence for faeces remained the same.

The complication rate in the present series was very low. Twice severe prolapse led to haemorhoidectomy and once a Barron band slipped off after one day causing a minor bleeding. Lau (80) twice mentioned severe bleeding requiring transfusion, once stenosis and once urine retention in a series of 202 patients. He also treated 3 haemorhoids at one time. In the present series all complications were seen in the group of patients treated with 3 bands.

It is not possible to draw conclusions from this fact. In the cases that 1 or 2 bands were used, there were only one or two haemorhoidal swellings present. In no cases haemorhoids were left untreated at the first visit.

In the present series we see a discrepancy between the personal judgement of the patients and the presence of remaining symptoms. Obviously these symptoms were less severe than preoperatively.

The very high figure of pathology found in the rectosigmoid in patients with bloodloss and almost no other complaints, justifies the use of the sigmoidoscope before treatment of haemorrhoids. It is hard to say. if a same high number of pathology could be found in a complete symptomfree group of patients. This has, as far as known, never been investigated.

Conclusion: Out of 100 patients treated with Barron bands 80 were completely symptomfree after 3 months. 94 Patients were satisfied and the 6 remaining patients were satisfied after haemorrhoidectomy or forced anal stretch. Barron ligature is a very good method to treat patients with first and second degree piles, if pain is not an important presenting symptom. The fact that neither anaesthesia nor expensive equipment are required and that the method is easy to learn. would make this treatment useful for the general practitionor, provided that other pathology is excluded. 


\section{Clinicall trial: Lord's method versus open haemorrhoidectomy ver- sus dilatation without aftertreatment.}

\subsection{Introduction and purpose of the study.}

Many forms of treatment for haemorrhoids have been described and it is impossible to determine on the base of literature review, which one is the best. Almost all are presented as retrospective studies or merely a description of a method. The several retrospective studies are incomparable, because of the lack of basic information. Most authors don't give a good classification in degrees of haemorrhoids and it is hard to objectivate their results. The personal judgement of the patients is often the only criterium to review the results. Of course the personal interpretation is the best evaluation for the patients themselves, but for statistical evaluation it is good to look also for objective data. Some controlled prospective randomized studies were performed $(4,20,49,59,66,82,110,118,147)$. Only by means of such studies it is possible to compare methods of treatment in a meaningful way.

In the Netherlands the method of forced anal dilatation has been first introduced by Delfgaauw and Greep in $1973(25,82)$. Their initial results were very good. There was an improvement in $97 \%$ of their cases after $1-2 \frac{1 / 2}{2}$ years. The same group of patients was followed for more than 7 years and the long term results published by Kenter (75) showed that in $76,3 \%$ of the cases the result was satisfactory. In literature only three prospective controlled studies are published in which Lord's method is compared with haemorrhoidectomy $(4,20,59)$. In none of these studies sphincter function was objectivated with anal pressure measurements as was done in other new retrospective series $(53,54,55,56,57)$.

Another point of discussion in literature is the value of the after treatment with the perspex dilator in Lord"s method. There are only two reports that compare the results of forced anal dilatation alone with anal stretch followed by an after treatment program as described by Lord $(49,147)$. The results in both studies are different.

To determine the value of Lord's method as an alternative for hatemorrhoidectomy in second and third degree piles. to evalluate the necessity of the aftertreatment with a dilator and to look at the economical aspects in both forms of treatment, a prospective randomized trial was done. Furthermore the value of 
anal pressure measurements in patients with haemorrhoids was studied. For this study a new method of anal pressure measurements was developed.

\subsection{Methods}

All patients with second and third degree piles could enter the study. Patients with fourth degree piles were always operated upon by means of an open haemorrhoidectomy (43). Patients with external haemorrhoids underwent a haemorrhoidectomy and were not included in this study.

The diagnosis second or third degree haemorrhoids was made by anamnesis, inspection of the anus during straining, rectal examination and endoscopy. In all cases the patients had complaints that could be related to second or third degree haemorrhoids. Symptomfree patients in whom the diagnosis was made during endoscopy for other reasons could not enter the trial. In almost all patients anal pressure measurements were performed.

\section{Anamnesis}

The patients were questioned about: spontaneous pain, pain related to defaecation, bloodloss, itching, prolapse, constipation, use of laxatives, prolonged straining and continence. All complaints were defined in 7.1.1.

All patients were further questioned about abdominal complaints (pain, borborygmi), about diarrhea, loss of mucus, melaena and so on to determine the presence of other pathology in the lower digestive tract. To evaluate the risks for general anaesthesia the anamnesis included questions about the general state of health.

\section{Inspection}

Physical examination of all patients included inspection of the perianal region with special attention to visible haemorrhoids. mucosa prolapse during straining, fissures, fistulae, skintags, haematomas, abscess, eczema, excoriations of the perianal skinn and scars of possible previous operations.

Rectal examination

Rectal examination gave information about anal polyps, thrombi in the piles, induration in cases of abscess and fistulae, about the tone of the sphincters, pain, and the rectal mucosa.

\section{Endoscopy}

In all patients a recto-sigmoidoscopy was done preoperatively, in the first patients with the rigid rectoscope up to $20 \mathrm{~cm}$, later on, when a flexible endo- 
scope was available with the Olympus CS IT S2 flexible sigmoidoscope up to $60 \mathrm{~cm}$ combined with proctoscopy. Special attention was paid to other anal pathology (fissures, anal polyps and inflammation). When other pathological entities were detected, such as Morbus Crohn, colitis and so on, the patients did not enter the trial.

Anal pathollogy such as abscess and fistulae was a cause to exclude the patients for this study.

Patients with anal fissures and anal polyps were not excluded. Therapy for haemorrhoids was not a contra-indication because of these intercurrent anal disorders.

Anal pressure measurement

To get more objective information about the condition of the anal sphincters in almost all cases anal pressure measurements were performed. These measurements were repeated at all control visits (at 1 week, 1 month, 6 months and 1
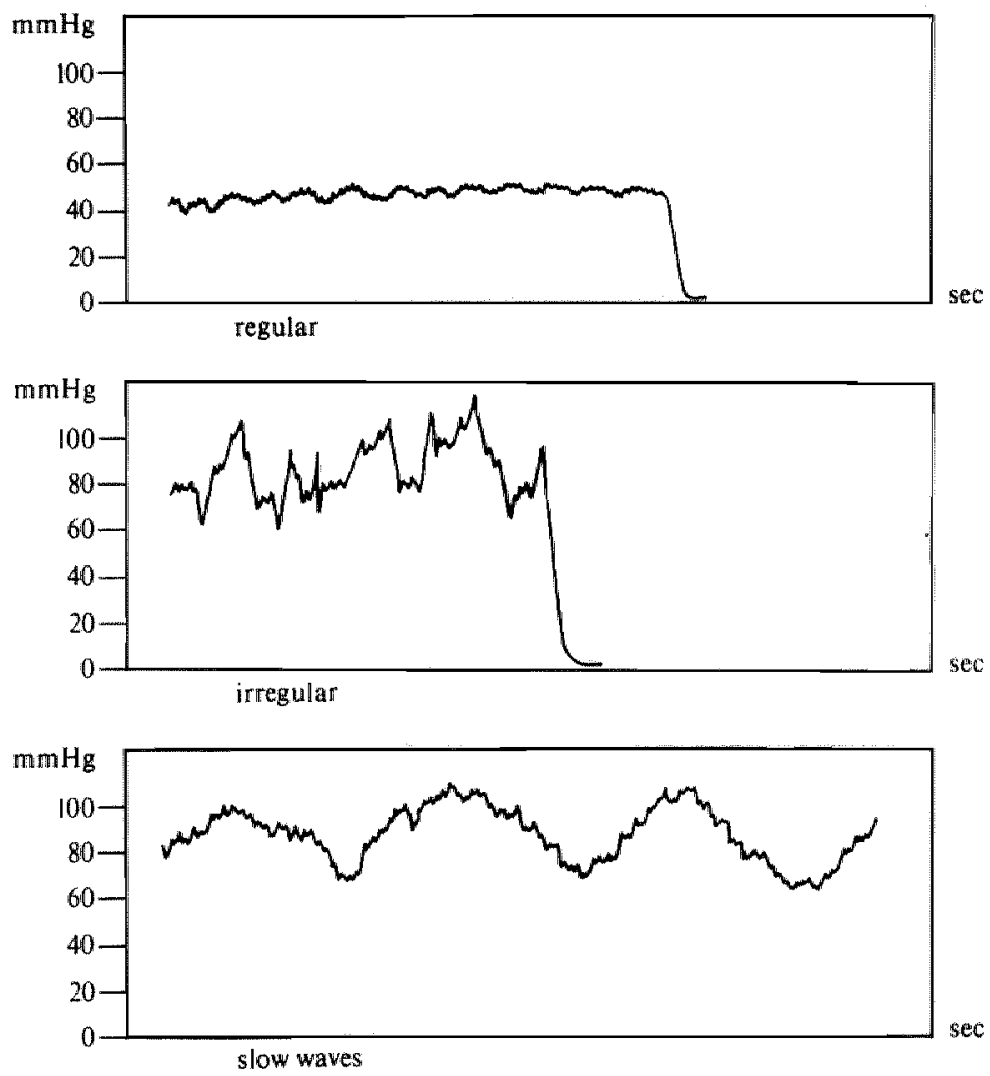

Figure 8.1 Superposition of breathing and pulse 
year after the procedure). For the measurements a Millar catheter was used (see chapter 4).

All measurements were done by inserting the lubricated tip of the Millar catheter in to the anal canal. After making a standard measurement, the catheter was manoeuvered into the rectum and then withdrawn through the anal canal until the point of the highest pressure was found. Here the catheter was maintained manually at the same level and for several minutes a registration of the pressure at that point was made. Three types of pressure patterns were found in these series. Figure 8.1 shows the several patterns. In some registrations it was possible to find superposition of breathing and pulse on the basic slow waves. The presence of an artery just in front of the sideopening of the Millar catheter gives this effect. By rotating the device in the anal canal the pressure level remained the same. It made no difference which side of the circumference of the anal canal was focused by the sideopening, as long as the opening was kept at the same distance from the anal verge. It also made no difference for the pressure pattern when the measuring device was turned to another side. Only the superposition of artery pulse could change or disappear.

Randomisation and therapy

After informed consent, the patients with second and third degree haemorrhoids eligible for the trial were divided at random into three groups: For the randomisation 150 envelopes, containing a note with one of the three treatment possibilities, were mixed and were numbered from 1 to 150 . At the moment a patient was eligable for the trial the envelope next in number was taken.

Group A (Haemorrhoidectomy)

These patients were operated upon according to the Milligan method. The patients were admitted to the hospital the day before surgery. All preoperative diagnostics were done before admission. These included labtests for all patients and chest $X$-ray and ECG for patients over 30 years old.

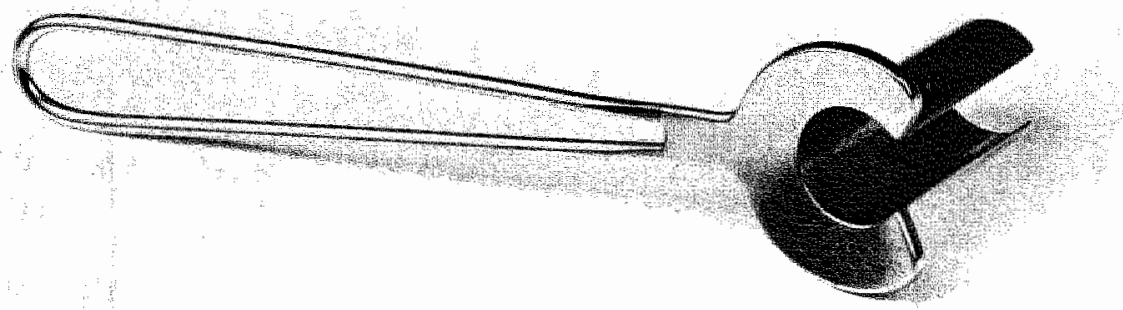

Figure 8.2 Operation proctoscope 
The operation was performed under general anaesthesia in lithotomy position. A proctoscope with a slit was brought into the anal canal in order to standardize the degree of anal stretch during the haemorrhoidectomy. The diameter of the proctoscope was $3 \mathrm{~cm}$ (see figure 8.2 ). By rotating the proctoscope the three main haemorrhoids at 3,7 and 11 oclock became visible in the slit. The three main haemorrhoicls were grasped and pulled outside the anal canal through the slit of the proctoscope. A haemostatic transfiction ligature with catgut was made through the base of the haemorrhoid and the haemorrhoid was resected. At the same time skintags were resected. The wound was left open and bleeding points were coagulated or ligated with catgut. Sufficiently large mucosal bridges (at least $1 \mathrm{~cm}$ ) were left between the three wounds. An anal Spongos$\tan ^{8}$ tampon was left in the anal canal after withdrawal of the proctoscope. The patient usually stayed in the hospital for a few days and was discharged after the first postoperative defaecation. If necessary a laxative was given, Agarol ${ }^{\text {i }}$.

Group B (complete Lord's method).

The second group of patients underwent the same preoperative screeningtests as group $\mathrm{A}$. These patients were not admitted to the hospital but were operated upon on an outpatient base. They came to the hospital at the day of the operation.

Forced anal stretch was performed under general anaesthesia with the patient in left lateral positon. Two fingers were brought into the anal canal and the anus was dilated crosshandedly until 6 fingers could pass. Then an ordinary household sponge soaked in Hibitane in water was inserted into the anal canal. This sponge was removed one to two hours after the procedure before the patient left the recovery room. The patient returned home the same day. No special recommendations for laxatives were given. Skintags, if any, were not removed at the same time. The next day the patients of this group had to start using the special large dilator (v.Bross, London)(see figure 6.2), which was also prescribed by Lord. They were advised to lubricate the dilator before inserting it into the anal canal and to keep it inserted for one minute each time. The program for the use of the dilator was the same as described by Lord ( 87 ):

The first two weeks once a day followed by once every two days for two weeks followed by twice a week for two weeks followed by once a week for two weeks followed by once in two weeks followed by once a month for six months

After this period the patients could stop the use of the dilator. 
This group of patients underwent the same preoperative screening procedure as described for groups A and B. The patients of this group were treated on an outpatient base. The same procedure of anal stretch was performed as described for groups B.

The only difference between the treatment in groups B and $C$ was that in group $C$ the after treatment with the dilator was omitted.

\section{Follow-up}

For all three groups the follow up was as follows:

All patients were seen I week, I month, 6 months and 1 year after surgery. Al each follow up visit a complete history was taken. Patients were questioned about all possible complaints in the same way as preoperatively. Special attention was given to problems of incontinence. They were asked about possible complications such as urine retention, infection of the wounds, of the respiratory tract and of the bladder.

All patients were questioned about the number of days they did not work after the operation. Finally, all patients gave their personal opinion about the results of the treatment, giving them the choice between: good, fair and bad.

At each follow up visit inspection and at indication reclal examination was performed. Presence of fissures, skintags, inflammation and remaining haemorrhoids were noted. The condition of the anal sphincters was evaluated each time with anal pressure measurements.

\subsection{Patients}

\subsection{General data.}

The patients in this study were operated upon between april 1979 and november 1981 . In these 2.5 years 211 patients were operated for haemorrhoids. Of these 211 patients 15 had first degree piles and underwent Lord's method (Barron ligation was not yet available by that time). Fourty-six patients had fourth degree piles and underwent a hatemorrhoidectomy. Of the remaining 150 patients 138 entered the trial (see Table 8.3).

Twelve of them did not participate in the study because of administrative problems, or because of their preference to be treated in a special way.

At random 41 patients were subdivided in group A (haemorrhoidectomy), 46 in group B (Lord) and 51 in group C (Lord without after-treatment)(see Table 8.4).

There were 86 men and 52 women ( $62 \%$ to $38 \%$ ). The sex rate in each group was almost similar. The average age in the whole series was $45.8 \pm 12.0$ for women and $42.2 \pm 13.2$ for men. In the three groups the women were somew- 
Table 8.3 Number of patients.

all patients with haemorthoids from aprill 1979 until november 1981 all patients with

urial patients

haemorhoids

$\begin{array}{llll}\text { Ist degree } & 15 & & \\ \text { 2nd degree } & 55 & 55 & 50 \\ \text { 3rd degree } & 95 & 95 & 88 \\ \text { 4rd degree } & 46 & 150 & 138\end{array}$

Table 8.4 General data of the three trial groups.

\begin{tabular}{|c|c|c|c|c|c|}
\hline & \multirow[b]{2}{*}{ number } & \multirow[b]{2}{*}{$\begin{array}{l}\text { sex rate } \\
\hat{a} / 9\end{array}$} & \multicolumn{3}{|c|}{ mean age in years $\pm S . D$} \\
\hline & & & total & men & women \\
\hline group A & 41 & $24 / 17$ & $45.1 \pm 11,9$ & $41.1 \pm 10.1$ & $50.6 \pm 12.1$ \\
\hline group B & 46 & $30 / 16$ & $41.2=11.6$ & $40.8 \pm 12.3$ & $41.9 \pm 10,7$ \\
\hline group C & 51 & $32 / 19$ & $44.6 \pm 1.4 .6$ & $44.4 \pm 16.2$ & $45.0 \pm 11,9$ \\
\hline total & 138 & $86 / 52$ & $43.6 \pm 12.9$ & $42.2 \pm 13.2$ & $45.8 \pm 12.0$ \\
\hline
\end{tabular}

hat older than the men. The age of the patients varied from 20 to 80 years. Of the total series 50 patients had second and 88 patients third degree piles. In every group there were more patients with third than with second degree piles. Second and third degree haemorrhoids were equally seen in both sexes. The three groups of patients do not seem to differ in their general data.

\subsubsection{Preoperative complaints}

All patients in each group were questioned about their complaints and examined in the same way.

Table 8.5 shows the results of each group and of the entire series of 138 patients.

The patients were questioned about pain. A hundred and three out of 138 patients (75\%) had pain during and after defaecation. In $57 \%$ the pain contimued during the day. Spontaneous pain was more frequent in group B $10.05<$ $p<0.1$ ), but in the defaecation related pain the groups were equal. $15 \%$ of the patients had no pain at all. Several patients had spontaneous pain that was not influenced by defaecation. 


\begin{tabular}{lllll}
\hline & $\begin{array}{c}\text { group A } \\
(n=41)\end{array}$ & $\begin{array}{c}\text { group B } \\
(\mathrm{n}=46)\end{array}$ & $\begin{array}{c}\text { group } \mathrm{C} \\
(\mathrm{n}=51)\end{array}$ & $\begin{array}{l}\text { total } \\
(\mathrm{n}=138)\end{array}$ \\
\hline pain spontaneous & $44 \%$ & $69 \%$ & $57 \%$ & $57 \%$ \\
pain at defaccation & $78 \%$ & $78 \%$ & $74 \%$ & $75 \%$ \\
no pain & $12 \%$ & $11 \%$ & $19 \%$ & $15 \%$ \\
inching & $61 \%$ & $48 \%$ & $55 \%$ & $54 \%$ \\
bleeding spontaneous & $32 \%$ & $41 \%$ & $27 \%$ & $33 \%$ \\
Bleeding at defaecation & $90 \%$ & $89 \%$ & $88 \%$ & $89 \%$ \\
no bleeding & $10 \%$ & $11 \%$ & $12 \%$ & $11 \%$ \\
constipation & $41 \%$ & $37 \%$ & $43 \%$ & $41 \%$ \\
\hline
\end{tabular}

Pruritus ani was found in 75 out of 138 patients (54\%). In group A this symptom was seen more frequently $(61 \%)$ than in group $B(48 \%)$ and $C(55 \%)$, but the difference is not significant $(p>0.5)$.

Bleeding during and after defaecation was the most common complaint: $89 \%$, equally divided in the three trial groups. Many patients had also problems with spontaneous bloodloss not related to defaecation. In the whole series this spontaneous bloodloss occurred in $33 \%$. In grou p B spontaneous bloodloss was seen most frequently ( $4 \mathrm{I} \%$ ) but the bloodloss related to defaecation was similar in the three trial groups. All patients with spontaneous bloodloss had also bloodloss at defaecation.

Constipation occurred almost equally in the three trial groups. Sixty-five patients out of $138(41 \%)$ had problems with firm stool and a low defaecation frequency. Table 8.6 gives the division of constipation in the three groups and the use of laxatives to deal with this problem.

Table 8.6 Constipation and use of laxatives in the three groups preoperatively

\begin{tabular}{lllll}
\hline & $\begin{array}{l}\mathrm{A} \\
(\mathrm{n}=41)\end{array}$ & $\begin{array}{l}\mathrm{B} \\
(\mathrm{n}=46)\end{array}$ & $\begin{array}{l}\mathrm{C} \\
(\mathrm{n}=5)\end{array}$ & $\begin{array}{l}\text { total } \\
(\mathrm{n}=138)\end{array}$ \\
\hline $\begin{array}{l}\text { Constipation } \\
\text { use of laxullives }\end{array}$ & $41 \%$ & $37 \%$ & $43 \%$ & $41 \%$ \\
\hline
\end{tabular}

Straining at stool was mentioned by 75 out of 138 patients $(54 \%)$. For these patients it took more than 2 minutes of abdominal pressure. The time varied from 2 minutes to 30 minutes (see table 8.7 ). Another important issue to compare the three groups of haemorrhoidal patients and to judge the results of the several treatments is the symptom of incontinence (see Table 8.8). Incontinence for thatus was present in $14 \%$ of the patients. Soiling was seen in $14 \%$ and an amazingly high figure of $5 \%$ of the patients had incontinence for faeces (see 2.3). The numbers are too small to speak about significant difference between the three groups. The incontinence for faeces was always minimal and not a real social problem for the patients. 


\begin{tabular}{|c|c|c|c|c|}
\hline & $\begin{array}{l}A \\
(n=41)\end{array}$ & $\begin{array}{l}B \\
(n=46)\end{array}$ & $\begin{array}{l}\mathrm{C} \\
(\mathrm{n}=51)\end{array}$ & $\begin{array}{l}\text { toral } \\
(n=138)\end{array}$ \\
\hline $\begin{array}{l}\text { straining } \\
>2 \text { minutes }\end{array}$ & $49 \%$ & $54 \%$ & $59 \%$ & 54 最 \\
\hline
\end{tabular}

Table 8.8 Occurence of various forms of inconinenes preoperatively in numbers and percentages

$\begin{array}{llll}A & B & C & \text { total } \\ (n=41) & (n=46) & (n=51) & (n=138)\end{array}$

incontinence

for flatus

incontimence

for mucus

incontinence

for freces

(5) $12 \%$

(5) 119

(9) $17 \%$

(19) 14\%

(8) $19 \%$

(4) $9 \%$

(7) $14 \%$

(19) $14 \%$

(4) $10 \%$

(1) $2 \%$

(2) $4 \%$

(7) $5 \%$

\subsubsection{Preoperative sigms}

The perianal region was inspected and a rectal examination was done in all patients to exclude other pathology that could be responsible for the complaints and to confirm the diagnosis of haemorrhoids. In some cases other pathology was found, such as fissura ani, skintags or anal polyps, not leading to exclusion of the trial.

Table 8.9 gives a list of synchroneous anal pathology in the various groups.

By inspection, rectal examination and endoscopy the diagnosis haemorrhoids was confirmed.

Table 8.10 gives the division of second and third degree piles in each group.

Tible 8.9 Concurrent pathology in anal region

\begin{tabular}{lcccc}
\hline & $\mathrm{A}(\mathrm{n}=41)$ & $\mathrm{B}(\mathrm{n}=46)$ & $\mathrm{C}(\mathrm{n}=51)$ & total (n=138) \\
\hline issuratian & $5 \%$ & $4 \%$ & $10 \%$ & $7 \%$ \\
skintags & $49 \%$ & $33 \%$ & $37 \%$ & $39 \%$ \\
polyps in & $7 \%$ & $0 \%$ & $4 \%$ & $4 \%$ \\
thorectum & $7 \%$ & & \\
\hline
\end{tabular}

Table 8.10 Classification of haemorthoids in the three tral groups in percentages.

\begin{tabular}{lllll}
\hline & $A(n=41)$ & $B(n=46)$ & $C(n=51)$ & total $(n=138)$ \\
\hline second degre & $34 \%$ & $35 \%$ & $39 \%$ & $36 \%$ \\
third degree & $66 \%$ & $65 \%$ & $61 \%$ & $64 \%$ \\
\hline
\end{tabular}


A group of 25 normal testees without any anal complaint and without previous anal operations underwent anal pressure measurements. general data and results are listed in Table 8.11 .

Table 8. II Pressure measurements in controll group.

\begin{tabular}{|c|c|c|c|}
\hline number of testees & $: 25$ & \multirow{2}{*}{\multicolumn{2}{|c|}{ \pm 14 years }} \\
\hline age & $: \quad 40.2$ & & \\
\hline sexale $/ f$ & $3: 2$ & \multirow{2}{*}{\multicolumn{2}{|c|}{ $\pm \$ 5.2 \mathrm{mmHg}$}} \\
\hline pressure level & $: 50.2$ & & \\
\hline \multirow[t]{3}{*}{ pressure pattern } & : slow wave & 4 & $16^{\mathrm{*}}$ \\
\hline & regular: & 17 & $68 \%$ \\
\hline & irregular: & 4 & $16 \%$ \\
\hline
\end{tabular}

The mean preoperative pressure level in the three trial groups was almost the same (see Table 8.12). Compared to the control group the mean pressure in haemorrhoidal patients is significantly higher: $50,2 \mathrm{mmHg}$ against $70.9 \mathrm{mmHg}$ $(\mathrm{p}<0.11)$. There is no significant difference between the mean pressure of men and women: $72.8 \mathrm{mmHg}$ for men against $70.6 \mathrm{mmHg}$ for women. Table 8.13 shows the division of the pressure ranges.

Table 8.12 Mean pressure level in the three groups of patients with 2 nd and 3rd degree hatemorrhoids

$\begin{array}{ll}\text { group } \mathrm{A}(\mathrm{n}=41) & 68.9 \mathrm{mmHg} \pm 18.3 \\ \text { group } \mathrm{B}(\mathrm{n}=44) & 72.1 \mathrm{mmHg} \pm 15,4 \\ \text { group } \mathrm{C}(\mathrm{n}=48) & 71.8 \mathrm{mmHg} \pm 15.8\end{array} \quad$ all patients $\quad: 70,9 \mathrm{mmHg} \pm 16.3$

Table 8.13 Mean pressure in several age categories in patients with haemorrhoids

$\begin{array}{lll}\text { patients under forly } & (n=53) & 70.6 \mathrm{mmHg} \pm 15.3 \\ \text { patients between forly and sixty } & (n=59) & 72.3 \mathrm{mmHg} \pm 17.2 \\ \text { patients over sixty } & (n=21) & 66.2 \mathrm{mmHg} \pm 16.1 \\ \text { all patients } & (n=133) & 70.9 \mathrm{mmHg} \pm 16.3\end{array}$

In a few cases anal pressure measurements could not be performed preoperatively because of problems with the equipment. The number of patients available for anal pressure measurements were in group $A: n=41$, in group $B: n=44$ and in group $\mathrm{C}: \mathrm{n}=48$.

The influence of age in the anal pressure measurements showed that younger people with haemorrhoids have almost the same pressure level as adults over 40. The mean pressure in patients over sixty is only slightly lower. In the 138 
haemorrhoidal patients 133 preoperative pressure measurements were made. In 5 patients there were technical problems with the recorder. The different pressure patterns that were found were: (see figure 8.1).

1. regular (an almost flat curve with only little changes due to breathing and pulse )

2. slow waves (slow waves are pressure waves with an amplitude of more than $20 \mathrm{mmHg}$ that last for more than ten seconds)

3. irregular (unexplicable, wild pressure pattern)

Almost two thirds of the haemorrhoid patients had a slow wave pattern.

Table 8.14 shows the presence of the three pressure patterns in the three groups and in the whole series of 133 patients preoperatively. The presence of slow waves is very common in patients with haemorrhoids $60 \%$. The irregular pattern was found in only $9 \%$ of the cases (see also figure 8.1).

Table 8.14 Presence of the three pressure patterns in the three groups of patienis and the whole series

\begin{tabular}{lllll}
\hline & $\begin{array}{l}\text { group A } \\
(\mathrm{n}=41)\end{array}$ & $\begin{array}{l}\text { group } \mathrm{B} \\
(\mathrm{n}=44)\end{array}$ & $\begin{array}{l}\text { group } \mathrm{C} \\
(\mathrm{n}=48)\end{array}$ & $\begin{array}{l}\text { iolat } \\
(\mathrm{n}=133)\end{array}$ \\
\hline slow waves & $54 \%$ & $65 \%$ & $60 \%$ & $60 \%$ \\
regular & $34 \%$ & $27 \%$ & $33 \%$ & $31 \%$ \\
irregular & $12 \%$ & $8 \%$ & $7 \%$ & $9 \%$ \\
\hline
\end{tabular}

The mean pressure level for patients with second degree haemorrhoids was $72.8 \mathrm{mmHg}$. For patients with third degree piles the mean level was 69.4 mmHg (see Table 8.15). A proportional larger number of patients showed a slow wave pattern in the 2 nd degree group.

Table 8.15 Pressure level and pressure pattern in second and third degree hatemorrhoids

\begin{tabular}{lllll}
\hline & pressure llevel & \multicolumn{3}{c}{ pressure pattern } \\
\cline { 4 - 5 } & slow wave & reg & irreg \\
\hline second degree $(n=82)$ & 72.8 & $63 \%$ & $28 \%$ & $9 \%$ \\
third degree $(n=51)$ & 69.4 & $50 \%$ & $40 \%$ & $10 \%$ \\
\hline
\end{tabular}

\subsection{Results after treatment}

In this chapter the various complaints and complications after treatment at the control moments 1 week, 1 month. 6 months and 1 year postoperatively will be shown.

The follow up was not complete. A few patients did not show up for their last control visits (see Table 8.16).

The follow up numbers for anal pressure measurement are slightly lower because of technical problems with the equipment (see Table 8.17). 
Table 8.16 folow up in the various groups (numbers of patients)

\begin{tabular}{lccccc}
\hline & preop & 1 week & 1 mont & 6 months & 1 year \\
\hline group A & 41 & 40 & 41 & 39 & 40 \\
group B & 46 & 46 & 46 & 44 & 44 \\
group C & 51 & 51 & 51 & 49 & 48 \\
total & 138 & 137 & 138 & 132 & 132 \\
\hline
\end{tabular}

Table 8.17 Anal pressure measurement postoperatively(number of patiens)

\begin{tabular}{lccccc}
\hline & preop & I weet & 1 month & 6 months & 1 year \\
\hline gronp A & 41 & 30 & 34 & 30 & 30 \\
group B & 44 & 33 & 41 & 33 & 33 \\
group C & 48 & 39 & 39 & 34 & 34 \\
totil & 133 & 102 & 114 & 97 & 97 \\
\hline
\end{tabular}

\subsubsection{Prolapse}

The complaint of prolapse diminished in short time. In group A the postoperative percentages of $8 \%$ and $2 \%$ after one week and one month are due to postoperative oedema in the mucosa bridges, appearing as prolapse outside the anal verge. In groups $\mathrm{B}$ and $\mathrm{C}$ prolapse diminished to $13 \%$ respectively $23 \%$ in one week and further to $5 \%$ respectively $2 \%$ after one year (see Table 8.18 ).

\subsubsection{Pain}

The symptom of spontaneous pain was evaluated at the several follow up moments. In groups B and C the spontaneous pain diminished immediatly during the first week and this remained so for I year. In group A we see a different pattern. Here the symptom of spontaneous pain increased from $44 \%$ to $52 \%$ in the first week, but then it decreased to the same level as in groups $B$ and $\mathrm{C}$ (see Table 8.19 ).

The difference between group $A$ and the groups $B$ and $C$ after one week is significant $(\mathrm{p}<0.02)$.

Table 8.20 shows the percentage of patients with pain during and after defaecation in the three groups. After 1 month the symptom of pain had almost disappeared in groups $B$ and $C$ and this situation kept stable during the first year. The percentage of pain at defaecation in group A only diminished gradually after an initial rise. After half a year almost one quarter of the patients still 
Table 8.18 Prolapse after treatment in the three groups

\begin{tabular}{lccccc} 
& preop. & 1 week & 1 month & 6 months & 1 your \\
\hline group A & $100 \%$ & $8 \%$ & $2 \%$ & $0 \%$ & $0 \%$ \\
group B & $100 \%$ & $13 \%$ & $11 \%$ & $5 \%$ & $2 \%$ \\
group C & $100 \%$ & $23 \%$ & $5 \%$ & $5 \%$ & $5 \%$ \\
\hline
\end{tabular}

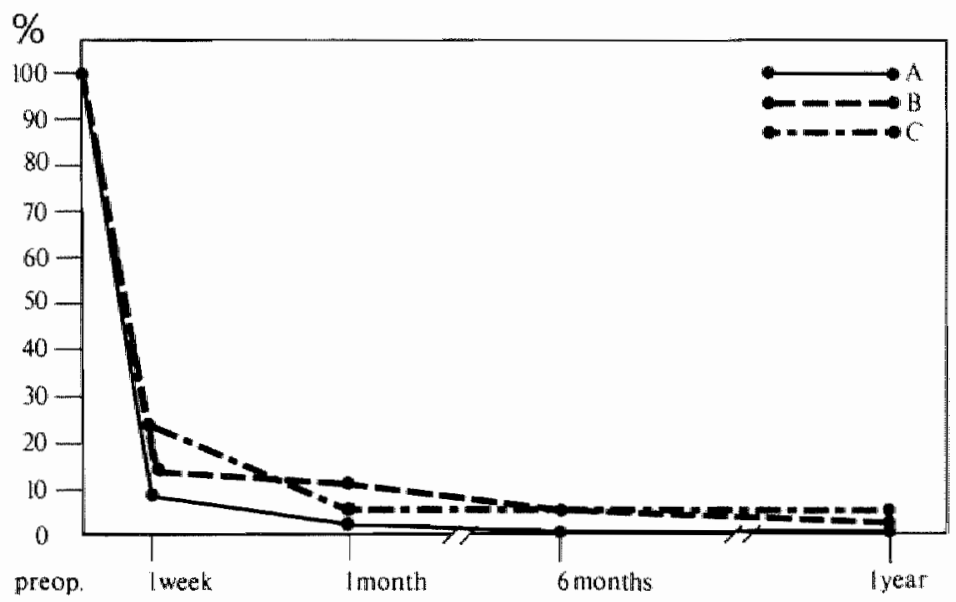

Table 8.19 Spontaneous pain

\begin{tabular}{lllccc}
\hline & preop & 1 week & 1 montin & 6 months & 1 year \\
\hline group A & $44 \%$ & $52 \%$ & $12 \%$ & $8 \%$ & $5 \%$ \\
group B & $70 \%$ & $35 \%$ & $7 \%$ & $9 \%$ & $14 \%$ \\
group C & $37 \%$ & $27 \%$ & $4 \%$ & $4 \%$ & $4 \%$ \\
\hline
\end{tabular}

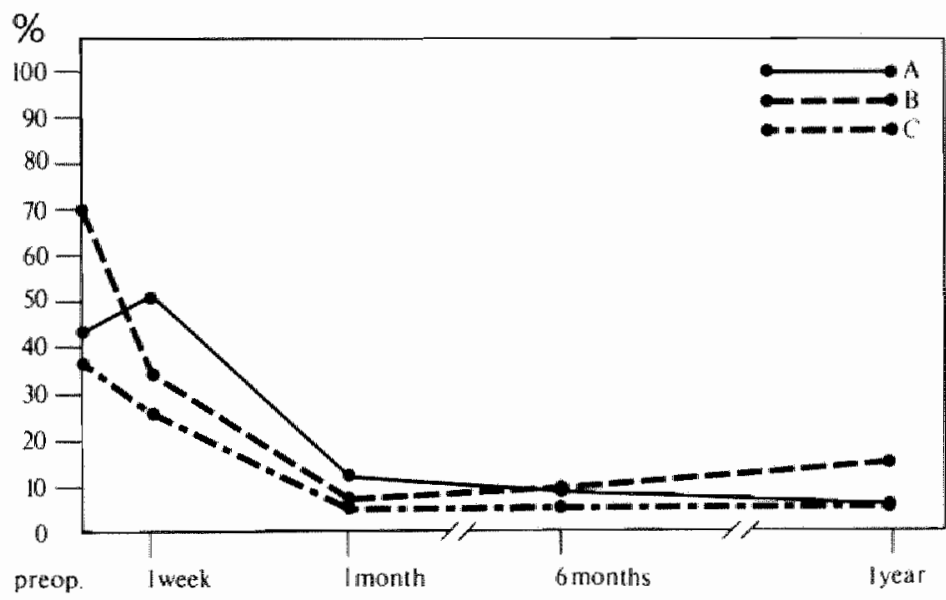




\begin{tabular}{lllccc} 
& preop & 1 werk & 1 month & 6 months & 1 year \\
\hline group A & $78 \%$ & $88 \%$ & $44 \%$ & $23 \%$ & $10 \%$ \\
group B & $78 \%$ & $50 \%$ & $7 \%$ & $11 \%$ & $14 \%$ \\
group C & $69 \%$ & $50 \%$ & $16 \%$ & $4 \%$ & $2 \%$ \\
\hline
\end{tabular}

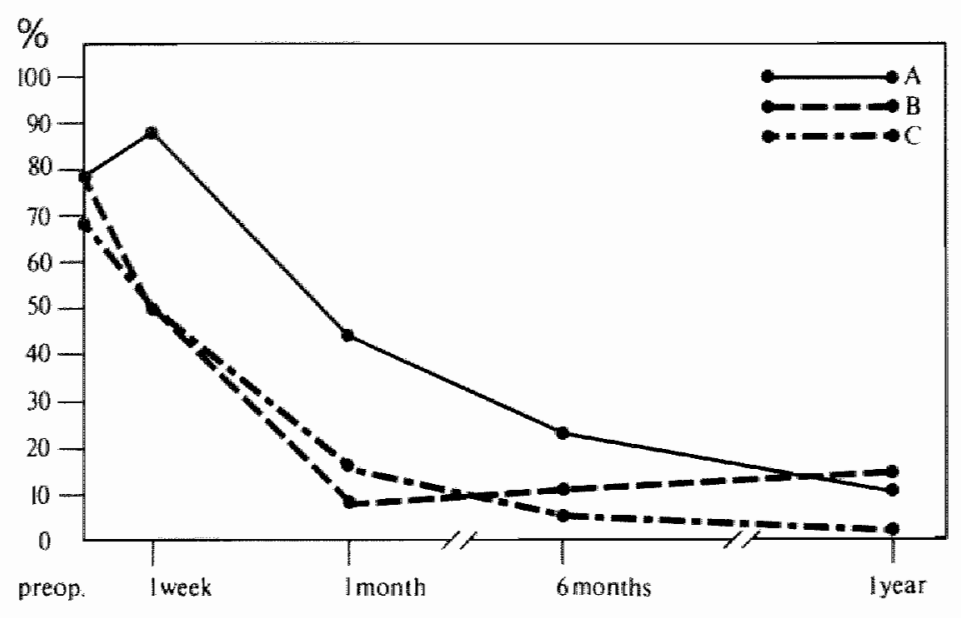

complained about pain. This is significantly higher $(p<0.05)$ than in the other groups. All forms of pain in every gradation or frequency were scored as positive. After 1 year the percentage of patients with pain at defaecation was in the same range in the three groups.

\subsubsection{Pruritus ani}

The postoperative development of pruritus ani is shown in table 8.21 . Pruritus ani reacts only poorly on haemorrhoidectomy and forced anal stretch. Only in the first weeks this decline in the curve can be attributed to the effect of haemorrhoidectomy or anal stretch. In a later stage patients with remaining complaints of itching were treated with anthelmintics and antimycotics if there were positive tests. So the effect of the haemorrhoidtherapy is not as successful as suggested in Table 8.21 .

In the three trial groups there is almost no difference in the effect on pruritus ani $(\mathrm{p}>0.5)$ after 1 week. 


\begin{tabular}{llllll}
\hline & preop & 1 week & 1 month & 6 months & 1 year \\
\hline group A & $61 \%$ & $40 \%$ & $37 \%$ & $28 \%$ & $18 \%$ \\
group B & $48 \%$ & $35 \%$ & $35 \%$ & $27 \%$ & $20 \%$ \\
group C & $55 \%$ & $49 \%$ & $30 \%$ & $27 \%$ & $17 \%$ \\
\hline
\end{tabular}

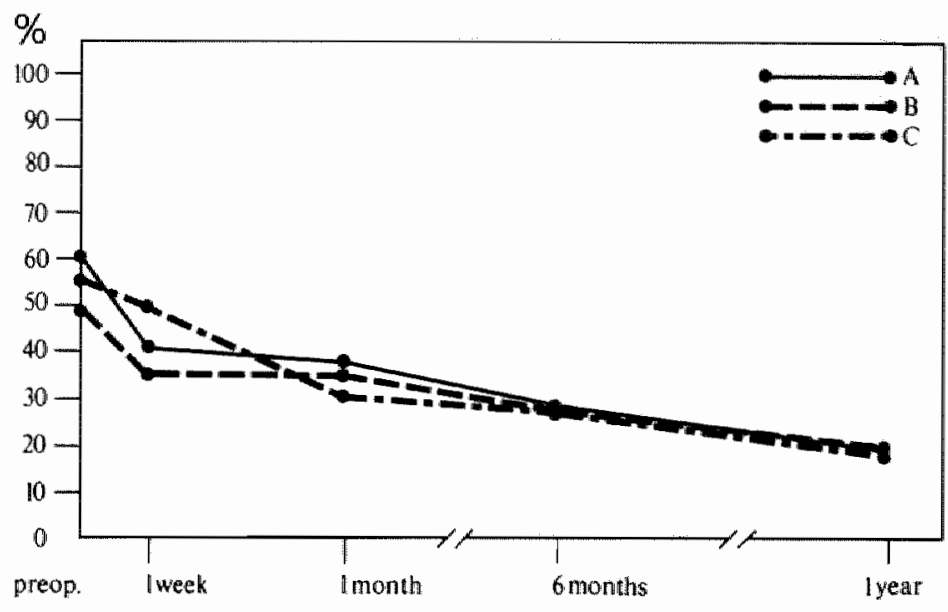

\subsubsection{Bloodloss}

Bloodloss at defaecation was the most common complaint in patients with haemorrhoids. Spontaneous bloodloss was present in about one third of these patients. Table 8.22 shows the effect of the three types of treatment on spontaneous bloodloss. After one week spontaneous bloodloss in groups $\mathrm{B}$ and $\mathrm{C}$ had diminished to $13 \%$ and $8 \%$. After I month the symptom had almost disappeared.

Only in the first week spontaneous bloodloss in group A differed significantly from groups $\mathrm{B}$ and $\mathrm{C}(\rho<0.01)$.

Bloodloss during and after defaecation reacted immediately on forced anal stretch after one week (see Table 8.23). Only one third of the patients of groups $B$ and $C$ still had this symptom. After 1 month the definite result was obtained. Almost no change was seen during the rest of the follow-up period. In trial group $A$ there is a different pattern: a much slower reaction on the treatment with respect to this symptom after one week $(\mathrm{p}<0.02)$. However, after 1 month the three groups reached the same level and after 1 year the results in group A were slightly better $(0,5<\mathrm{p}<0.1)$ : 


\begin{tabular}{llllll}
\hline & preop & 1 week & 1 month & 6 month & 1 year \\
group A & 32 g & $35 \%$ & $5 \%$ & $0 \%$ & $0 \%$ \\
group B & 410 & $13 \%$ & $0 \%$ & $4 \%$ & $0 \%$ \\
group C & $27 \%$ & $8 \%$ & 29 & $2 \%$ & $4 \%$ \\
\hline
\end{tabular}

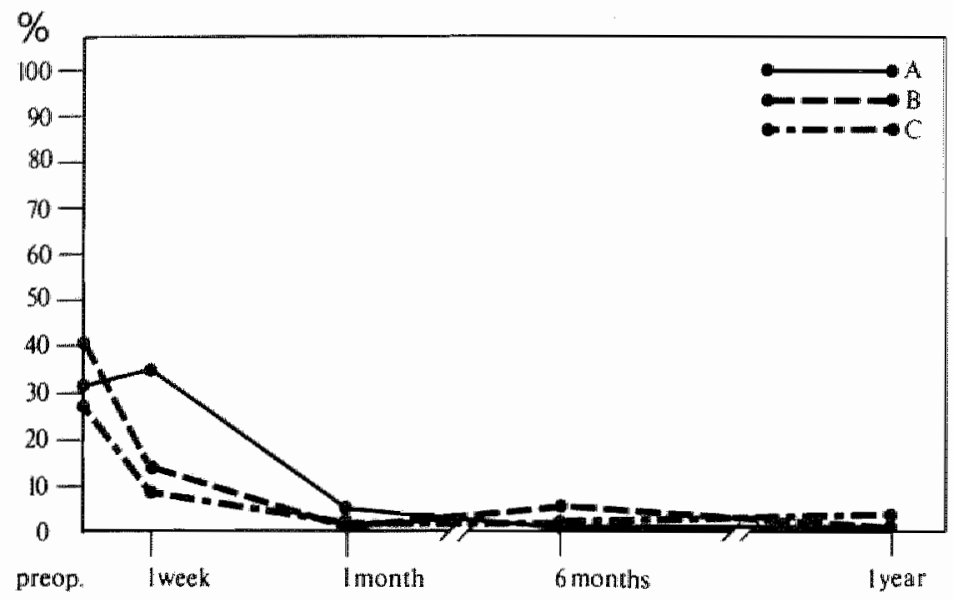

Table 8.23 Bloodloss al defaccation

\begin{tabular}{llllll} 
& preop & 1 week & 1 month & 6 month & 1 year \\
\hline group A & $90 \%$ & $70 \%$ & $22 \%$ & $13 \%$ & $5 \%$ \\
group B & $89 \%$ & $33 \%$ & $17 \%$ & $18 \%$ & $18 \%$ \\
group C & $88 \%$ & $29 \%$ & $14 \%$ & $12 \%$ & $10 \%$ \\
\hline
\end{tabular}

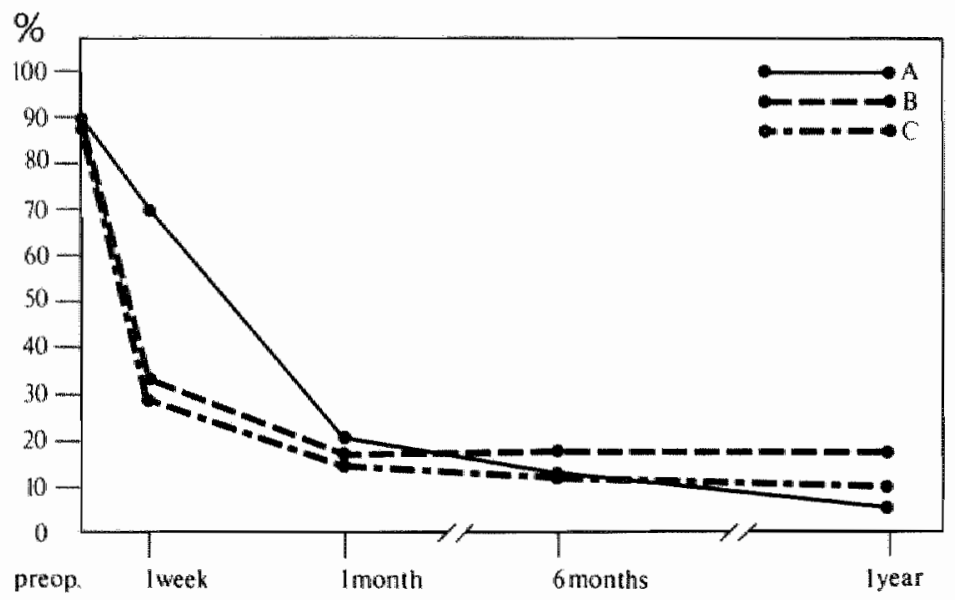


The same differences in pattern between trial groups A, B and C were seen for constipation, at one week and one month $(p<0.5$ respectively $p<0.5)$ see tables 8.24 and 8.25 . The patients were free to use laxatives if there was any need to. All patients were advised to use a fibrerich diet. This may have decreased the need for medication. The use of laxatives after one year was not significantly higher in group A $(0.5<\mathrm{p}<0.1)$.

\subsubsection{Straining at stool}

The effect of the treatment of haemorrhoids on straining at stool is shown in Table 8.26. On short and long term follow up there is a difference between the haemorrhoidectomy group and the 2 anal stretch groups. After 1 year about half of the patients with prolonged straining in group $A$ and one quarter of the patients in groups $B$ and $C$ still have problems with prolonged straining $(\mathrm{p}<$ $0.05)$.

Table 8.24 Constipation after traament

\begin{tabular}{lllllc}
\hline & preop & 1 week & 1 month & 6 months & 1 year \\
\hline group A & $41 \%$ & $41 \%$ & $32 \%$ & $13 \%$ & $13 \%$ \\
group B & $37 \%$ & $24 \%$ & $13 \%$ & $9 \%$ & $9 \%$ \\
group C & $43 \%$ & $22 \%$ & $20 \%$ & $14 \%$ & $10 \%$ \\
\hline
\end{tabular}

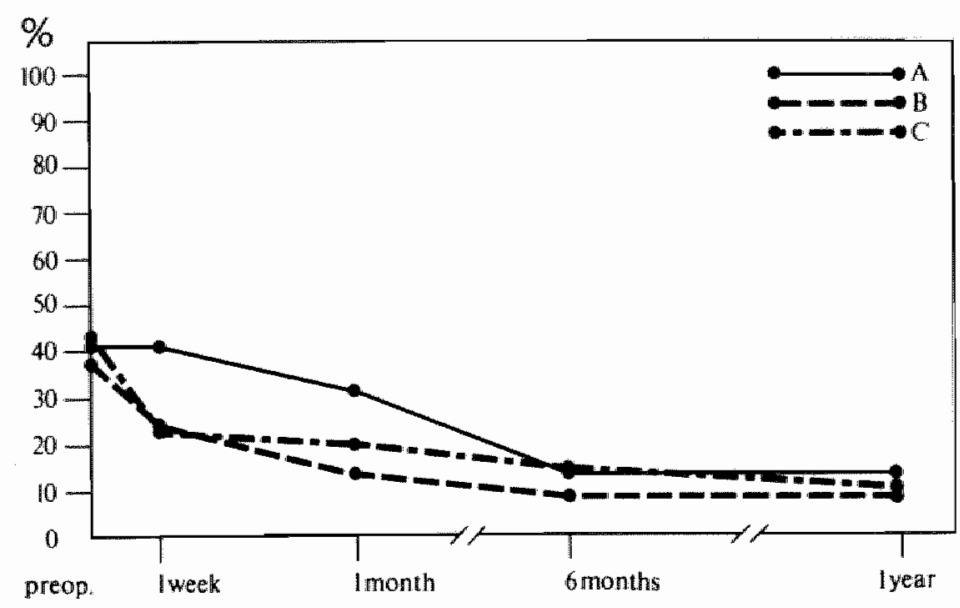


Table 8.25 Usa of laxatives

\begin{tabular}{llllll}
\hline & preop & 1 week & 1 month & 6 months & 1 year \\
\hline group A & $44 \%$ & $54 \%$ & $32 \%$ & $28 \%$ & $28 \%$ \\
group B & $22 \%$ & $22 \%$ & $20 \%$ & $18 \%$ & $16 \%$ \\
group C & $41 \%$ & $39 \%$ & $31 \%$ & $22 \%$ & $17 \%$ \\
\hline
\end{tabular}

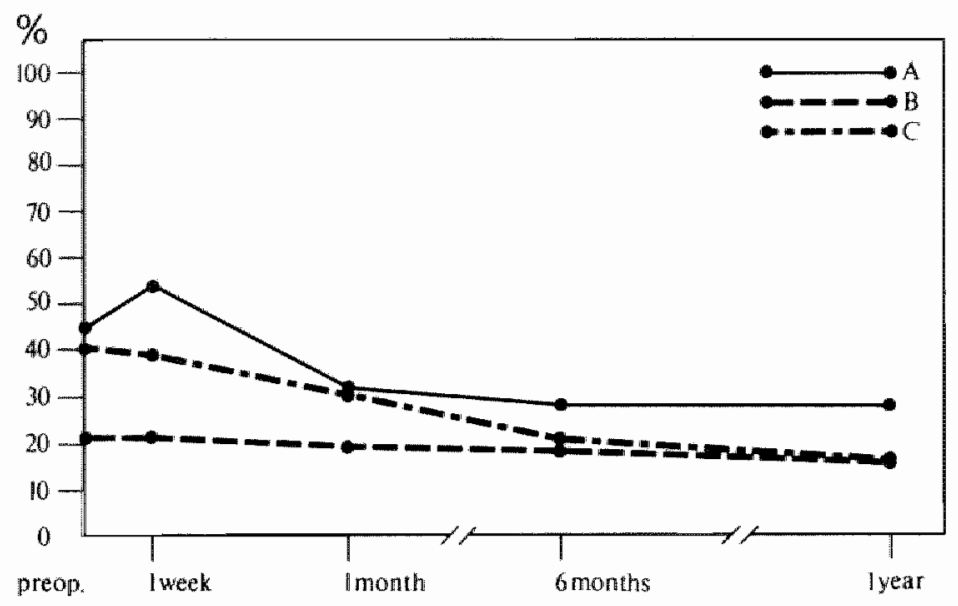

Table 826 Straining at stool

\begin{tabular}{llllll}
\hline & preop & lweek & 1 month & 6 months & 1 year \\
\hline group A & $49 \%$ & $51 \%$ & $41 \%$ & $31 \%$ & $25 \%$ \\
group B & $54 \%$ & $30 \%$ & $20 \%$ & $14 \%$ & $14 \%$ \\
group C & $59 \%$ & $27 \%$ & $22 \%$ & $18 \%$ & $15 \%$ \\
\hline
\end{tabular}

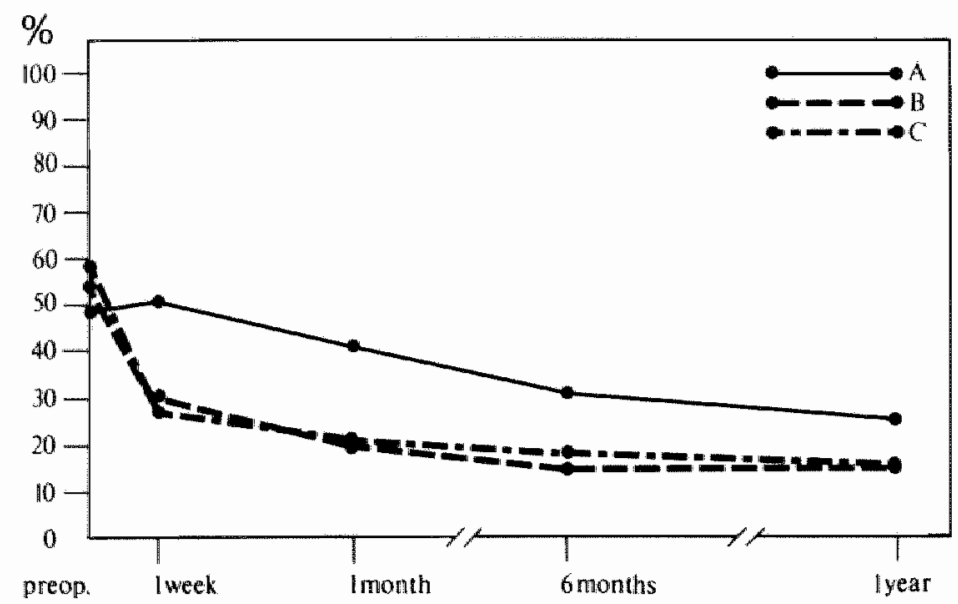




\subsubsection{Skintags}

Table 8.27 shows that the number of skintags in group A decreased after operation. This can be explained by the fact that they were for the greater part removed during operation. In groups $B$ and $C$ they were not removed and we see a slight increase after treatment for haemorrhoids.

\subsubsection{Pressure level postoperatively:}

The pressure level dropped in the first week from a high level to a subnormal level in groups B and C. In 1 year the pressure level returned to normal. In group A the pressure was at a normal level after one week and stayed so for 1 year (see Table 8.28 ).

The difference between group $A$ and the groups $B$ and $C$ is significant during the whole folluw-up period $(\mathrm{p}<0.05)$.

Table 8.27 Skintags pre- and postoperatively

\begin{tabular}{llllll}
\hline & preop & 1 week & 1 month & 6 months & 1 year \\
\hline group A & $49 \%$ & $42 \%$ & $34 \%$ & $36 \%$ & $30 \%$ \\
group B & $33 \%$ & $37 \%$ & $46 \%$ & $52 \%$ & $45 \%$ \\
group C & $37 \%$ & $39 \%$ & $39 \%$ & $41 \%$ & $40 \%$ \\
\hline
\end{tabular}

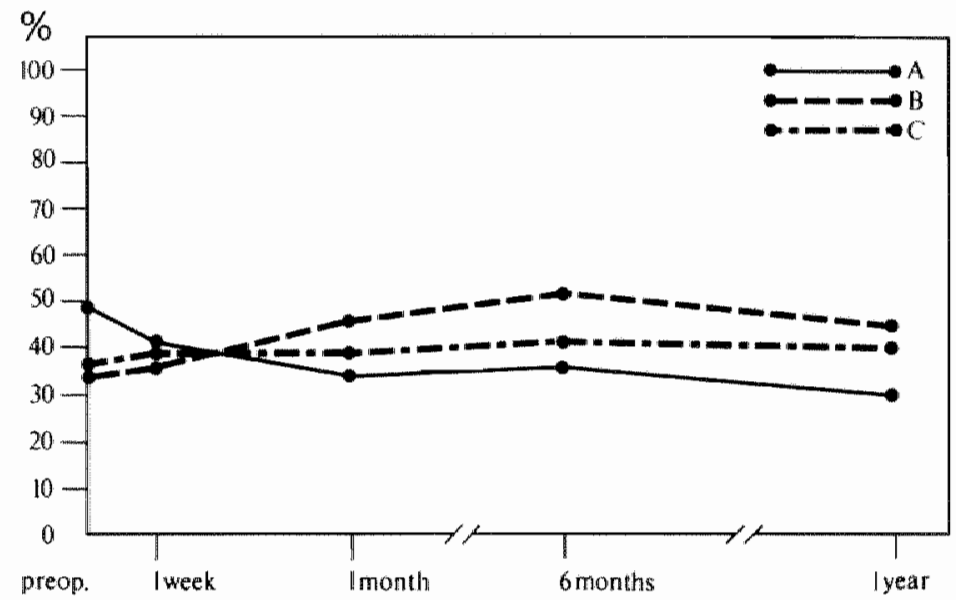




\begin{tabular}{|c|c|c|c|c|c|}
\hline & preop. & I weck & 1 month & 6 months & 1 year \\
\hline A & $68.9 \pm 18.3$ & $48.3 \pm 17.5$ & $49.0 \pm 18.6$ & $53.4 \pm 17.5$ & $55.0 \pm 15.8$ \\
\hline M & $72.1 \pm 15.4$ & $34,6 \pm 13,5$ & $39.2 \pm 14.1$ & $43.7 \pm 13.3$ & $46,0+15,3$ \\
\hline$C$ & $71.8 \pm 15.8$ & $35.8 \geq 1: 1.4$ & $40,0=13.8$ & $40.4 \pm 14.3$ & $48.0 \pm 16.0$ \\
\hline
\end{tabular}

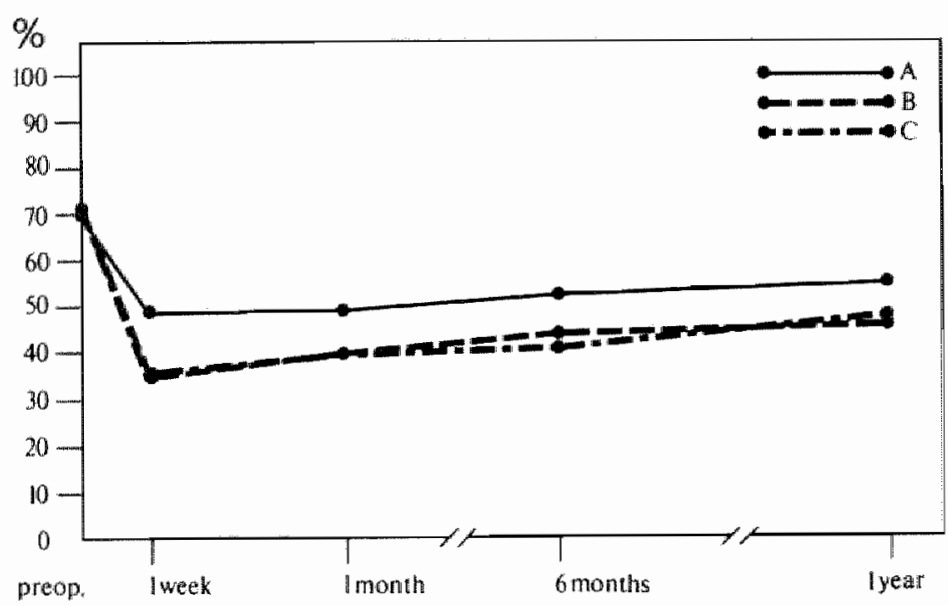

\subsubsection{Postoperaive pressure pattern}

The pressure pattern of slow waves most common in patients with haemorrhoids almost disappeared in 1 week in the three trial groups. After 1 year the presence of slow waves was in the same range as in a group of normal testees (see table 8.29).

\subsection{Complications}

In group A some complications were seen (see Table 8.30). One patient had a severe bleeding after haemorrhoidectomy requiring blood transfusion. One patient had a stenosis requiring dilation and in two patients a fissure had to be treated with forced anal stretch. In group A 4 patients had superficial wound infections that could be treated conservatively. Problems with urine retention and painful miction after operation was experienced in 14 cases. Three times catheterisation was necessary, in the other 11 cases medication (Carbachol ${ }^{\text {P) }}$ ) solved the problem. A bladder infection was found in one patient postoperatively after catherisation. In groups $B$ and $C$ there were only minor complaints of urine retention. No catheterisation was necessary. Two patients in group B and 
Table 8.29 Pre- and posioperative pressure patterns

\begin{tabular}{|c|c|c|c|c|c|c|}
\hline & & preop. & I week & 1 month & 6 months & 1 yeat \\
\hline \multirow{3}{*}{$A$} & slowe wave: & 549 & $10 \%$ & $13{ }^{2}$ & 139 & $23 \%$ \\
\hline & regular & 349 & $80 \%$ & 83 管 & $83 \%$ & $77 \%$ \\
\hline & integular & $12 \%$ & $10 \%$ & $4 \pi$ & $4 \%$ & $0 \%$ \\
\hline \multirow{3}{*}{ B } & slow wave & 65 䈨 & $7 \%$ & $10 \mathrm{n}$ & $11 \%$ & $18 \%$ \\
\hline & regular & $27 \%$ & 848 & $83 \%$ & $86 \%$ & $79 \%$ \\
\hline & irregular & $8 \%$ & 90 & $7 \%$ & $3 \%$ & 3 管 \\
\hline \multirow{3}{*}{$\mathrm{C}$} & Slow wave & $60 \%$ & $2 \%$ & $2 \%$ & $8 \%$ & $8 \%$ \\
\hline & regular & $33 \%$ & $96 \%$ & $96 \%$ & $92 \%$ & 879 \\
\hline & irregular & $7 \%$ & $2 \%$ & $2 \%$ & $0 \%$ & $5 \%$ \\
\hline
\end{tabular}

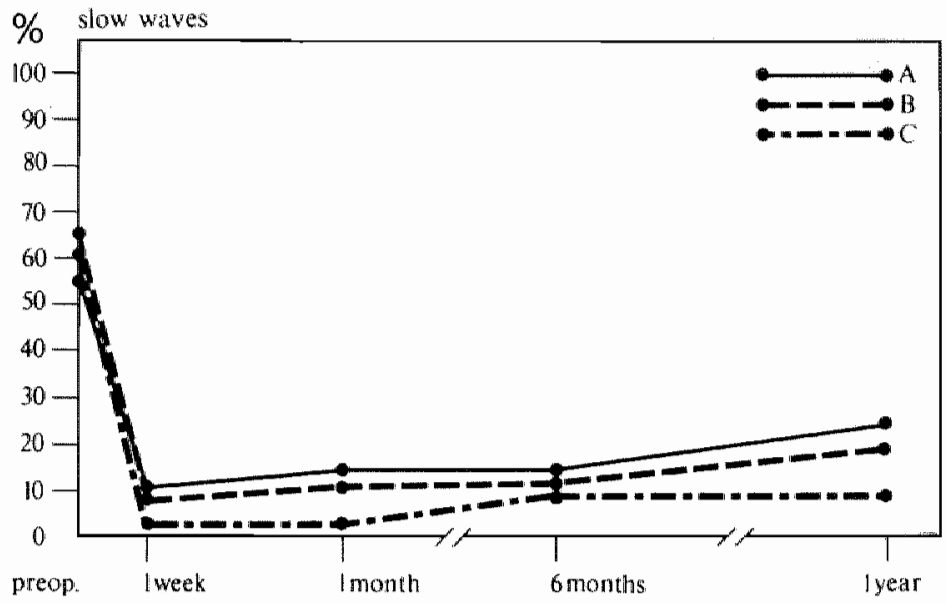

Table 8.30 Complications in rumber of patients

\begin{tabular}{|c|c|c|c|}
\hline & $A(n=41)$ & $\mathbb{3}(n=46)$ & $C(n=51)$ \\
\hline fissure & 2 & $\|$ & . \\
\hline stenosis & $\|$ & - & - \\
\hline bleeding & $\Downarrow$ & . & - \\
\hline prolapse & - & $\mathbb{1}$ & 1 \\
\hline wound infection & 4 & - & 1 (abscess) \\
\hline mild urine retention & $1 \rrbracket$ & 3 & 2 \\
\hline catheterisation & 3 & - & - \\
\hline bladder infection & $\Downarrow$ & $\|$ & 1 \\
\hline
\end{tabular}


one in group $\mathrm{C}$ underwent haemorrhoidectomy for a severe prolapse. One patient in group $C$ had a small absces that spontaneously perforated and could be treated conservatively in the first postoperative week. No haematomas and no pulmonary complications were found.

\subsubsection{Incontinence.}

Incontinence for flatus in the three groups increased in the first week, but it turned back to normal in group A in 1 month and in groups B and C after 6 months. Incontinence for mucus showed a remarkable decrease in groups $A$ and $C$, but stayed the same in group $B$.

Incontinence for faeces in the three groups increased in the first week but then fell gradually down to the level of the preoperative state (see table 8.31 ).

Table 8.34 Incontinence in number of patients and percentages

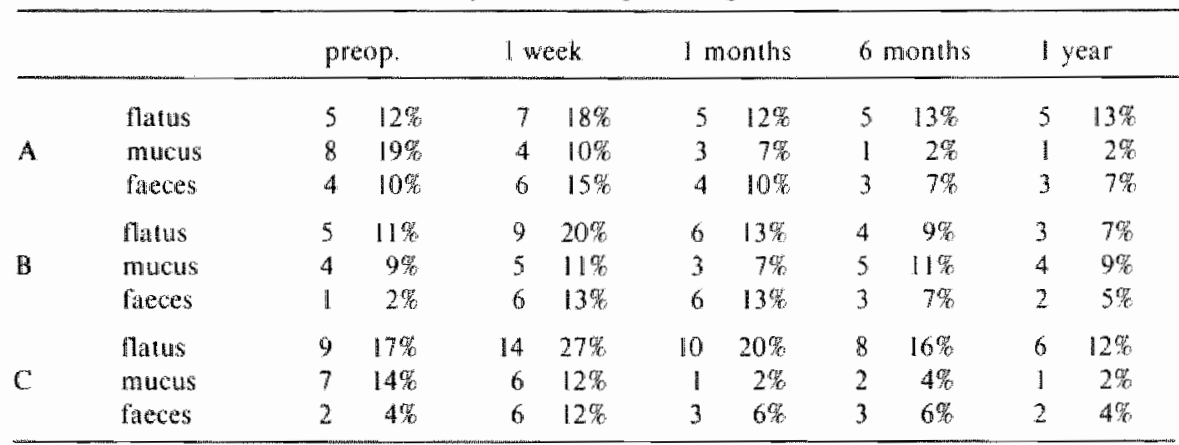

整 Incontinence for faces and flatus

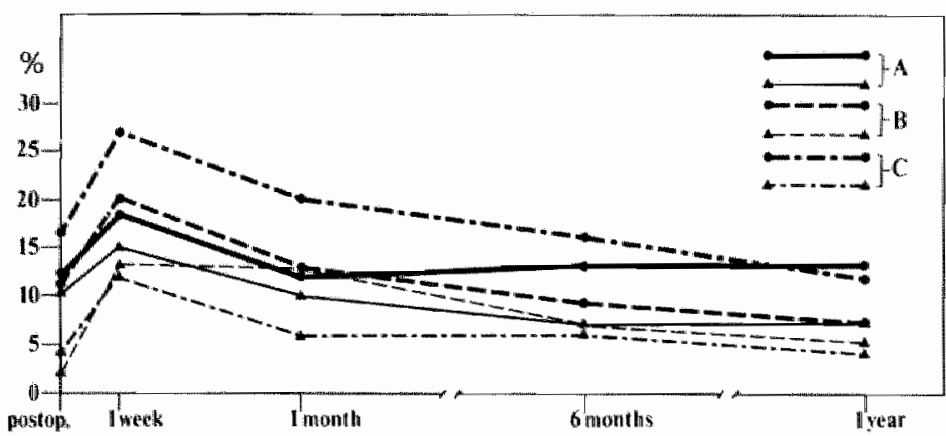


All patients were questioned about the number of days after treatment before they returned to work or for patients without a job the time that they were able to return to all normal activities. There was a significant difference between the time absent from work in the three trial groups $(p<0.01)$. See Table 8.32.

Table 8.32 Time from work after treatment of haemorrhoids.

\begin{tabular}{lrl} 
& lime from work & \multicolumn{1}{c}{ time in hospital } \\
\hline A & 20.4 days \pm 5.3 & 7.9 days \pm 3.2 \\
B & 5.6 days \pm 2.1 & 0.5 day \\
C & 3.6 days \pm 1.6 & 0.5 day \\
\hline
\end{tabular}

\subsubsection{Economical aspects.}

Average time in hospital for the patients in the haemorrhoidectomy group was: 7.9 days \pm 3.2 .

All patients in groups B and C stayed in the hospital for a few hours to recover from the general anaesthesia. Time from work included the hospital stay. The average costs made for patients in the three groups is listed in table 8.33 .

The real costs for hospital stay, surgeon and anaesthesist are given. There were $20 \%$ private and $80 \%$ ziekenfonds patients, costs for preoperative screening. equal in the three groups are not included.

(ziekenfonds is a kind of National Health Care Insurance).

Table 8.33 Mean costs of treatment per patient.

\begin{tabular}{|c|c|c|c|c|}
\hline & hosp.stay & surgeon & anaesth. & total \\
\hline $\mathrm{A}$ & 2680 & f198. & $\int 54,-$ & $\int 2932$, \\
\hline$B$ & j 137.- & $f 55$. & f 36. & $\int 2290^{\circ}$ \\
\hline$c$ & i 137. & 55. & $\int 36,-$ & f 229 \\
\hline
\end{tabular}

\subsubsection{Personal judgement of the patients.}

All patients gave their personal opinion about the success of the treatment at each controll visit. The results in groups $B$ and $C$ are almost equal (Table 8.34). In group A the subjective appreciation was significantly less in the first month $(\mathrm{p}<0.05)$. The results of the few patients, who needed further treatment are included until the moment of the second intervention. 
Table 8.34 Personal judgement of the patien as

\begin{tabular}{|c|c|c|c|c|c|}
\hline & & week & 1 month & 6 months & 1 year \\
\hline \multirow{3}{*}{$A$} & good & $21 \%$ & $60 \%$ & $80 \%$ & $83 \%$ \\
\hline & fair & $45 \%$ & $20 \mathrm{~K}$ & $9 \%$ & $6 \%$ \\
\hline & bad & $34 \%$ & $20 \%$ & $11 \%$ & 15 \\
\hline \multirow{3}{*}{$\mathrm{B}$} & good & $60 \%$ & $85 \%$ & 889 & $88 \%$ \\
\hline & foir & $31 \%$ & $13 \%$ & 76 & $100 \%$ \\
\hline & band & $9 \%$ & $2 \%$ & $5 \%$ & $2 \%$ \\
\hline \multirow{3}{*}{ C } & good & $61 \%$ & $78 \%$ & $83 \%$ & $87 \%$ \\
\hline & fair & $25 \%$ & $14 \%$ & $13 \%$ & $9 \%$ \\
\hline & bad & $14 \%$ & $8 \%$ & $4{ }^{4}$ & $4 \%$ \\
\hline
\end{tabular}

good results

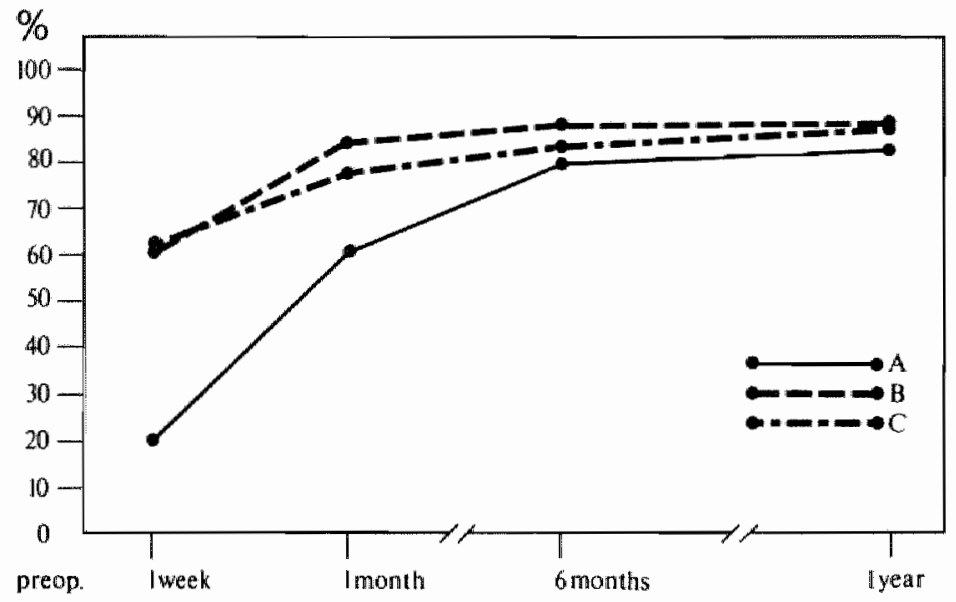

Table 8.35 Reintervention

\begin{tabular}{|c|c|c|c|c|}
\hline group & $\begin{array}{l}\text { age } \\
\text { in yealls }\end{array}$ & $\begin{array}{l}\text { lime of reinterv. } \\
\text { afer lst treatm. }\end{array}$ & $\begin{array}{l}\text { indication } \\
\text { for reinterv. }\end{array}$ & $\begin{array}{l}\text { type of } \\
\text { reinterw. }\end{array}$ \\
\hline \multirow{4}{*}{$A$} & 30 & 2 months & stenosis & manual dilatation \\
\hline & 53 & 2 months & pain & mantal diatation \\
\hline & 36 & 6 moniths & finsure & manual dilatation \\
\hline & 46 & 2 montlis & füsure & manual dilatation \\
\hline \multirow{4}{*}{ B } & 24 & 6 months & $\begin{array}{l}\text { itching and } \\
\text { skintag }\end{array}$ & skintang excision \\
\hline & 36 & 1 yesr & fissure & manual dilatation \\
\hline & 47 & 6 months & anal fibroma & excision libroma \\
\hline & 33 & 1 year & prolapse & hatmorrhoidectomy \\
\hline C & 57 & 4 months & prolapse & haemorrhoidectomy \\
\hline
\end{tabular}


Among the patients with bad results it was necessary to reintervent in a few cases. In some other cases listed as "bad" no other treatment was necessary (see Table 8.35). After reintertvention the results were good in all cases.

\subsection{Discussion}

The various aspects of the results of haemorrhoid treatment in the three groups will be discussed in the next chapter and compared to data from literature.

\subsubsection{Prolapse}

Of course the complaint of prolapse, present in all cases preoperatively disappeared completely in group $\mathrm{A}$. The small percentages present after one week and one month were due to the oedema and disappeared spontaneously.

The fact that in the groups $B$ and $C$ prolapse almost disappeared is surprising. In these cases no haemorrhoidal tissue was removed and the fact that the haemorrhoidal tissue no longer appeared at the anal verge can only be explained by the diminished shear force during defaecation and the not complete disrupture of the muscle of Treitz (see 1.6.2).

The difference between groups $B$ and $C$ after one year was not significant $(p>$ $0.5)$.

Forced anal stretch can cure the symptom of prolapse when the muscle of Treitz is not disrupted too much.

\subsubsection{Pain}

The 138 patients of this study seem to be a group of patients with more preoperative complaints than the groups described in other prospective studies $(4,20,59)$. Bleeding, itching and especially pain were seen more frequently in the present series. Pain, often seen in literature as a symptom not directly related to haemorrhoids. but to concurrent pathology, was present in $75 \%$ of the patients in this study. In only $7 \%$ an anal fissure was present in this series. All patients with fissures had pain. No other causes for pain were found. Therefore, it can be concluded that in $68 \%$ haemorrhoids were the only pathology found in the presence of pain.

The problem is to find out whether pain is a symptom or the cause of haemorrhoids. In the theory of the vicious circle where pain causes hypertony of the sphincters and hypertony causes pain during defaecation, haemorrhoids can develop as a sequel of this hypertony. The hypertonic condition of the sphincters is found in almost all haemorrhoid patients with a mean pressure level of $70,9 \mathrm{mmHg}$.

In groups B and $\mathrm{C}$ the pressure dropped postoperatively to a subnormal level. In the same time pain disappeared almost in all cases. In these cases the hatemorrhoidal tissue remained untouched. This suggests that pain is not a symp- 
tom of the haemorthoids, but is the cause of the development of piles.

When haemorrhoids grow larger and especially when inflammation thrombosis and necrosis develop, as seen in large third and fourth degree piles. pain can become a symptom of these piles. The prolapse of the haemorrhoidal tissue pulls sensitive anal skin outside the anal canal and this can cause pain (see chapter 2). So pain can be the first cause and last symptom of haemorrhoids (see Table 8.36).

\section{Table 836 Irritation of the anal canal}

Pain (l)

Hightonus of the anal sphincters

More resistance to open the sphincter during motion

Propulsion hatemorhoidal tissue to cadad

Dišruption connective tissue in baemomhoids

Prolapsis of hamorthoidal tissue with sensitive anal skin

Inflat trmation, thrombosis. incarceration (4th degree)

Pain (2)

In the present series a large number of patients complained about continuous pain and pain during sitting. In literature this type of pain was never seen as an item different from pain during defaecation.

The continuous pain was significantly $(p<0.01)$ more related to patients with third degree piles (see table 8.37). It is likely that this continuous pain is a symptom of severe piles, while pain at defaecation is the type of pain from which the haenorrhoids developped.

Table 8.37 Spontaneous puin preoperatively in second and degree piles in percentages

\begin{tabular}{lll}
\hline & second degree & third degree \\
\hline$A(n=41)$ & $(n=15): 33^{\circ}$ & $(n=26): 50 \%$ \\
$B(n=46)$ & $(n=17): 47 \%$ & $(n=29): 83 \%$ \\
$C(n=51)$ & $(n=18): 28 \%$ & $(n=33): 73 \%$ \\
$T n t a n$ & $(n=50): 36 \%$ & $(n=88): 69 \%$ \\
\hline
\end{tabular}

The postoperative pain in the three groups shows a remarkable difference in the first week between group $A$ and the groups B and C. In the haemorrhoidectomy group the complaints about spontaneous pain and pain at defaecation raise with about $10 \%$ while in the anal stretch groups ( $B$ and $C$ ) the complaints dropped with about $20 \%$. For group $\mathrm{A}$ it is clear that spontaneous pain and pain al defaccation could be increased by the open wounds.

With respect to spontaneous pain the three methods are equal in their results after one month (table 8.19).

The pain at defaecation is after 6 months still higher in the haemorrhoidectomy 


\begin{tabular}{|c|c|c|}
\hline Hardyer an? & $(5 y)$ & I momb - year \\
\hline Chant et al & 20 & 6 nonths \\
\hline Anscombe of al s & 4 & of weres -3 months \\
\hline Lewis ell all & $(82)$ & 6 wark -6 monthe 5 yet \\
\hline
\end{tabular}

group (table 8.20$)(p<0.05)$. In one year the results of the three groups don"t differ significantly.

The after-treatment with the Lord dilator (group B) has no additional effect after forced anal stretch with respect to spontaneous or defaecation pain.

In literature. most of the time the follow up moments chosen were 6 weeks to 1 year (see table 8.38). In these studies the directly postoperative pain is missed. Goligher (43) mentioned that the pain experienced in the first postoperative days is determined by a considerable personal factor. Nevertheless. almosi all patients experienced some form of pain. In three studies he looked at the benefit of forced anal stretch additional to several types of haemorrhoidectomy. There was a suggestion but no statistical proof that additional anal stretch gave less postoperative pain in all types of haemorrhoidectomy. In this series in group $A$ all patients underwent a standardized stretch by insertion of the slit proctoscope $(\varnothing 3 \mathrm{~cm})$.

With respect to pain forced anal stretch for 2 nd and $3 \mathrm{rd}$ degree haemorrhoids gives better results on short time than open haemorrhoidectomy. On long term forced anal stretch has equally good results as haemorrhoidectomy with respect to pain. The use of the dilator gives no additional benifit with respect to pain.

\subsubsection{Pruritus}

It is doubted in literature whether or not pruritus is a symptom of haemorihoids. Pruritus seems to be secondary to a number of anal diseases. All these pruritus related diseases have in common that normally they tend to produce at discharge. A sodden perianal skin is often seen in patients with pruritus. Discharge is common in patients with prolapsing haemorrhoids. Soiling was mentioned by $14 \%$ of the patients in this trial preoperatively.

$76 \%$ Of the patients who had soiling pre- and postoperatively had also pruritus ani. Pruritus can be caused by several other diseases, like thread worms, mycotic and bacterial infections, etc.etc., but in about half of all pruritus cases no cause can be found (43). In this series itching dropped about $20 \%$ in one month after treatment for haemorrhoids almost equally in the three groups. After one month when pruritus was still present in some patients further investigation was done. In 6 cases equally divided in the three groups, mycotic infections were found and could be treated with antymicotic ointments. In 2 cases pruritus could be attributed to worms. In the other cases no cause was found.

In general the results of haemorrhoidectomy and forced anal stretch on pruri- 
tus ani are poor. When itching is the single complaint in the presence of hatmorthoids it is advisable first to look for other causes of pruritus and only use haemorrhoid treatment as ultimate resort.

\subsubsection{Bloodloss}

Bloodloss was wery common in the three trial groups. The bloodloss related to defaccation was seen in about $90 \%$. It is not sure that spontaneous bloodloss has to say anything about the nature of haemorrhoids. It probably indicates only the severity of bloodloss. The group of patients with spontaneous bloodloss had to use sanitary pads to protect their underwear. All patients with spontaneous bloodloss had also bloodloss at defaecation.

Most patients in groups $B$ and $C$ showed an almost immediate relief of bloodloss at defacation. In one week the complaints dropped from about $90 \%$ to about $30 \%$ in both groups. In the haemorrhoidectomy group the bloodloss at defaecation diminished significantly less $(p<0.01$ ). The spontaneous bloodloss even increased in the same time. This is understandable, because the patients in trial group A have open wounds. After one month the complaints about bloodioss are almost the same in the three groups. In group $A$ all wounds were healed by that time.

The use of the dilator (group B) seems to have no additional benefit for bloodloss during the whole follow up period. The complaints in this group were even more frequent (not significantly) $(\mathrm{p}>0.5$ ) than in group $\mathrm{C}$. Anscombe (4) found comparable percentages of bloodloss after 6 months in his groups ( $11 \%$ in dilatation group and $6 \%$ in the haemorrhoidectomy group).

Bloodloss is treated better with anal dilatation on short term. On long term anal dilatation and haemorrhoidectomy give equal results. The use of the dilator gives no additional benefit with respect to bloodloss.

\subsubsection{Constipation and straining at stool}

In literature constipation and straining are always named as important factors in the development of haemorrhoids (43). However. almost never numbers are published about this problem. Constipation, defined as firm stool or low defaecation frequency was experienced in about $40 \%$ of the patients in the present study. Most of them used laxatives to deal with this problem. Some others used laxatives and had no problems with constipation. So there is an overlap between the numbers of table 8.24 and 8.25 .

In the complete group (of 138 patients) $41 \%$ had actual constipation and $7 \%$ had had constipation in the past but had preoperatively well regulated bowel movement with laxatives. So $48 \%$ has or had constipation. Postoperatively the constipation problem dropped in one week to $23 \%$ of the patients in group B and $\mathrm{C}$ and diminished further to $10 \%$. In the same time the need for laxatives diminished from $32 \%$ to $17 \%$. 
In the haemorrhoidectomy group all patients got laxatives for their first postoperative bowel movement. After one week the use of laxatives was slightly higher than preoperatively and diminished furher to $28 \%$ after one year. This is not significantly more than in groups $\mathrm{B}$ and $\mathrm{C}(0.5<\mathrm{p}<0.1)$.

Prolonged straining, defined as high abdominal pressure for more than two minutes to initiate the defaecation was a complaint in $54 \%$ of the patients preoperatively. Of course not all patients sat on the toilet with a stopwatch in their hands, but they related the time to defaecate to that of relatives or friends and judged their own efforts as normal or abnormal straining (mostly more than 2 minutes). The absolute figure of $54 \%$ of the patients can be disputed but the effect of haemorrhoid treatment is clear. In groups B and $C$ prolonged straining dropped to $15 \%$ after a year, in group $\mathrm{A}$ it diminished to $25 \%$. The difference is significant $(\mathrm{p}<0.05)$.

Forced anal stretch is a better method to deal with this problem than haemorrhoidectomy. Dilatation with or without after treatment with the dilator gives no significant difference for constipation, use of laxatives or prolonged straining at stool.

\subsubsection{Skintags}

The results of remaining skintags in the three trialgroups are incomparable. In group A preexisting tags are (partially) excised during haemorrhoidectomy. Therefore, the postoperative figures are a contribution of the few remaining tags and new formed marisques.

In groups $\mathrm{B}$ and $\mathrm{C}$ the number of skintags postoperatively is a combination of all preoperatively present tags and new formed tags. In literature skintags are sometimes mentioned, but numbers have never been published. Normally skintags give no symptoms. Only large tags may give problems with cleaning after defaecation. In a small minority large tags are associated with pruritus (43). In this series the presence of remaining lags is statistically not significantly associated with pruritus, pain or bleeding $(\mathrm{p}>0.5)$, see Table 8.39 .

This confirms the idea that skintags normally give no symptoms.

Tabile 8.39 Remaining symptoms and skinags after 1 year

\begin{tabular}{llc}
\hline & skintags & no skintags \\
\hline remaining symptoms & 20 & 27 \\
no symptoms & 31 & 54 \\
\hline
\end{tabular}


The pressure level of $70.9 \pm 16.3 \mathrm{mmHg}$ in haemorrhoid patients was significantly higher than in the controll group $50,2 \pm 15,2 \mathrm{mmHg}(\mathrm{p}<0.01)$. The same significancy was found by Hancock (53.55.57) and Araby (6). The pressure pattern of slow wave was seen more frequently in haemorhoidal patients $(60 \%)$ than in the controll group (16\%). A same observation was found by Hancock (55).

A possible relation between a high pressure level and preoperative complaints was studied.

The mean pressure level of patients with pain, $72.1 \mathrm{mmHg}$, was not significantly different from patients without pain, $70.1 \mathrm{mmHg}$. The same could be said of patients with and without bleeding and with or without itching. see table 8.40 . A similar observation was published by Hancock $(55,57)$.

Table 8.40 Mzan pressure lewel in haemorrhoid patients with and without symptoms $(n=138)$ in $\mathrm{mmHg}$

\begin{tabular}{|c|c|c|}
\hline & + & - \\
\hline pain & 72.5 & 70.1 \\
\hline inching & 71.4 & 69.9 \\
\hline bleading & 70.9 & 70.9 \\
\hline conslipation & 71.3 & 70.0 \\
\hline
\end{tabular}

Arabi (6) found in his study that patients with high pressure levels should benefit more from manual dilatation or sphincterotomy than patients with lower pressure levels.

The patients that underwent manual dilatation (groups B and C) were divided into a group with very high pressure levels ( $80 \mathrm{~mm} \mathrm{Hg}$ ) and a group with pressure levels under $80 \mathrm{~mm} \mathrm{Hg}$ (see Table 8.41 ).

The linal results of the patients with high pressure levels were not better than in the lower level group.

Table 8.41 Preoperative pressure levels and final results in patients treated with forced anal stretch $(\mathrm{groups} B$ and $\mathrm{C}$ )

\begin{tabular}{lll}
\hline & good results & faim/bad results \\
\hline $\begin{array}{l}\text { pressurelevel }>80 \\
(n=38) \\
\text { pressurelevel }<80 \\
(n=46)\end{array}$ & 33 & 5 \\
\hline
\end{tabular}


It can be concluded that a high level of the anal pressure gives no prediction about the definite results after one year in patients that underwent forced anal dilatation.

Hancock (57) supports the idea that pressure level has no predictive value in the longterm results of manual dilatation, but he finds a positive correlation between the slow wave pattern and the final outcome. In the present study there is no indication that these patients benefit more from forced anal stretch than patients with regular or irregular patterns, see Table 8.42 .

Table 8.42 Preoperative pressure patterns and final results in palients treated with forced anal stretch in percentages

\begin{tabular}{llll}
\hline & slow waves & regular & irregular \\
\hline good results & $85 \%$ & $87 \%$ & $86 \%$ \\
bad/fair results & $15 \%$ & $13 \%$ & $14 \%$ \\
\hline
\end{tabular}

It can be concluded that anal pressure measurements give significantly higher levels and higher percentages of slow wave pattern in haemorrhoid patients than in a controll group, but that these measurements have no value to determine in which way the patient can best be treated and which patients should benefit most from forced anal stretch.

In the postoperative period the pressure level dropped to subnormal in the forced anal stretch groups ( $B$ and $C$ ) and returned to normal after a year. In the haemorrhoidectomy group the mean pressure was normal within a week and stayed so for one year. The difference between the haemorrhoidectomy group and the forced anal stretch groups is significant. The postoperative treatment with the Lord dilator gives no significant differences in the development of the mean anal pressure levels. The pressure patterns changed significantly after treatment for haemorhoids. After one year the percentage of slow waves was in a normal range in the three trial groups. The same drop in pressure level and in frequency of slow wave patterns was found by Hancock (57) in patients after forced anal stretch. To examine the possibility that high postoperative pressure levels or slow wave patterns could be related to remaining pain the mean pressure level and pressure pattern was taken of the patients with pain after one year. The mean pressure level of $58.3 \mathrm{~mm} \mathrm{Hg}$ and the percentage slow wave of $20 \%$ was not significantly different from that of the wholle group after one year.

The anal pressure measurement seems to have no value in selecting patients for manual dilatation or haemorrhoidectomy, and gives no reliable objective datal for evaluation of the treatment. However, the much higher tone of the sphincter in patients with haemorrhoids gives support to the idea that hatemorrhoids may be caused by hypertony which causes outlet obstruction. The preexistent 
cushions formed by the internal haemorrhoidal plexus and the supporting tissue, described by Thomson (145) and Haas (51) could be displaced by a high shearing force during bowel action. The manual dilatation corrects the tightness of the sphincters and allows the cushions to regress provided that the connectiwe supporting lissue is not disrupted too much. The regression of the haemorrhoids and the replacement into the anal canal was well observed in these series of patients after forced anal stretch.

\subsubsection{Complications}

The number of complications in group A was significantly higher than in group $B$ and $C$. The patients with stenosis and fissures and prolapse are also mentioned in Table 8.35 because they needed reintervention. All the patients with mild urine retention experienced minor problems with miction postoperatively and could be treated with Carbachol ${ }^{(9)}$.

In literature only in a few cases minor complications were mentioned (39.59.95). After anal dilatation the same complications were seen in very low frequency. The use of the dilator does not protect against complications.

Forced anal stretch gives less complications than haemorrhoidectomy.

\subsubsection{Incontinence}

Incontinence for flatus, mucus and faeces are in literature almost always mentioned as real or possible complications of forced anal dilatation. Table 8.43 gives percentages of longterm incontinence ( 3 months - I year).

The temporary increase of incontinence for flatus and faeces named by the authors in Table 8.43 was also seen in the present study in groups $\mathrm{B}$ and $\mathrm{C}$. However, the same increase was seen in group $A$. This was also mentioned by Goligher (43).

Table 8.43 Percentages of incontinence after treatment for haemorrhoids in literature

\begin{tabular}{|c|c|c|c|c|}
\hline author & operation & $\mathrm{n}$ & $\begin{array}{l}\text { inconti } \\
\text { flattus }\end{array}$ & $\begin{array}{c}\text { inence for: } \\
\text { faeces }\end{array}$ \\
\hline Machntyre et al (95) & Lordproced ture & 66 & $21.8 \%$ & 3.68 \\
\hline Ortiz $(118)$ & Lordprocedure & 28 & $30 \%$ & $0 \%$ \\
\hline Velacoll $(147)$ & Lordprocedure & 20 & $5 \%$ & $0 \%$ \\
\hline Vellacotl (147) & Stretch without dilator & 20 & $0 \%$ & $0 \%$ \\
\hline Anscombe (4) & Lordprocedure & 49 & $6 \%$ & $4 \%$ \\
\hline Sanis $(126)$ & Lordprocedure & $\| 44$ & - & $0 \%$ \\
\hline Hardy $(59)$ & Lordprocedure & 20 & $5 \%$ & $5 \%$ \\
\hline Fussel $(39)$ & Lordprocedure & 53 & $13 \%$ & $2 \%$ \\
\hline Golighar (43) & Harmorthoidectomy & 100 & $13 \%$ & $3 \%$ \\
\hline Present series & Haemorrhoidectomy & 41 & $13 \%$ & $7 \%$ \\
\hline Present serits & Lordproced ure & 46 & $7 \%$ & $5 \%$ \\
\hline Present series & Stretch without dilator & $5 !$ & $12 \%$ & $4 \%$ \\
\hline
\end{tabular}


In this study a relatively large number of preoperative continence problems is present.

In group A one of the 3 patients with longterm incontinence for faeces had this problem preoperatively and in groups B and C one out of two patients. Almost all patients with incontinence for faeces did not experience this as a serious problem. Only one male in group $\mathrm{A}$ had problems with this incontinence, all the others judged the result of the treatment good.

It can be concluded that forced anal stretch gives a short term increase in continence problems. In the longterm the problem does not exceed that of haemorrhoidectomy. The use of the dilator has no influence on the number of patients with incontinence.

\subsubsection{Time from work}

In the present studies it was striking to see how many times patients who judged themselves as cured and felt able to return to work, stayed at home. The experience with a part of this group of patients gave support to the dutch expression ziek vieren (celebrate illnes).

The real time from work or in the patients without a job the time before returning to all normal activities was significantly longer in the patients of group $A$ $(\mathrm{p}<0.01)$. The difference between patients of groups $B$ and $C$ was not significant. It is hard to estimate the economical impact of the additional two weeks that the patients from group A were not at work compared to the patients of the groups B and C. A publication of Anscombe (4) gives figures about the time from work in a group of patients that underwent forced anal stretch and haemorrhoidectomy. The same difference was found between the two groups. However, the dutch disease seems to be worse in Manchester. $30 \%$ of patients who underwent forced anal stretch did not return to work before two weeks and $90 \%$ of the patients with haemorrhoidectomy.

We can conclude that forced anal stretch for patients with second and third degree haemorrhoids gives a much shorter recovery time than haemorhoidectomy.

\subsubsection{Economical aspects}

The difference between haemorrhoidectomy and manual dilatation in the cost aspects is enormous. Table 8.33 shows that the average costs for hospital stay and surgical and anaesthesiological treatment for the haemorrhoidectomy group was 13 times higher than for manual dilatation. Beside that there must be a big difference in the costs related to abscence from work. This was 4 times longer for the haemorrhoidectomy group. A third aspect are the costs of laxatives that were significantly higher in the haemorrhoidectomy group after one year.

From the economical point of view manual dilatation is incomparably better 
than hatemorrhoidectomy for patients with second and third degree haemorrhoids.

\section{5./I Personal judgment}

The subjective opinion about the results of the treatment for haemorrhoids shows that after 6 months there is almost no difference in the three groups. In the first month however the percentage of patients that judged the result as good was significantly lower in group A $(p<0.05)$. The curve of figure 8.34 may be somewhat flattered for the three groups because of the fact that some of the patients with bad results needed further treatment and were excluded after the second operation. These bad results are لisted in Table 8.35 .

In literature we find similar figures for results of forced anal stretch. Our percentages for good results after haemorrhoidectomy seem lower than normally given in literature (see Table 8.44).

Anal stretch gives at least equally good results as haemorrhoidectomy in patients with second and third degree haemorrhoids on long term, but is better on short term. The dilator has no influence on the personal judgement of the patients.

Table 8.44 Percentage of good results $>1$ year (personal assessment)

\begin{tabular}{lllll}
\hline author & & $\begin{array}{l}\text { anal stretch with } \\
\text { after-treatment }\end{array}$ & $\begin{array}{l}\text { anal } \\
\text { stretch }\end{array}$ & $\begin{array}{l}\text { haemor- } \\
\text { rhoidectomy }\end{array}$ \\
\cline { 2 - 5 } & $(4)$ & $84 \%$ & - & $98 \%$ \\
Anscombe & $(39)$ & $76 \%$ & - & - \\
Fussel & $(147)$ & $85 \%$ & $80 \%$ & - \\
Velacott & $(95)$ & $80 \%$ & - & - \\
Macintyre & $(66)$ & $82 \%$ & - & - \\
Hood & $(110)$ & - & - & $93 \%$ \\
Murie & $(45)$ & - & - & $88 \%$ \\
Gopalakrishnan & & $88 \%$ & $87 \%$ & $83 \%$ \\
Present series & & & & \\
\hline
\end{tabular}




\section{Conclusions and proposal for treatment of haemorrhoids}

- Pressure measurements with a microtip transducer give a precise information about the working of the anal sphincters.

- A microtip transducer has advantages above other measurement devices for measurements in the anal camal.

- Anal manometry gives support to the idea that a hypertonic condition is significant in the development of haemorrhoids. For this reason manometry was valuable in this study. However, no predictive value for the final results could be found in the measurements. Therefore for normal clinical purposes anal manometry is superfluous in the preoperative screening of patients with haemorrhoids.

- Treatment of first and second degree haemorrhoids with Barron bands is very easy. It causes almost no complications. The results for bloodloss and prolapse are good. Pain and itching react poorly on Barron banding.

- In every aspect groups B and C are almost equal. We can conclude that the use of a dilator has no additional benefit. The dilator remembers the patient that something was wrong in the anal canal. Perhaps the prolonged stay at home after anal stretch in group B can be related to this psychological factor. Some of the patients in group B found the thought of passing the dilator distasteful, but none of them refused after-treatment. To our opinion there is no indication for the use of the Lord dilator in the therapeutic possibilities for patients with haemorrhoids.

- In the comparison of forced anal dilatation and haemorrhoidectomy for the treatment of second and third degree haemorrhoids it was clear, that in the first month haemorrhoidectomy gave worse results in every aspect. After a longer period both methods were almost equal in their results. The much longer hospitalization and stay at home. the 13 times higher costs and the fact that the haemorrhoidectomy gave no better results, made us abandon haemorrhoidectomy for patients with second and third degree piles. (Haemorrhoidectomy remains the best solution for fourth degree haemorrhoids). - Therapy for haemorrhoids gives a solution for only a small number of patients when it concerns pruritus ani.

- The problem of possible incontinence after forced anal stretch was minimal in this study and did not exceed the findings in haemorrhoidectomy. The short time increase of incontinence for flatus is acceptable for the patients. 
- A high figure of concurrent pathology justifies a sigmoidoscopy before treatment of hamorrhoids in all patients over forty years old suffering from bloodloss.

- Pruritus ani without other symptoms in the presence of haemorrhoids forms no direct indication for treatment for haemorrhoids.

Figure 9.1 Proposal for treatment of haemorrhoids

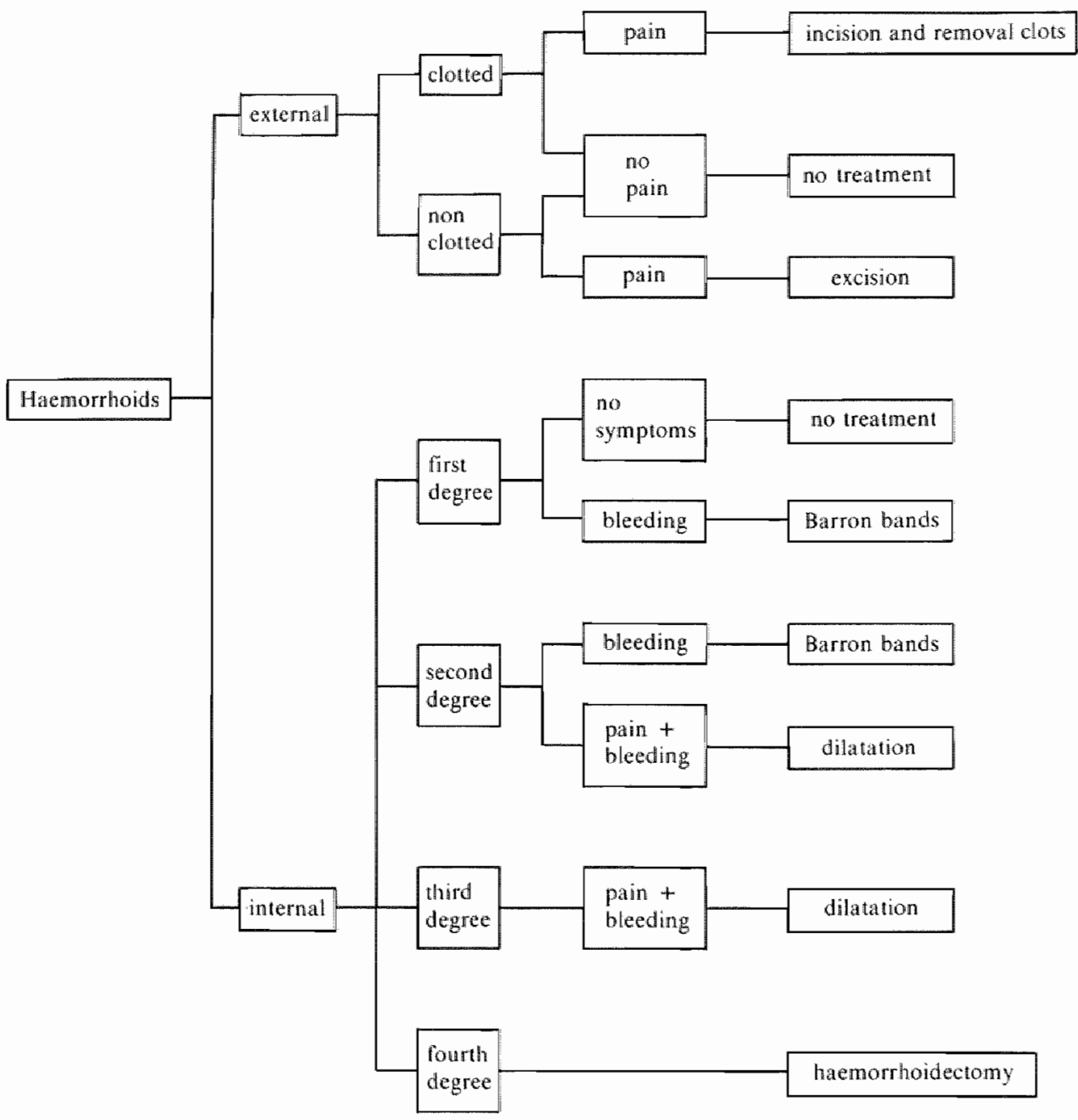


Treatment of haemorhoids is based on different concepts about the nature of these piles. To understand these concepts, understanding of anatomy, fysiology and pathofysiology is necessary.

- Chapter I gives a review of the anatomy of the anal canal and the rectum. The arterial and venous bloodsupply is discussed and special attention is given to the nerve supply and the various muscles of the anal canal and the pelvic floor.

- In chapter 2 the fysiology of the rectum and the anal canal is described with attention for the sensibility and motor innervation of this continence organ. Several theories about continence and defaecation are described.

- Chapter 3 focusses attention on anal pressure measurements as a method to objectivate the working of the anal sphincters. Three different methods of anal pressure measurements are described. With these methods it is possible to make withdrawal curves and pressure curves as a function of time.

- In chapter 4 a new method of pressure measurement is described. A microtip transducer was used to overcome some disadvantages of other pressure measurement methods. With the microtip transducer a normal pressure level of $50.2 \mathrm{mmHg}$ was found. In patients with anal fissures and haemorrhoids a much higher level was present. Pressure measurements during inflation of a rectal balloon gave information about the ano-rectal inhibitory reflex.

- In chapter 5 the symptomatology and the pathofysiology of haemorrhoids is discussed. A combination of straining at stool and hypertony of the anal sphincters seems responsible for the development of haemorrhoids. Prollapse of haemorthoids is caused by disrupture of the supporting tissue. Haemorr" hoids can develop in hypertone sphincters. The higher shearing force during defaecation can damage the muscle of Treitz and lead to prolapse of haemorrhoidal tissue.

- In chapter 6 several forms of therapy for haemorrhoids are given, classified in medical therapy, operative treatment and methods of dilation of the anal sphincters. Of all forms of therapy haemorrhoidectomy seems the most reliable one on the long term. However, there are so many disadvantages to haemorrhoidectomy in the postoperative period, that it is mandatory to look for alternatives especially for low grade pilles. Barron ligature and Lord"s 
method give good results, are easy to perform and are economically well justified.

- Chapter 7 gives the results of a prospective study on 100 patients with first and second degree piles treated with Barron ligation. The symptoms of bloodloss and prolapse reacted very well on Barron banding. Pain and itching were symptoms treated less satisfactorily. The complication rate was very low. Sigmoidoscopy before treatment is justified by the very high number of additional pathology found in these series. The results were almost equal in first and second degree piles. In their opinions $94 \%$ of the patients were satisfied. There was discrepancy between the judgement of the patients and the presence of remaining symptoms. After 3 months $80 \%$ of the patients was symptomfree.

- In chapter 8 a clinical prospective ranclomized trial is described in which haemorrhoidectomy is compared to Lord's method and to forced anal stretch without aftertreatment with a dilator for patients with second and third degree haemorrhoids. Pain, prolapse and bloodloss reacted equally well on the three methods on the long term but the short term results were much better in the dilatation groups. The results for itching were poor in the three methods. Prolonged constipation and the use of laxatives diminished more after forced anal stretch than after haemorrhoidectomy. Skintags remaining after treatment gave no complaints in the three groups. Anal pressure measurements gave higher pressure levels and a higher percentage of slow wave pattern in patients with haemorrhoids than in a symptomfree controll group. However, pressure measurements had no predictive value to select patients for one treatment or another and could not predict which patients would benefit most from anal stretch. The complication rate in the dilatation groups was lower than in the haemorrhoidectomy group.

Incontinence problems for flatus and faeces showed a short term increase after treatment in the three groups.

The use of the dilator after forced anal stretch turned out to have no value. For all symptoms the results of Lord's method and those of forced anal stretch without aftertreatment with the dilator were equal.

The methods of forced anal stretch gave a much shorter recovery time than haemorhoidectomy. Economically seen manual dilatation is incomparably better than haemorrhoidectomy. To their opinions the patients were equally satisfied in the three groups after one year, but the percentage of satisfaction on short term was much higher in the dilatation groups.

- In chapter 9 a proposal for surgical decision making for several degrees of haemorrhoids is presented. 
De behandeling van haemorrhoiden is gebaseerd op verschillende opvattingen over het ontstaan van haemorrhoiden. Om deze opvattungen te begrijpen is kennis van anatomie. fysiologie en pathofysiologie noodzakelijk.

- Hoofdstuk I geeft een overzicht van de anatomie van het anale kanal en het rectum. De arteriële en veneuze bloedvoorziening wordt besproken en er wordt aandacht besteed aan de zenuwvoorziening en de verschillende spieren van het anale kanaal en de bekkenbodem.

- In hoofdstuk 2 wordt de fysiologie van het rectum en het anale kanaal beschreven, met name de sensibiliteit en de motoriek van dit continentieorgaan. Diverse theorieên over continentie en defaecatie worden behandeld.

- In hoofdstuk 3 wordt alandacht geschonken aan anale drukmeingen. Dil is een methode om de sphincterwerking te objectiveren. Drie verschillende methoden van anale drukmeting worden beschreven. Met deze methoden is het mogelijk om terugtrekcurven te maken van het anale kanaal en om drukcurven als functie van de tijd te maken op één plaats in het anale kanaal.

- In hoofdstuk 4 wordt een nieuwe methode van anale drukmeting gepresenteerd. Een microtransducer werd gebruikt voor deze metingen, om enkele nadelen van andere meetmethoden te omzeilen. Met de microtransducer wordt een gemiddeld anaal drukniveau van $50.2 \mathrm{mmHg}$ gevonden in een gezonde controlegroep. Bij patienten met haemorrhoiden en fissuren blijkt het drukniveau significant hoger te liggen. Anale drukmetingen tijdens het opblazen van een ballon in het rectum laten een ano-rectale inhibitiereflex. zien.

- In hoofdstuk 5 worden het symptomencomplex en de pathofysiologic van haemorrhoiden besproken. Langdurig persen en een hoge sphincterspanning lijken de hoordoorzaken te zijn voor het ontstaan van haemorrhoiden. Blijvende prolaps van aambeien wordt veroorzaakt door het ruptureren van het steunweefsel rond de plexus haemorrhoidalis superior. Haemorrhoiden kunnen ontstaan in een hypertoon sphincterapparat. De hoge wrijvingsweerstand tijdens het defaeceren kan het ophangmechanisme (musculus van Treitz) beschadigen en leiden tot het prolaberen van het haemorrhoidale weefsel. 
In hoofdstuk 6 worden therapieen beschreven woor hatemorrhoiden. onderverdeeld in medicamenteuze en operatieve therapie en in methodes voor het oprekken van de anale sphincters. Haemorrhoidectomie lijkt op lange termijn het meest betrouwbaar. Er kleven zoveel nadelen aan haemorrhoidectomieen in de direct postoperatieve fase dat het zaak is alternatieven te vinden, met name voor laaggradige haemorrhoiden. Ligeren volgens Barron en het dilateren volgens Lord geven goede resultaten, zijn eenwoudig uitwoerbaar en economisch verantwoord.

- In hoofdstuk 7 worden de resultaten gegeven van een prospectief onderzoek bij 100 patienten met eerste en tweedegraads haemorrhoiden behandeld met Barron bandjes. De symptomen anaal bloedverlies en prolaps reageerden uitstekend op deze ligeringsmethode. Voor pijn en jeuk was de behandeling minder succeswol. Het aantal complicaties was laag. Het pre-operatief verrichten van een sigmoidoscopie bleek nuttig, getuige het hoge percentage additionele pathollogie, dat werd aangetroffen in het rectosigmoid. De resultaten bij patienten met eerste en tweedegraads haemorrhoiden waren nagenoeg gelijk. In $94 \%$ van de gevallen gaven de patienten aan tevreden te zijn. Er bestond een discrepantie tussen de frequentie van tevredentheid en de aanwezigheid van nog bestaande symptomen. Na 3 maanden was $80 \%$ van de patienten geheel symptoomvrij.

- In hoofdstuk 8 wordt een klinische, prospectief gerandomiseerde trial beschreven, waarin haemorrhoidectomie wordt vergeleken met dilatatie volgens Lord en met manuele dilatatie zonder nabehandeling met een dilatator bij 138 patienten met tweede en derdegraads haemorrhoiden. Op lange termijn reageerden pijn, prolaps en bloedverlies even goed op de drie behandelingsmethoden. De korte termijn-resultaten waren beter in de beide dilatatiemethoden. De resultaten met betrekking tot perianale jeuk waren pover bij de drie methodes.

Langdurig persen, obstipatie en het gebruik van laxantia namen sterker af na manuele dilatatie dan na haemorrhoidectomie. Na de behandeling overblijvende anale skintags gaven geen klachten in de drie groepen. Bij anale drukmeting werd in de drie groepen preoperatief een hoger gemiddeld drukniveau en een hoger percentage golfpatronen gezien dan in een symptoomloze controlegroep. De hoogte van de druk noch het drukpatroon had enige betekenis in het voorspellen welke patienten het meest bij dilatatie en welke bij haemorthoidectomie gebaat zouden zijn. Complicaties kwamen minder voor bij patienten behandeld met dilatatie dan bij patienten uit de haemorrhoidectomiegroep. Na behandeling was er een kortdurende toename te zien van incontinentieproblemen in de drie groepen. De nabehandeling met de dilatator gaf geen enkel voordeel te zien. De resultaten in de groep behandeld met de methode van Lord en in de groep behandeld met manuele dilatatie zonder nabehandeling. waren nagenoeg gelijk. In beide dilatatiemethoden was een weel snellere herstelperiode te zien dan in de haemorrhoidectomiegroep. 
Manuele dilatatie was economisch gezien onvergelijkbaar beter dan haemorrhoidectomie. Na één jaar waren de patienten in de drie groepen in gelijke frequentie tevreden met het resultat van de behandeling. De tevrew denheid was veel groter in de dilatatiegroepen gedurende de eerste maanden van de behandeling.

- In hoofdstuk 9 wordt een voorstel gepresenteerd voor protocollaire behandeling van de verschillende graden van haemorrhoiden. 
1. Alexander-Wiliams $J$ "Crapp AR. Conservative management of haemorhoids. Pant 1: injection, freezing and ligation. Clin in Gastroenterology 1975: 4 no. 3: 595.

2. Allgower $M_{*}$ Risedi Th. What about a vicious circle causing and perpetuating various bengn anal diseases? Progr Surg 1972; 10: 125.

3. Allgower M. Conservative management of hamorrhoids. Part 3: partial lateral sphincterotomy. 1975; 4 no. $3: 608$.

4. Anscombe A, Hancock B. Humphreys W. A clinical trial of the treatments of haemornoids by operation and the Lord procedure. Lancet 1974 (A.ugustus): 250.

5. Amson and MeVay. Surgical anatomy, volume 2, Saunders.

6. Arabi $Y$, Alexander-Willams J, Keighley $M$. Anall pressures in haemorhoids and anal fissure. Am J Surg 134: 608.

7. Barron J. Office ligation of internal haemorrhoids. Am J Surg 1963; 105: 563.

8. Bartolo D. Jarrat J Read N. The cutaneo-anal reflex. Br J Surg 1983;70-660-663.

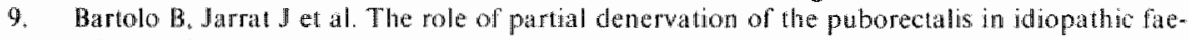
cal incontinence. Br I Surg 1983; 70:664-667.

10. Blassdel॥ PC. Prevention of massive hemorrhage secondary to haemorrhoidectomy. Surg Gynecol Obstet 1958: 107: 485.

11. Braad C. Reducing strangulated haemorhoids with alhylchloride. Lancet 1968; 729 .

12. Brandes H. Multicenterstudie mit den kortikoidfeien Hämorrhoidalpräparar Faktu. Z Algg Med 1980:56:284.

13. Brodie B. Lectures on diseases of the rectum, praternatural contraction of the sphincter ani. London. Med Gazette 1835; 16:26-31.

14. Bunte Lingeman. Proktologie für die Praxis. 1. Chir Praxis 1976: 22: 437

15. Bunte, Lingeman. Proktologie fir die Praxis. 2. Chir Praxis 1977: 23: 575.

16. Burnstock. Purinergic nerves. Pharm Rev 1972; 24: 509.

17. Cerdan FJ, Perez de Leon A, Azpiroz. IF. Martin J Balibrica JL. Anal sphincteric pressure in fissature in anus before and after lateral internal sphincterolomy. Dis Colon Rectum 1982: 25:199.201.

18. Changyul OH. Treatment of hamorrhoids and application of cryotherapy. Monnt Sinai J Med. $1975: 42: 3$.

19. Changyu $\mathrm{OH}$. One thousand cryohaemorroidectonies. Dis Colon and Rectum 1981; 24: 613.

20. Chant A. May A. Wilken B. Haemorrhoidectomy versus manual ditatation of the anus. Lancei 1972 (Augustus): 398 .

21. Christensen J. Colonic motility. View points on digestive diseases 1981:13:9.

22. Collins CD, Duthie HL, Shelley $\mathrm{T}$, Whitaker GE. Force in the anal canal and anal continen. ce. Gun 1967:8: 354 .

23. Cortesini C. Anorectial reflex following sphincter saxing operations. Dis Colon Rectum 1980 (July): 320 .

24. Deligauw P. De behandeling valn hatmorthoiden wolgens Lond. NTVG 1973: 117:246.

25. Delfgaw P. Greep J. De behandeling van hamorrhoiden volgens de methode van Lord. NTVG 1973; 117:708 
26. Devreed G. Anal incontinence (symposium). Dis Colon Rechum 1982: 25:90*95.

27. Duthie HL. Colonic motility in man. Mayo Clin Proc $50: 519$.

28. Duthie HL, Garns FW. Sensory nerve endings and sensation in the anal region of nan. Br. Surg 1960; 47: 585

29. Duthie HL. Bennett $\mathrm{RC}$. The relation of sensation in the anal canal of the functional anal sphthincter. Gut 1963:4: 179 .

30. Duthie HL. Watts JM. Contribution of the external anal sphincter to the pressure zone in the anal canal. Gut 1965:6:64.

31. Duthie HL. Kwong NK, Brown B. Adaptability of the anal canal to sensation. Bt I Surg 1970: $57: 388$.

32. Eisenhammer $\mathbf{S}$. Internal anal sphinctarotomy plus free dilatation versus anal stretch with special criticisn of the anal stretch procedure for haemorthoids. Dis Colon Rectum 1974: 17: 493.

33. El-Meguid Farag A. Pile suture: a new technique for the treament of haemorhoids. Br J Surg 1978: 65:293

34. Faverdin $C$. Dornic $C$, Dewreede $G$ et al. Quantitative analysis of anorectal pressure in Hirschsprung"s disease. Dis Colon Rectum 1981: 24:422-427.

35. Frenckner B. Euler $v$ Chr. Influence of pudendal block on the function of the anal sphincters. Gut 1975: 16:482-489.

36. Frenckner B. Ithe $T$. Function of the anal sphincters in patients with intussusception of the rectum. Gut 1976; 17: 147.

37. Frenckner B, Ihre T. Influence of autonomic nerves on the internal sphineter in man. Gut $1976 ; 17: 306-312$.

38. Frenckner B. Function of the anal sphincters in spinal man. Gut 1976:16:638.

39. Fussell K. Follow-up of Lord's procedure for haemorrhoids. Proc Rayal Soc Med 1973;66: 4.

40. Gabriel W. Principles and practice of rectal surgery. Thomas Springfield, llinois (USA). 5th ed. 1963.

41. Gemzenjäger E. Preserving Treitz muscle in haemorthoidectomy. Dis Colon Rectum 1982; $25: 533-537$.

42. Gershon $M$. The enteric nerwous system. An apparature for intrinsic control of gastro-intestinal motility. Viewpoints on digestive diseases $1981 ; 13: 13$.

43. Goligher JC. Surgery of the anus, rectum and colon. Bailliere and Tindall. 4th ed.. London, 1980.

44. Goligher JC. Hughes ESR. Sensibility of the rectum and colon; its rolle in the mechanism of anal continence. Lancet $\mathbb{1}: 543$.

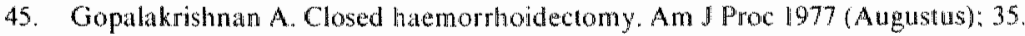

46. Granet E. Haemorrhoidectomy failures. Dis Colon Rectum 1968: 11:45.

47. Granet E. Anorectoptasty prevents haemorthoidectomy failures. South Mod I 1972:65: 1467.

48. Gray. Anatomy of the human body. Lee and Febiger, 28th, Philadelphis.

49. Greca $F$. et al. Value of an anal diator atter anal stretcl for hatemorthoids. J Royal Soc Mod $1981: 74: 368$.

50. Hads P et al. The prewalence of hatemorthoids. Dis Colon Rectum 1983:26:435.439

51. Hads P. Fox T. Haas P. Pathogenesis of haemorrhoids. Dis Colon Rectum 1984: 27:442.450. 52. Hamillon. Boyd. Messman. Human embryology. Williams and Wilkins Cie., 4 th ed. Baliimore. 1972.

53. Hancock BD. Smith K. The intermal sphincter and Lord's procedure for haemorrhoids. BrJ Surg 1975: 62: 833.

54. Hancock BD. The internal sphincter and anal fissure. Br ISurg 1977; 64: 92-95.

55. Hamcock BD. Internal sphincter and the nature of hatemorrhoids. Gut 197\%: 18:651-655.

56. Hancock BD. Measurement of and pressure and motility, Gut 1977: 17: 645-651.

57. Hancock BD. Lord's procedure for hatemorrhoids: a prospective antal pressure study. Br $\mathrm{I}$ Surg 1981: 68: 729-730.

58. Greca $F$ etal. Value of an anal diator after anal stretch for haemorhoids. I Royal Soc Med 1981: $74: 368$. 
59. Hardy KJ. Wheatey IC. Heffernan IA. Anal dilatation and haemorthoidectomy: a prospective study. Med I Aust 1975:2:88.

60. Harris LD. Winans CS. Pope CE. Detemination of yield pressures. A method for measuring anal sphincter competence. Gastroenterology $1966: 50: 754$.

61. Hedberg S. Pursonal communicanion about diatation method in M. G.H. Boston. 1982.

62. Hochuli R, Algöwer M. Weitere Erfahrungen mit der Spallung des Sphincters Internus nach Eisenhammer bei Analissuren. Fistelen und Hamorhoiden. Helv Chir Act 1968:1-2:268.

63. Holschneider M. Eine tragbare Dreikanaldruckmesseinheit zur Elektromano-metrischen Prifung von Kontinenz, Inkontinenz und chronischer Obstipation. Chir Praxis 1976:21: 199.

64. Holsckneider M. Elektromanonetrie des Enddarms. Urbani Schwarzenberg. Munchen 1983.

65. Holzherg R. Das falsche oder unbehandelte Hämorthoidalleiden. Z Allg Med 1980: $56: 397$.

66. Hood TP. Alexander. Williams J. Aral dilatation wersus rubber band ligation for internal haemorrhoids. Am I Surg 122:545.

67. Katchian A. Haemorrhoids. Am J Proc 1976 (A pril): 65.

68. Katchian A. Strangulated internal haemorrhoids. Am J Proc 1977 (June)

69. Katchian A. Haemorrhoidal banding. Dis Colon Rectum 1982: $25: 392$.

70. Katchian A. Haemorthoids: measuring the constrictive force of rubber bands. Dis Colon Rectum 1984: $27: 471-474$.

71. KaL L... Kaufman HJ. Spiro HM. Anal sphincter pressure characteristics. Gastroenterology $1967 ; 52: 513$

72. Katuman HD. Haemorrhoids "an outpatient package". J.R. Coll Surg Edinburgh 1978: 23: 40.

73. Kaufman HD. Otipatient treatment of haemorrhoids by cryotherapy. Br J Surg 1976; 63: 462.

74. Keighley D. Proctology ed. Exposition Press Hickswille. New York.

75. Kenter J, Keeman J. Longterm follow-up of Lord"s procedure for haemornoids. Neih J Surg $1983 ; 35: 17-19$.

76. Khubchandani IT, Trimpi HD, Sheets JA. Evaluation of polyglycolic acid suiture v.s. catgut in closed haemornoidectony with local anaesthetic. Southern Med I 1974; 67: 1504.

77. Katkman NF. Post haemorrhoidectomy pain. Proc Roy Soc Med 1970:63: 80.

78. Kuypers $\mathrm{JHC}$ Over de perianale fistel. Thesis $198 \mathrm{~L}$. Nijmegen.

79. Laird D. Campell N, Hardwich C. McMathon W. Parkinson E. Anoplasiy. What, when, how. why. Dis Col Rect 1969: 12: 179.

80. Lin WY, Chow HP, Poon GP, Wong SH. Rubber band ligation of three primary hamorrhoids in a single session. Dis Colon Rectum 1982;25:336.

81. Leebron W. Cryohaemorthoidectony in rural practice. Am J Proct 1976 (October) 25

82. Lewis A, Rogers H, Leighton M. Triat of maximal anal diatation. cryotherapy and elastio band ligation as alternat lives to haemorthoidectomy in the treament of large prolapsing that morthaids. Br J Surg 1983:70:54:56.

83. Lewis MI et al Crysurgical hamorthoidectomy. Dis Colon Reetum 1969: 12: 371 .

84. Lieberman W. Objective measurement of extermal anal sphincter tension. Am J Proct 1964 : 15:375

85. Lord P. A new regime for the treatment of hacmorthoids. Proc of the Royal Soc of Med 1968: $61: 935$

86. Lord P. A dengase procedure for the cure of third degree haemorthoids. Br J Surg $1969 ; 56$ : 747 .

87. Lord P. A new approach to haemorthoids. Progr in Surg 1972: 10: 109.

88. Lord P. Letter about hatemorhoidectomy versus manual dilatation of the an urs. Lancet 1972 ; 11: 1021. 89. Lord P. Diverse methods of managing haemorhoids: diatation. Dis Colon RecIum $1973: 16: 180$.

90. Lord $P$. Conservative management of haemorrhoids. Part 2: ditatation treament. Clin in Gastroenterology $1975 ; 4$ n10. 3;601.

91. Lord P. Approach to the treatment of anorectal disease with special reference to haemorrhoids. Surg Amn 1977: $9: 195$. 
92. Lord P. Personal communication. January 1979.

93. Lurz KH. Golner E. Behandlung des Hamormoidalleidens in Schwangerschaf und Wochenbed. Münch Med Wschr 1978; 120: 993.

94. McCaffrey J. Lord treatment of haemorrhoids. Lancel 1975: 18: 133.

95. Maclntyre 1, Balfour T. Results of the Lord non-operative treatment for haemorrhoids. Lancet 1972: 20: 1094. 96. Macleod J. In delense of cryotherapy for hamorthoids. Dis Colon Rectum 1982:25:32.

97. McLeod J. In dafense of cryotherapy for haemorthoids Dis Colon Rectum 1982: 25: 332-339.

98. McLeod J. Biofeedback in the maragement of partial anal incontinence. Dis Colon Rectum 1983; 26: 244-246.

99. MeNeil N. Rampton D. Is the rectum usually empiy? Dis Colon Rectum 1981: 24: $596-597$.

100. Malin L. Pollinzi V. Sulla alliwita terapeutica di un novo preparata ad uso topico nella palologia waricosa ano rettale. G Clin Med 1978: $59: 521$.

101. Martelli H. Mechanisms of idiopathic constipation: outlet obstruction. Gastroenterology 1978: 75:623-631.

102. Martelli $H$ el al. Some parameters of harge bowel mothity in nomal men. Gastroenterology $1978 ; 75: 623$.

103. Mazier WP. Emargency maemorrhoidectomy - a worthwhile procedure. Dis Colon Rectum $1973 ; 16: 200$.

104. Meyer B, Donovan W. Cryohaemorrhoidectomy: an experimental study and dinical apprai. sal. Am Surgeon 1975 (December): 799.

105. Miles E Observations upon internal piles. Surg Gynecol Obstet 1919:29:497.

106. Militarev JM. Protasevinch NN. Haemorrhoidectomy. Am J Proc; 1977 (Auguslus).

107. Millyan ETC. Morgan CN. Surgical anatomy of the anal canal. Lancet $1934: 2: 1150-1213$

108. Moesgaard F. Nielsen ML. Hansen JB, Knudsen JT. High fibre diet reduces bleeding and pain in patients with haemorrhoids. Dis Colon and Rectum 1982: 25: 454.

109. Möller C. Kiviluoto O. Santavirta S. Rubber band ligation of haemorrhoids. Ann Char Gynecoll 1977: 66: 184

110. Murie J. Mackenzie J. Sin A. Comparison of rubber band ligation and haemorthoidectomy for second and third degree haemorrhoids, a prospective clinical trial. Br J Surg 1980; 67 : 786.

111. Nair V. Experience of anal stretch in treament of piles. Med J Zambia 1975: 95: 127.

112. Neill M, Parks A. Swash M. Physiological studies of the anal sphincter musculature in faecul incontinence and rectal prolapse. Br I Surg 1981; 68: 53 ॥.

113. Nesselirod J. Clinical proctology. W. B. Saunders Cic., Philadelphia * London, 1964.

114. Netter. Atlas, Ciba Collection, volume 3, part 11.

115. Nivatwongs $S$. Stern H. Frijd D. The length of the anal canal. Dis Colon Recium 1981: 24: $600-601$.

116. OConnor J. Manual anal dilatation. Am J Proc 1976 (October): 32.

117. OHara $V$. Fatal clostridial infection rollowing hatemorhoidal banding. Dis Colon Rectum $1980 ; 23: 570$.

118. Orliz H. Marti I, Jauriete E, Masdevall C. Ferrer J, Sitges A. Lord"s procedure: a criticul study of its basic principle. Br J Surg 1978: 65:281.

119. Otio. Die Proktologie ein Stiefkind der Gistroenterologie. Z Gastroenterologie 1973: 11 : 107.

120. Parks AG. The surgical treatment of hamormoids. Br J Surg 1956:43: 337.

121. Parks AG. Hacmorrhoidectomy. Adv in Surg: $5: 1$.

122. Parks AG. Pathogenesis and treatment of fistula in ano. Br Med $j \| 961: 1: 463$.

123. Pulten vd. WJ. Atresia Ani et Recti. Thesis $196 \%$. Amsterdiam.

124. Rand A. Whitehead's radianl cireumferential hamorhoidectomy. Surg Chir N Am 1972: 52 1031.

125. Read N, Bartolo D et al. Differences in anorectal manometry between patients with hacmorr hoids and patients wih descending perineum syndrome: Implications for management. Br Surg 1983: 70:656-659 
126. Sames $P$. Experiences or Lord's procedure for the treatment of hamorrhoids. Proc Royal Soc Med 1972:65:782.

127. Sichuster M. Molor action of rectum and anal sphificters in continence and defaection. Handbook of Plysiology. sect a Amentary candl. wolume IV. chapter 103. 2121 . American Physiological sociely. 1968.

128. Schweiger. Funktoxthe Analsphincterunterstohungen. Springer Verag. Berlin-HeidebergNew York 1982.

129. Scoma J. Catherization in anorectal surgery. Arc Surg 1975: 110: 1506

130. Seghers $\mathbb{K}$, verbeek $G$. De behandeling van ambeien en de operane wolgens Parks. Tijdschr Gastroendorologie $1968: 12: 38$.

131. Shatik A. new concept of the anatomy of the and sphincter VIt and fistula: a simplifed classification. Dis Coton Rectum 1979 (September): 408.

132. Shafik A. A new concept of the anatomy of the anal sphoter mechanism and the fysiology of defaceation Vill, lewator hiatus and lumel anatomy and function. Dis Colon Recum $\$ 979$ (December): 539 .

133. Shatik A. A new concept of the anatomy of the anal sphincter $\mathrm{XX}$. single loop continence: a new theory of the mechanism of and coninence. Dis Colon Rectum 1980 (January): 37.

134. Sharik $A$. A new concept of the anatomy of the anal sphincter $X$ anorectal sinus and band: anatomic nature and surgical significance. Dis Colon Rectum 1980 (April): 170.

135. Starp S. Oordeelkundige aanmerkingen over de heelkunde in hel algemeen en de behandeling der operation in het bijzonder (In het nederlands vertald en uitgegeven te Amsterdam. F.Houturn 1751).

136. Shaw A. Bosher P. Blair K. Anorectal manometry for evaluating defatecation disorders. Virgiw nia Medical 1980; 107:366.

137. Singh I. Lal P. Submucous haemorhoidectomy versus low ligation excision. J of Indian Med Ass 1975; 64: III 1 .

138. Smith LE. How to treath hemorrhoids: tive non surgical alternatives. Geriatrics 1978 (Octom ber): 43 .

439. Snel QS. Clinical anatomy. Litue Brown and Co., Boston. 1981

140. Steinberg D, Liegors $H$. Alexander-Willams J. Long-term review of the results of rubber band ligallion of haemorrhoids. Br $₫$ Surg 1975; 62: 1.44

141. Stelzner P. Kontinenz. Superkontinenz und Inkontinenz im Anorektalbereich. Disch Med Wochr 1968: 2275

142. Stephens F, Smith E. Anorectal maformations in children, 1971. Yearbook Med Publ ine. Chicago.

143. Tohirkov G. Haas P. Fox T. Injection of a local anaesthetic solution into haemonthoidal bundels following rubber band ligation. Dis Colon Rectum 1982; 25:62-63.

144. Teller H. Die Pharmakotherapie bei Enddarmerkrankungen. Arch Derm Forsel: 244.385.

145. Thomson P. The mature of hamorrhoids. Br I Surg 62:542.

146. Thomson 1". Hatmornoids and fissure. Br J Hosp Med 1978 (November): 600.

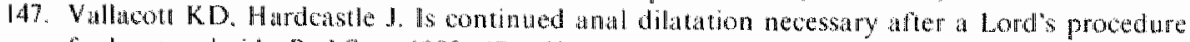
for haemorrhoids. Br \Surg 1980;67:658.

148. Vernon B. Mouracastle MD. Medical phystology. Physiology of the Digestive System, volume II. The C.V. Mosby Co., 14th ed.. 1980.

149. Walls A. Ruckley C. A five years follow-up of Lord's dilatation for haemorrhoids, Lancet $1976: 1213$.

150. Walls 3. Mennet RC. Duthie HL. Golgher JC. Healing and pain after hatemorhoidectony. Br J Surg 1964:51:808.

151. Webster D, Gough D. Craven J. The use of bulk evacuane in patents with hatemorrhoids. $\mathrm{Br}$ J Surg $1978 ; 65: 291$.

152. Whitehead W. The surgical treament of haemorhoids. Br Med J 1882: 1: 148. Republished in: Dis Col Reet 1980: 125 in the classical articles in Colonic and Rectal Surgery.

153. Wienbeck $\mathrm{H}$. Altapaminakow 1 . Simultane Elektromyografische und Manometrische Funk-

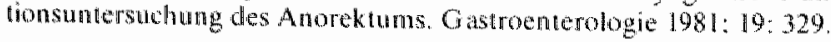


154. Whlwend R、Amgwerd R. Die chirurgische Behandhug des Hamorhoidalleidens und seimer Folgen. Gastroenterologie Fortbildungsk Praxis 1973: 3: 46.

155. Wrobleski D. Cormann M. Vedenhemer M. Coller J. Long-term evaluation of nubber ring ligation in haemorrhoidal disease. Dis Col Rect 1980:23:478.

156. Wullink F. Ontstaan an conservatieve behandeling van haemorrhoiden. NTVG 1983: $127(19): 880$.

157. Wunderlich M. Parks A. Physiology and pathophysiology of the anal sphincters. In Surg 1.982: 67: $291-298$. 
This thesis would not have been realized without the help of many others. I would like to express may gratitude towards those without whom this thesis would never have been accomplished. Professor J. M. Greep, who initiated and stimulated this study and gave me the opportunity to spend a year in Boston. where I could get experience in endoscopy.

I express my utmost gratitude to Prof. S. E. Hedberg, who helped me so much in these studies and taught me all the possibilities of endoscopy. Steve Hedberg died a few months ago and $I$ regret he can not be witness of the final version of this thesis. I thank Betsy Hedberg for all the work he has done and for the opportunity she and her husband gave us to spend a great year in Boston.

I thank Karin not only for ther support but also for her substantial help in typewriting the first versions and correcting the english texts.

I feel grateful to Dr. J. H. C. Kuypers, Professor J. A. Flendrig and Professor W. B. J. M. van de Staak for their critical contributions to this thesis,

I thank Marie-José Blondeau for her patience and understanding in typing and retyping the manuscript and Marcia Steegmans-van Puijenbroek, who registrated all the results of the study.

I am grateful to Paul Breslau who stimulated and helped me with the last fase of this thesis.

I thank Chris Voskamp for his illustrations, lay out and cover design.

I like to thank Mar. Lucie and Daisy for their help in the endoscopy unit. where all Barron-band patients were treated.

I am grateful to all my collegues who helped me with treatment and controll of the patients in these studies and to Jan Kersemakers, who helped me with the pressure measurement equipment.

Finally I thank my parents for their confidence and their stimulation. 
Curriculum Vitae

Cor Baeten was born April 4th 1949 in Maastricht, the Netherlands. He attended gymnasium B at 'Henric van Veldeke' College in Maastricht, where he graduated in 1968. He went to Medical School in Nijmegen and graduated in 1976. In May 1976 he started his surgical residency at the Surgical Department of St. Annadal Hospital, Maastricht, University of Limburg (Head: Prof. Dr. J. M. Greep). From December 1981 till December 1982 he worked as a fellow at the Endoscopy Department of Mass. General Hospital, Harvard University, Boston, U.S.A. (Head: Prof. S. Hedberg, M.D.). He was registered as a surgeon in May 1982. From January 1983 till December 1984 he worked as a "chef de clinique' at the Surgical Department of St. Annadal Hospital. In January 1985 he was appointed staff surgeon. 